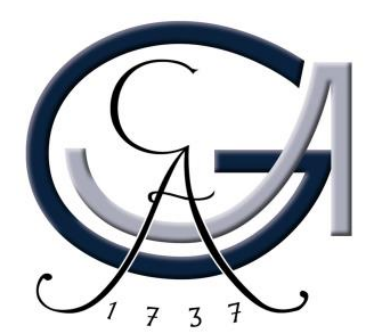

\title{
From Copper to Gold: Identification and Characterization of Coinage-Metal Ate Complexes by ESI Mass Spectrometry and Gas-Phase Fragmentation Experiments
}

\author{
Dissertation \\ for the award of the degree \\ "Doctor rerum naturalium" (Dr.rer.nat.) \\ of the Georg-August-Universität Göttingen \\ within the doctoral program Chemisty \\ of the Georg-August University School of Science (GAUSS)
}

submitted by

\section{Sebastian Weske}

from Berlin-Spandau

Göttingen, 2018 


\section{Thesis Committee}

Prof. Dr. Konrad Koszinowski

Institut für Organische und Biomolekulare Chemie

Georg-August-Universität Göttingen

Prof. Dr. Franc Meyer

Institut für Anorganische Chemie

Georg-August-Universität Göttingen

\section{Members of the Examination Board}

Reviewer: $\quad$ Prof. Dr. Konrad Koszinowski, IOBC, Georg-August-Universität Göttingen

Second Reviewer: Prof. Dr. Franc Meyer

IAC, Georg-August-Universität Göttingen

Further members of the Examination Board:

Prof. Dr. Manuel Alcarazo, IOBC, Georg-August-Universität Göttingen

Prof. Dr. Inke Siewert, IAC, Georg-August-Universität Göttingen

Dr. Franziska Thomas, IOBC, Georg-August-Universität Göttingen

Dr. Michael John, IOBC, Georg-August-Universität Göttingen

Date of the oral examination: $\quad 30.01 .2019$ 




\section{Danksagung}

Zu allererst möchte ich mich bei Prof. Dr. Konrad Koszinowski bedanken. Durch seine stets ruhige sowie immer interessierte und hilfsbereite Art hat er maßgeblich zum Gelingen dieser Arbeit beigetragen. Wie schon während der Zeit meiner Diplomarbeit stand seine Tür bei Anliegen jeder Art stets offen.

Des Weiteren möchte ich Herrn Prof. Dr. Franc Meyer meinen Dank für die Übernahme des Zweitgutachtens ausdrücken. Die Gespräche mit ihm waren immer angenehm und stets geprägt von Interesse und Hilfsbereitschaft.

Herrn Prof. Dr. Manuel Alcarazo, Frau Prof. Dr. Inke Siewert, Frau Dr. Franziska Thomas und Herrn Dr. Michael John danke ich für die Bereitschaft, als Mitglieder der Prüfungskommission zur Verfügung zu stehen.

Außerdem darf Prof. Richard O'Hair aus Melbourne an dieser Stelle nicht unerwähnt bleiben. Sein Aufenthalt in unserer Gruppe hat dieser Arbeit entscheidende Impulse gegeben, und dank seiner neugierigen und enthusiastischen Art war es eine Freude, mit ihm zusammen zu arbeiten.

Mein Dank gilt ebenfalls der DFG für finanzielle Unterstützung.

Natürlich sollen an dieser Stelle auch meine Mitstreiter aus dem Arbeitskreis Erwähnung finden; insbesondere Christoph, Marlene und Thomas möchte ich an dieser Stelle nicht nur für fachliche Diskussionen aller Art, sondern auch für viel Freude abseits des Labores danken. Außerdem seien Arne und Ramona lobend erwähnt für ihre Leistungen während der Zeit ihrer Bachelor-Arbeiten. Ebenso habe ich mich immer gefreut, in der Kaffeerunde des AK Tietze bei Kaffee und Konversation willkommen zu sein.

Und schließlich möchte ich mich ganz herzlich bei meiner Familie und meiner Freundin AnnChristin bedanken. Ohne Eure Geduld, Unterstützung und Vertrauen wäre das alles nicht möglich gewesen. 
Parts of this thesis have been published:

The Role of Ate Complexes in the Copper-Mediated Trifluoromethylation of Alkynes

S. Weske, R. Schoop, K. Koszinowski, Chem. Eur. J. 2016, 22, 11310-11316.

DOI: $10.1039 / \mathrm{c} 8 \mathrm{cc0} 01707 \mathrm{~g}$

https://onlinelibrary.wiley.com/doi/full/10.1002/chem.201601261

Copyright Wiley-VCH Verlag GmbH \& Co. KGaA. Reproduced with permission.

Argentate(I) and (III) complexes as intermediates in silver-mediated cross-coupling reactions

S. Weske, R. A. Hardin, T. Auth, R. A. J. O'Hair, K. Koszinowski, C. A. Ogle, Chem. Commun. 2018, 54, 5086-5089.

DOI: $10.1039 /$ c8cc01707g

https://pubs.rsc.org/en/content/articlelanding/2018/cc/c8cc01707g\#!divAbstract

Reproduced with permission from the Royal Society of Chemistry. 


\section{Table of Contents}

1 Introduction 10

1.1 Preparation of Group-11 Organometallates 10

1.2 Application in Synthetic Organic Chemistry 11

1.3 Structure, Solution Speciation, and Reactivity of Group 11-Organometallates 12

1.3.1 Solid-State Structure 12

1.3.2 Speciation in Solution 13

$\begin{array}{lll}\text { 1.3.3 Reactivity } & 14\end{array}$

1.4 ESI Mass Spectrometry of Organometallates - Potential and Limitations 16

2 Objectives $\quad 19$

3 ESI Mass Spectrometry and Gas-Phase Fragmentation Experiments 20

3.1 General Aspects of Mass Spectrometry 20

3.2 Electrospray lonization $\quad 20$

3.3 Mass Analyzer 21

3.3.1 Time-of-Flight Mass Analyzer 21

3.3.2 Linear Quadrupole Mass Analyzer 22

3.3.3 Three-dimensional Quadrupole Ion Trap 22

3.4 Instrumental Setup 23

3.4.1 Bruker micrOTOF-Q II Mass Spectrometer 23

3.4.2 Bruker HCT Mass Spectrometer 23

$4 \quad$ Results and Discussion 24

4.1 Association and Aggregation of Magnesium Organocuprates 24

4.1.1 ESI Mass Spectrometry of Magnesium Organocuprate Solutions and Gas-Phase Fragmentation Experiments $\quad 24$

4.1.2 Speciation and Aggregation of Magnesium Organocuprates 29

4.1.3 Stoichiometry and Stability of Magnesium Organocuprates 30

4.1.4 Comparison of Magnesium Organocuprates with Lithium Organocuprates 30

4.2 From Organocuprates to -aurates: Trends in Transition Metal Chemistry 32

4.2.1 ESI Mass Spectrometry of Group-11 Organometallate Solutions 32 
4.2.2 Gas-Phase Fragmentation Experiments of Group-11 Organometallates 36

4.2.3 Formation of Organometallate Anions $\quad 40$

4.2.4 Formation of Cationic Species 41

4.2.5 Gas-Phase Reactivity of Organocuprates, -argentates, and -aurates 42

4.3 The Role of Ate Complexes in the Copper-Mediated Trifluoromethylation of Alkynes $\quad 47$

4.3.1 In-Situ Formed Homoleptic Cuprate Complexes 47

4.3.2 In-Situ Formed Heteroleptic Cuprate Complexes 48

4.3.3 Cuprates Formed in the Presence of 1,10-Phenanthroline 49

$\begin{array}{lll}\text { 4.3.4 Solvent Effects } & 51\end{array}$

4.3.5 Genesis of Heteroleptic Cuprates 52

4.3.6 Oxidation of $\mathrm{Cu}(\mathrm{I})$ Complexes 53

4.4 Argentate(I) and (III) Complexes as Intermediates in Silver-Mediated CrossCoupling Reactions 56

4.4.1 In-situ Formed Organoargentate(III) Complexes 56

4.4.2 Gas-Phase Fragmentation Reactions of Organoargentate(III) Complexes 58

5 Conclusions $\quad 62$

6 Experimental Section 66

6.1 Materials and Methods 66

6.2 Sample Preparation 66

$\begin{array}{lll}6.3 & \text { ESI Mass Spectrometry } & 68\end{array}$

$7 \quad$ References and Notes 71 
Parts of the following section (" 1 Introduction") were taken from or are based on the publications given below.

The Role of Ate Complexes in the Copper-Mediated Trifluoromethylation of Alkynes Sebastian Weske, Ramona Schoop, Konrad Koszinowski, Chemistry - A European Journal, 2016, 22, 11310-11316.

DOI : 10.1002/chem.201601261

https://onlinelibrary.wiley.com/doi/full/10.1002/chem.201601261

Copyright Wiley-VCH Verlag GmbH \& Co. KGaA. Reproduced with permission.

Argentate(I) and (III) complexes as intermediates in silver-mediated cross-coupling reactions Sebastian Weske, Richard A. Hardin, Thomas Auth, Richard A. J. O'Hair, Konrad Koszinowski, Craig A. Ogle, Chemical Communications 2018, 54, 5086-5089.

DOI: $10.1039 / \mathrm{c} 8 \mathrm{cc} 01707 \mathrm{~g}$

https://pubs.rsc.org/en/content/articlelanding/2018/cc/c8cc01707g\#!divAbstract

Reproduced with permission from the Royal Society of Chemistry. 


\section{Introduction}

\subsection{Preparation of Group-11 Organometallates}

The beginning of organocopper chemistry dates back to 1859, when Boettger reported the preparation of the copper(I) acetylide $\mathrm{Cu}_{2} \mathrm{C}_{2}{ }^{[1]}$ More than sixty years later, Reich reported the isolation of phenylcopper from the reaction between Cul and a phenyl Grignard reagent. ${ }^{[2]}$ In 1952, Gilman et. al. demonstrated in a seminal publication that the treatment of copper iodide or thiocyanate with one equivalent of methyl lithium leads to neutral methyl copper, which forms lithium dimethylcuprate upon addition of a second equivalent of methyl lithium (Scheme 1). ${ }^{[3]}$

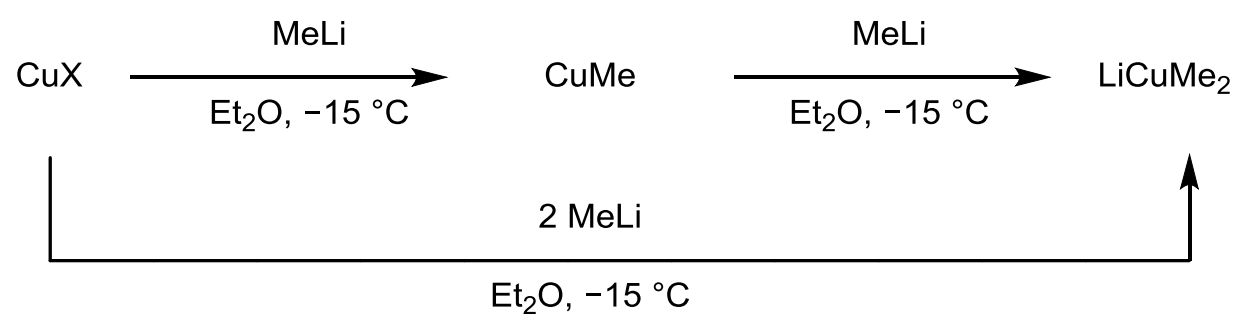

Scheme 1. Preparation of dimethylcuprate reagents by Gilman et. al. $(\mathrm{X}=\mathrm{I}, \mathrm{SCN}) .^{[3]}$

Indeed, the transmetallation of copper precursors with organometallic reagents constitutes a general route to organocuprates and leads to distinct classes of these compounds. Among them, notable examples are the already mentioned Gilman cuprates (Scheme 1 ) as well as the Lipshutz, ${ }^{[4]}$ Normant, ${ }^{[5]}$ and Knochel cuprates ${ }^{[6]}$ (Scheme 2). The transmetallation of silver and gold precursors with two equivalents of organolithium or Grignard reagents, respectively, is also the method of choice for the preparation of organoargentates ${ }^{[7]}$ and -aurates ${ }^{[8]}$.

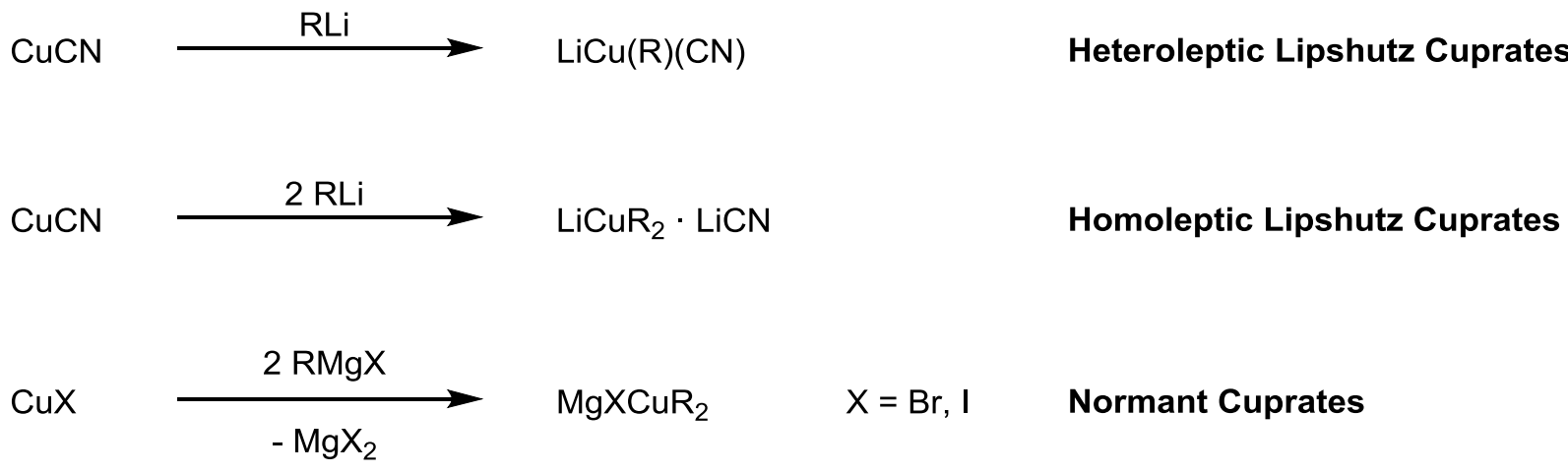

$\mathrm{CuCN} \cdot 2 \mathrm{LiX} \stackrel{\mathrm{RZnl}}{\longrightarrow} \mathrm{ZnICu}(\mathrm{R})(\mathrm{CN}) \quad \mathrm{X}=\mathrm{Cl}, \mathrm{Br} \quad$ Knochel Cuprates

Scheme 2. Preparation of Lipshutz, Normant, and Knochel cuprates. ${ }^{[4-6]}$

Beyond these "classical" organometallic reagents, the use of the silicon-based compound $\mathrm{Si}\left(\mathrm{CH}_{3}\right)_{3} \mathrm{CF}_{3}$, the so-called Ruppert-Prakash reagent, has been reported for the generation of trifluoromethylcuprates, ${ }^{[9]}$-argentates, ${ }^{[10]}$ and -aurates ${ }^{[11]}$. Such reactions usually require a Lewis base as an activator and presumably involve pentacoordinated siliconate species $\left[\mathrm{Si}\left(\mathrm{CH}_{3}\right)_{3}\left(\mathrm{CF}_{3}\right) \mathrm{X}\right]^{-}\left(\mathrm{X}=\right.$ Lewis base). ${ }^{[12]}$ 


\subsection{Application in Synthetic Organic Chemistry}

Organocuprates are valuable and versatile reagents in synthetic organic chemistry. ${ }^{[13]}$ In 1941, Kharasch and Tawney discovered that methylmagnesium bromide undergoes an 1,4-addition to the $\alpha, \beta$-unsaturated ketone isophorone in the presence of catalytic amounts of $\mathrm{CuCl}$, while the 1,2addition is observed in the absence of $\mathrm{CuCl}$ (Scheme 3). ${ }^{[14]}$

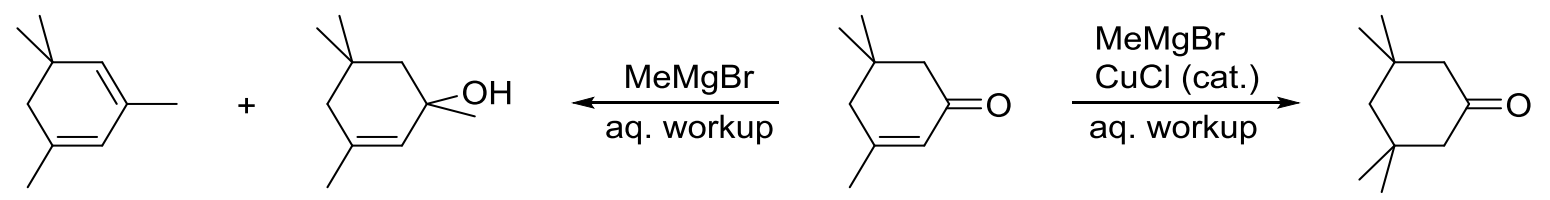

Scheme 3. 1,2- and 1,4-addition of MeMgBr to the conjugated enone isophorone in the absence and presence of catalytic amounts of $\mathrm{CuCl}^{[14]}$

Corey, ${ }^{[15]}$ House, ${ }^{[16]}$ Whitesides, ${ }^{[17]}$ and Posner ${ }^{[18]}$ pioneered in demonstrating the potential of organocuprates in preparative organic chemistry. Nowadays, the numerous applications of these reagents include conjugate additions, ${ }^{\left[{ }^{[g, 19-21]}\right.}$ nucleophilic substitution of alkyl halides, ${ }^{[4, \mathrm{~h}, 19,20,22]}$ epoxide-opening reactions, ${ }^{[4,19]}$ and carbocupration of alkynes ${ }^{[19 a, 23]}$. Organocopper reagents have also successfully been used in in the preparation of trifluoromethylated compounds, a substance class of increasing importance, especially in the fields of pharmaceutical chemistry and agrochemistry. ${ }^{[24,25]}$ A possible way to bring about this transformation is the copper-mediated trifluoromethylation employing the so-called Ruppert-Prakash reagent, that is, $\mathrm{Si}\left(\mathrm{CH}_{3}\right)_{3} \mathrm{CF}_{3} .{ }^{[26]}$ The preparation of the latter was reported by Ruppert et. al. in 1984, and its use as a trifluoromethylating reagent was first described by Prakash, Krishnamurti, and Olah in $1989 .{ }^{[27]}$ Since then, it has been used in trifluoromethylation reactions of a broad range of substrates, ${ }^{[26]}$ including arenes, ${ }^{[28]}$ heteroarenes, ${ }^{[28 c, d, f-h, j-1, n-q, 29]}$ alkenes, ${ }^{[28 f, 30]}$ and alkynes ${ }^{[9 b, 25 e, g, 26 a, 31]}$. Trifluoromethylated alkynes are of particular interest as versatile building blocks for pharmaceuticals and agrochemicals.

In contrast, the use of ate complexes of the heavier homologues silver and gold in synthetic organic chemistry is less explored. The first reports about silver-mediated coupling reactions were published between 1929 and 1940 by Gardner and coworkers, who discovered that reactions of Grignard reagents with stoichiometric amounts of silver salts gave rise to homo- and cross-coupling reactions. ${ }^{[32]}$ During the 1970s, Kochi and Tamura demonstrated silver-catalyzed coupling of Grignard reagents and alkyl halides. ${ }^{[3]}$ Almost a decade later, Vermeer, Kleijn, Westmijze, Meijer, and coworkers showed that organosilver compounds, $\mathrm{RAg}$, and organoargentates $(\mathrm{I}), \mathrm{R}_{2} \mathrm{AgMgCl}$, are able to undergo addition reactions with various substrates, including enynes, 2-alkyne-nitriles, carbon disulfide, propargylic esters, conjugated enynes, enynenitriles, 2,4-pentadiynynl sulfinates, as well as enynyl sulfides, -sulfoxides, and -phospines. ${ }^{[34]}$ These transformations often proceeded with regioand stereoselectivity complementary to those of the analogous organocopper reagents. Kochi and coworkers also reported the preparation of dialkylaurate(I) species by treatment of a gold(I) precursor with organolithium reagents, and their use in the preparation of trialkylgold(III) complexes by oxidative addition reactions with various alkyl or aryl halides. ${ }^{[35]}$ They noticed that the organoaurates undergo oxidative addition much faster than a neutral gold(I) species and observed reductive elimination reactions of the resulting $A u(I I I)$ species. ${ }^{[35,36]}$ Notably, the latter reaction proceeded without significant $\beta$-hydrogen elimination as side reaction. ${ }^{[36]}$ Despite this synthetic potential, organoargentate and -aurate reagents are not widely employed in synthetic organic 
chemistry. ${ }^{[37-39]}$ In part, this neglect may be attributed to the higher prices of silver and gold compared to copper, especially when these metals are used in stoichiometric amounts. However, since the beginning of the $21^{\text {st }}$ century, there has been a growing interest in silver- and goldmediated transformations. ${ }^{[40]}$ This holds promise to increase the interest in organoargentates and aurates, as their use might offer alternative modes of reactivity that complement those of the wellestablished cuprates, thereby providing alternatives for synthetic chemistry.

\subsection{Structure, Solution Speciation, and Reactivity of Group 11-Organometallates}

\subsubsection{Solid-State Structure}

The structures of organocuprates in the solid state have been extensively studied by X-ray crystallography and depend on a variety of factors such as the nature of the organic group $R$, the solvent from which the crystals were obtained, and the presence of additives or byproducts. ${ }^{[41]}$ Crystallization from polar solvents such as 1,2-dimethoxyethane or THF can afford structures with separated ion pairs, which consistently feature linear $\left[\mathrm{CuR}_{2}\right]^{-}$anions. ${ }^{[41]}$ In particular, $\left[\mathrm{CuMe}_{2}\right]^{-},{ }^{[42]}$ $\left[\mathrm{CuPh}_{2}\right]^{-},{ }^{[42 a]}\left[\mathrm{Cu}\left\{\mathrm{CH}_{2}\left(\mathrm{SiMe}_{3}\right)\right\}_{2}\right]^{-},{ }^{[42 c]}\left[\mathrm{Cu}\left\{\mathrm{C}\left(\mathrm{SiMe}_{3}\right)_{3}\right\}_{2}\right]^{-[43]}$ and $\left[\mathrm{Cu}\left(\mathrm{CF}_{3}\right)_{2}\right]^{-[9 a]}$ have been observed. Furthermore, polynuclear organocuprate anions have also been identified by $\mathrm{X}$-ray crystallography. Particularly noteworthy is a series of anions that comprise the pentanuclear species $\left[\mathrm{Li}_{2} \mathrm{Cu}_{3} \mathrm{Ph}_{6}\right]^{-}{ }^{-[44]}$ $\left[\mathrm{LiCu}_{4} \mathrm{Ph}_{6}\right]^{-},{ }^{[45]}$ and $\left[\mathrm{Cu}_{5} \mathrm{Ph}_{5}\right]^{-[46]}$ (Figure 1). While the first species crystallized from the reaction of $\mathrm{CuCN}$ and two equivalents of $\mathrm{PhLi}$ in $\mathrm{Et}_{2} \mathrm{O}$, the latter two were obtained from the reaction of $\mathrm{CuBr}$ with two equivalents of $\mathrm{PhLi}$ in THF or $\mathrm{Et}_{2} \mathrm{O}$, respectively. The structure of the $\left[\mathrm{Li}_{2} \mathrm{Cu}_{3} \mathrm{Ph}_{6}\right]^{-}$anion can be regarded as an aggregate of three $\left(\mathrm{CuPh}_{2}\right]^{-}$units forming the edges of a distorted trigonal prism, and two lithium cations sitting at the centers of the two trigonal faces of the prism. Thus, the three metals form a trigonal bipyramid with the copper cations residing at the equatorial vertices and the lithium cations occupying the axial sites. $\left[\mathrm{LiCu}_{4} \mathrm{Ph}_{6}\right]^{-}$and $\left[\mathrm{Cu}_{5} \mathrm{Ph}_{5}\right]^{-}$adopt analogous structures with $\mathrm{Li}^{+}$ successively replaced by $\mathrm{Cu}^{+}$. The reaction of $\mathrm{CuCl}$ with thienylmagnesium bromide in THF yielded a magnesium cuprate with the $\left[\mathrm{Cu}_{5} \mathrm{R}_{6}\right]^{-}$anion $(\mathrm{R}=$ thienyl), which is structurally directly comparable to $\left[\mathrm{Cu}_{5} \mathrm{Ph}_{5}\right]^{-[47]}$
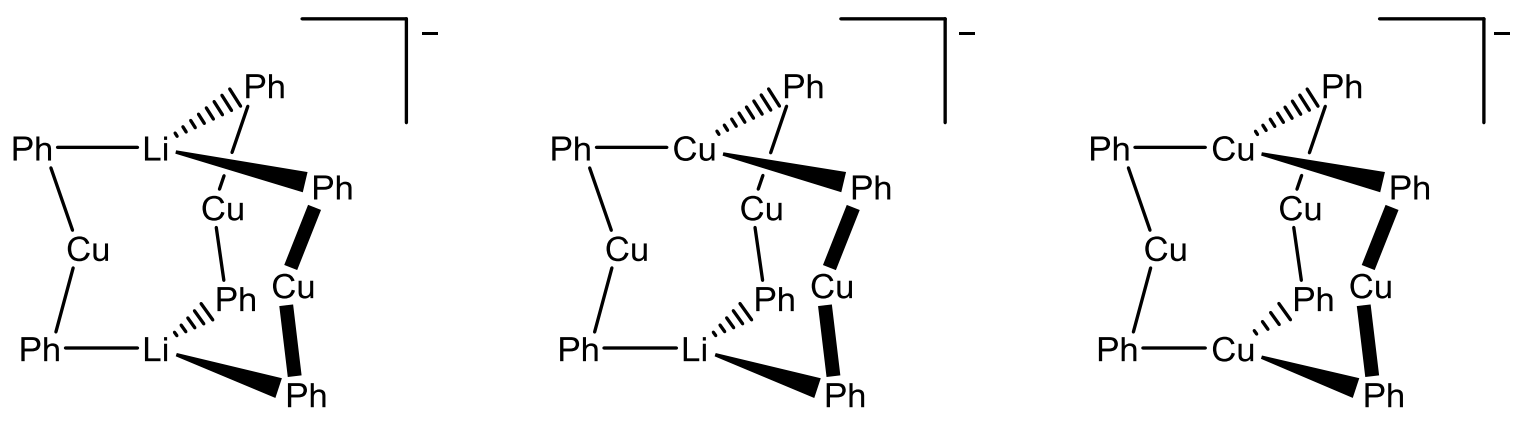

Figure 1. Pentanuclear phenylcuprate anions identified by X-ray crystallography. ${ }^{[4,45,46]}$

The solid-state structures of organoargentates and -aurates have not been explored to this extent, but still, crystal structures exist that show $\left[\mathrm{MR}_{2}\right]^{-}$anions. In particular, coinage metallates with perfluorinated organic groups such as $\left[\mathrm{Ag}\left(\mathrm{CF}_{3}\right)_{2}\right]^{-},{ }^{[48]}\left[\mathrm{Ag}\left(\mathrm{CF}_{3}\right) \mathrm{Cl}\right]^{-},{ }^{[49]}\left[\mathrm{Ag}\left(\mathrm{C}_{2} \mathrm{~F}_{5}\right)_{2}\right]^{-[50]}\left[\mathrm{Ag}\left\{\mathrm{CF}\left(\mathrm{CF}_{3}\right)_{2}\right\}_{2}\right]^{-[51]}$ $\left.\left[\mathrm{Au}\left(\mathrm{CF}_{3}\right)_{2}\right]^{-},{ }^{[52]}\left[\mathrm{Au}\left(\mathrm{C}_{6} \mathrm{~F}_{5}\right)_{2}\right]^{-}\right]^{[53]}$ and $\left[\mathrm{Au}\left(\mathrm{CF}_{3}\right)\left(\mathrm{C}_{6} \mathrm{~F}_{5}\right)\right]^{-[54]}$ have been identified. The halogen-free, monomeric anions $\left[\mathrm{Ag}\left\{\mathrm{C}\left(\mathrm{SiMe}_{3}\right)_{3}\right\}_{2}\right]^{-[55]}\left[\mathrm{Ag}\left(\mathrm{C}_{3} \mathrm{H}_{3}\right)_{2}\right]^{-[56]}$, and $\left[\mathrm{AuMe}_{2}\right]^{-[57]}$ have also been found in the 
solid state. Like the mononuclear organocuprates, these argentates and aurates exhibit a linear coordination geometry. The pentanuclear argentate $\left[\mathrm{Li}_{2} \mathrm{Ag}_{3} \mathrm{Ph}_{6}\right]^{-}$has also been characterized by $\mathrm{X}$-ray crystallography and exhibits a structure analogous to the pentanuclear cuprates discussed above. ${ }^{[58]}$

Crystal structures of organometallates(III) feature $\left[\mathrm{MR}_{4}\right]^{-}$anions with a square-planar geometry for all three coinage metals. Notable examples include $\left[\mathrm{Cu}\left(\mathrm{CF}_{3}\right)_{4}\right]^{-},{ }^{[59]}\left[\mathrm{Ag}\left(\mathrm{CF}_{3}\right)_{4}\right]^{-},{ }^{[48,60]}\left[\mathrm{Au}\left(\mathrm{CF}_{3}\right)_{4}\right]^{-}$, ${ }^{[61]}$ $\left[\mathrm{Cu}\left(\mathrm{CF}_{2} \mathrm{H}\right)_{4}\right]^{-},{ }^{[62]}\left[\mathrm{Ag}\left(\mathrm{CF}_{2} \mathrm{H}\right)_{4}\right]^{-},{ }^{[63]} \quad\left[\right.$ trans- $\mathrm{Ag}\left(\mathrm{CF}_{3}\right)_{2}\left(\mathrm{CN}_{2}\right]^{-},{ }^{[64]} \quad\left[\mathrm{Ag}\left(\mathrm{CF}_{3}\right)_{3}\left(\mathrm{CH}_{3}\right)\right]^{-[64]}\left[\mathrm{Au}\left(\mathrm{CF}_{3}\right)_{3}(\mathrm{CN})\right]^{-},{ }^{665]}$ $\left[\mathrm{Au}\left(\mathrm{C}_{6} \mathrm{~F}_{5}\right)_{4}\right]^{-},{ }^{[66]}$ and $\left[\mathrm{Au}\left(\mathrm{C}_{6} \mathrm{Cl}_{5}\right)_{4}\right]^{-[67]}$ as well as the non-halogenated complexes $\left[\mathrm{AuMe}_{4}\right]^{-[57]}$ and $\left[\mathrm{AuPh}_{4}\right]^{-[68]}$.

\subsubsection{Speciation in Solution}

The frequent use of organocuprates in organic synthesis has evoked investigations regarding their speciation in solution. ${ }^{[69]}$ In particular, several studies of lithium organocuprates by Bertz ${ }^{[70]}$ and others ${ }^{[71]}$ found the $\left[\mathrm{CuR}_{2}\right]^{-}$anion to be the main component of both Gilman and cyanocuprates. These studies employed NMR and X-ray absorption spectroscopy as well as theoretical calculations and, thereby, settled the controversy between lower-order cuprates, $\mathrm{LiCuR}_{2} \cdot \mathrm{LiCN}$, and the so-called higher order cuprates, $\mathrm{Li}_{2} \mathrm{CuR}_{2}(\mathrm{CN})$, in favor of the former one. ${ }^{[72]}$ Further NMR studies from the Boche group revealed an equilibrium between solvent-separated ion pairs of $\left[\mathrm{CuR}_{2}\right]^{-}$and $[\mathrm{Li}(\mathrm{Solv})]^{+}$ and a dimeric contact ion pair (solv) $\mathrm{Li}_{2} \mathrm{Cu}_{2} \mathrm{R}_{2}$ (Scheme 4). ${ }^{[73]}$ The latter species, the so-called homodimer, is believed to prevail in weakly coordinating solvents such as $\mathrm{Et}_{2} \mathrm{O}$, while the results indicate the preferred formation of solvent-separated ion pairs in the more strongly coordinating solvent tetrahydrofuran (THF).
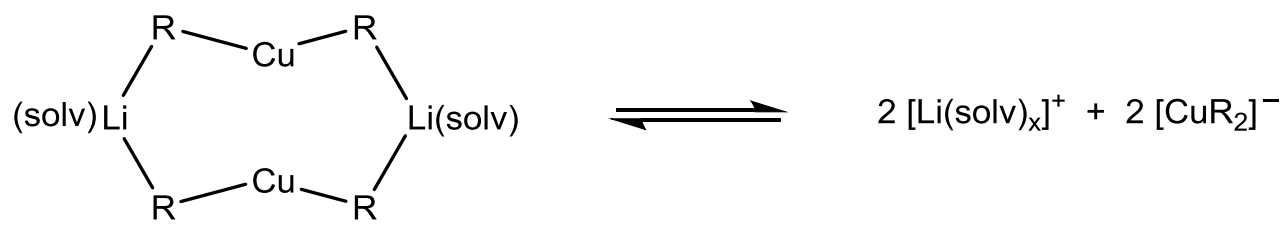

Scheme 4. Association/dissociation equilibrium of lithium organocuprates. ${ }^{[73]}$

Putau et. al. used ESI mass spectrometry and gas-phase fragmentation experiments to determine the structure and aggregation state of organocuprates in ethereal solvents. ${ }^{[74]}$ They observed the cyanide-free anions $\left[\mathrm{Li}_{n-1} \mathrm{Cu}_{n} \mathrm{R}_{2 n}\right]^{-}(n=1$ and 3$)$ together with $\left[\mathrm{Li}_{2}(\mathrm{CN})(\mathrm{solv})_{n}\right]^{+}$cations as predominant species upon mass-spectrometric analysis of $\mathrm{LiCuR}_{2}$. LiCN solutions. The anionic species were found to be in equilibrium with each other. The authors could show that the position of this equilibrium strongly depends on the solvent. Additional electrical conductivity measurements fully confirmed the ESI MS results. ${ }^{[74 b]}$ While the mononuclear cuprate $\left[\mathrm{CuR}_{2}\right]^{-}$is the dominating species in the more polar THF, higher aggregation states prevail in less polar solvents like $\mathrm{Et}_{2} \mathrm{O}$. Furthermore, they concluded from the results of fragmentation experiments that $\left[\mathrm{Li}_{2} \mathrm{Cu}_{3} \mathrm{R}_{6}\right]^{-}$can be regarded as an adduct of anionic $\left[\mathrm{CuR}_{2}\right]^{-}$and neutral $\mathrm{Li}_{2} \mathrm{Cu}_{2} \mathrm{R}_{4}$. Both species had previously been identified as major components of ethereal cyanocuprate solutions (see above). While the molecular composition of lithium cuprates has been well studied, the solution speciation of magnesium cuprates remains only poorly understood. ${ }^{[41]}$ This lack in understanding of magnesium cuprates might - at least partially - be attributed to the spectroscopic properties of magnesium. In contrast to lithium that can be readily studied by NMR spectroscopy, magnesium is more reluctant to analysis by NMR. 
NMR spectroscopy was also used to study organoargentates and -aurates. Eaborn et. al. deduced from ${ }^{6} \mathrm{Li}$ - and ${ }^{7} \mathrm{Li}-\mathrm{NMR}$ spectroscopic experiments that the lithium organoargentate $\left[\mathrm{Li}(\mathrm{THF})_{4}\right]\left[\mathrm{Ag}\left\{\mathrm{C}\left(\mathrm{SiMe}_{3}\right)\right\}_{2}\right]$ dissociates into the corresponding ions upon dissolution in heptane or toluene. ${ }^{[55]}$ Burch and Calabrese used ${ }^{19} \mathrm{~F}$-NMR techniques to study perfluoroalkylsilver(I) compounds. They were able to show that in acetonitrile, neutral $\operatorname{AgR}\left(\mathrm{CH}_{3} \mathrm{CN}\right)$ is present in an equilibrium with solvated $\mathrm{Ag}^{+}$and the argentate $\left[\mathrm{AgR}_{2}\right]^{-}\left(\mathrm{R}=\mathrm{CF}\left(\mathrm{CF}_{3}\right)_{2}\right){ }^{[51]}$ Stating that this behavior is related to the known equilibrium of the silver halides (Eq. 1), ${ }^{[75]}$ the authors suggested to regard the perfluoroalkyl groups as pseudohalogens. Naumann et. al. also performed ${ }^{19} \mathrm{~F}$-NMR experiments to examine the solvent dependency of this equilibrium and found hints for higher aggregates in solution. ${ }^{[76]}$

$$
2 \mathrm{AgX} \rightleftharpoons \mathrm{Ag}^{+}+\left[\mathrm{AgX}_{2}\right]^{-}
$$

Based on the results of ${ }^{1} \mathrm{H}$-NMR experiments of dimethylaurate solutions, Tamaki and Kochi noticed an exchange of ligands in solution, ${ }^{[7]}$ but suggested that association of $\left[\mathrm{AuMe}_{2}\right]^{-}$with excess MeLi takes place only to a small extent, or not at all. ${ }^{[78]}$ Rice and Tobias published results of ${ }^{1} \mathrm{H}-\mathrm{NMR}$ and Raman spectroscopy of lithium methylaurates(I) and (III) in diethyl ether, which were in accordance with solvent separated ion pairs of solvated $\mathrm{Li}^{+}$and $\left[\mathrm{AuMe}_{2}\right]^{-}$or $\left[\mathrm{AuMe}_{4}\right]^{-}$, respectively. ${ }^{[79]}$ They found the aurate(I) to be coordinated by the two methyl group in a linear way, and the aurate(III) featuring a square-planar geometry.

Usón et. al. reported the preparation and characterization of several anionic arylgold complexes. ${ }^{[80]}$ The infrared spectra of the aurates $(\mathrm{I})\left[\mathrm{Au}\left(\mathrm{C}_{6} \mathrm{~F}_{5}\right) \mathrm{X}\right]^{-}(\mathrm{X}=\mathrm{Cl}, \mathrm{Br})$ and the related aurates(III) $\left[\mathrm{Au}\left(\mathrm{C}_{6} \mathrm{~F}_{5}\right)_{3} \mathrm{Br}\right]^{-}$and $\left[\mathrm{Au}\left(\mathrm{C}_{6} \mathrm{~F}_{5}\right) \mathrm{Br}_{3}\right]^{-}$were consistent with a linear coordination of the aurates $(\mathrm{I})$ and a square-planar geometry of the aurates(III). ${ }^{[80 a]}$ Furthermore, the examination of their electric conductivities showed that these organoaurates behaved as 1:1 electrolytes, thereby pointing to the presence of solvent-separated ion pairs in solution. ${ }^{[80 \mathrm{a}]}$ Various trifluoromethyl-argentates ${ }^{[81]}$ and -aurates ${ }^{[61,65]}$ were also characterized by ${ }^{1} \mathrm{H}-,{ }^{13} \mathrm{C}-,{ }^{19} \mathrm{~F}-$, and ${ }^{109} \mathrm{Ag}-\mathrm{NMR}$. However, in contrast to the organocuprates, little is known about possible equilibria between solvent-separated ion pairs and contact ion pairs of organoargentates and -aurates or the presence of higher aggregates of these metallates.

\subsubsection{Reactivity}

The high reactivity of organocuprates and their use in synthetic organic chemistry has led to a number of mechanistic investigations, ${ }^{[82]}$ because a deeper understanding of their mode of action at the molecular level is not only of scientific interest by itself, but also promises the directed use of rationally designed reagents under optimized conditions. Usually, organocuprate reagents employed in synthesis feature $\mathrm{Cu}(\mathrm{I})$ species with a $3 d^{10}$ valence electron configuration. However, the involvement of $\mathrm{Cu}(\mathrm{III})$ species with a $3 d^{8}$ configuration has long been postulated for several types of transformation of organocuprates. ${ }^{[17,82 a, 83]}$ Indeed, seminal results obtained from low-temperature NMR spectroscopic experiments by Bertz, Ogle, and coworkers as well as the Gschwind group showed $\mathrm{Cu}(\mathrm{III})$ intermediates. ${ }^{[84,85]} \mathrm{ESI}$ mass spectrometry and gas-phase fragmentation experiments allowed the examination of their unimolecular reactivity. ${ }^{[86]}$ Gas-phase fragmentation experiments of the tetraalkylcuprates(III) $\left[\mathrm{RCuMe}_{3}\right]^{-}$prepared from $\mathrm{CuCN}, \mathrm{MeLi}$, and alkyl halides RX revealed that these species undergo reductive elimination, resulting in the release of both the cross-coupling product $\mathrm{RMe}$ and the homo-coupling product $\mathrm{Me}_{2}$ (Scheme 5). ${ }^{[86 \mathrm{a}]}$ The ratio between these two fragmentation pathways was found to depend on the nature of the substituent $R$. 


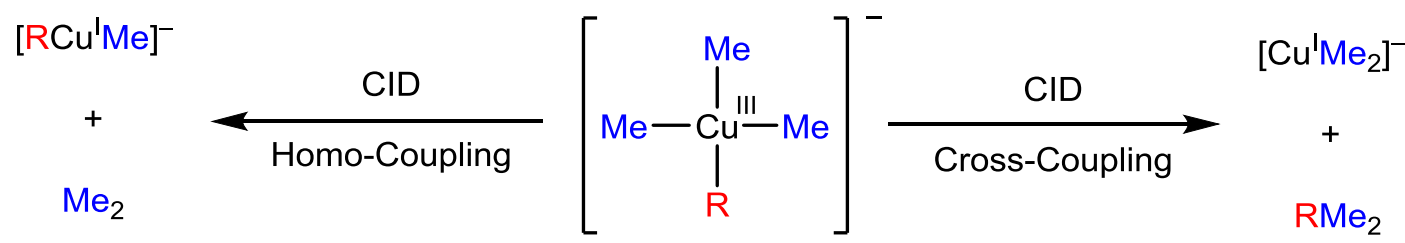

Scheme 5. Gas-phase reactivity of tetraalkylcuprates(III) observed in collision-induced dissociation (CID) experiments. ${ }^{[86]}$

A reaction mechanism involving $\mathrm{Cu}(\mathrm{III})$ intermediates has also been developed for the conjugate addition of organocuprates to $\alpha, \beta$-unsaturated carbonyl compounds, one of the most important applications of organocuprates. ${ }^{[87]}$ This mechanism features as key steps the oxidative addition of an enone to the cuprate, resulting in the formation of a $\mathrm{Cu}(\mathrm{III})$ intermediate, and a subsequent reductive elimination. ${ }^{[82 b, 83 a, b, 88]}$ The selectivity for 1,4-addition over 1,2-addition is ascribed to the preference of $\mathrm{Cu}(\mathrm{l})$ to form a $\pi$-complex with the $\mathrm{C}-\mathrm{C}$ double bond rather than with the $\mathrm{C}-\mathrm{O}$ double bond. ${ }^{\left[{ }^{[2 b]}\right.}$ Also, the presence of the Lewis-acidic lithium is regarded necessary for the activation of the substrate through electrophilic assistance. ${ }^{[83 a]}$

Furthermore, Chu and Qing reported the copper-mediated trifluoromethylation of terminal alkynes in an oxidative fashion. ${ }^{[26 a, 281,31 a]}$ These authors also conducted preliminary mechanistic studies and proposed a mechanism for this reaction, in which 1,10-phenanthroline-bound cuprate anions play a key role in the formation of both the desired trifluoromethylated product as well as an unwanted diyne byproduct (Scheme 6). ${ }^{[26 a, 281,31 a]}$

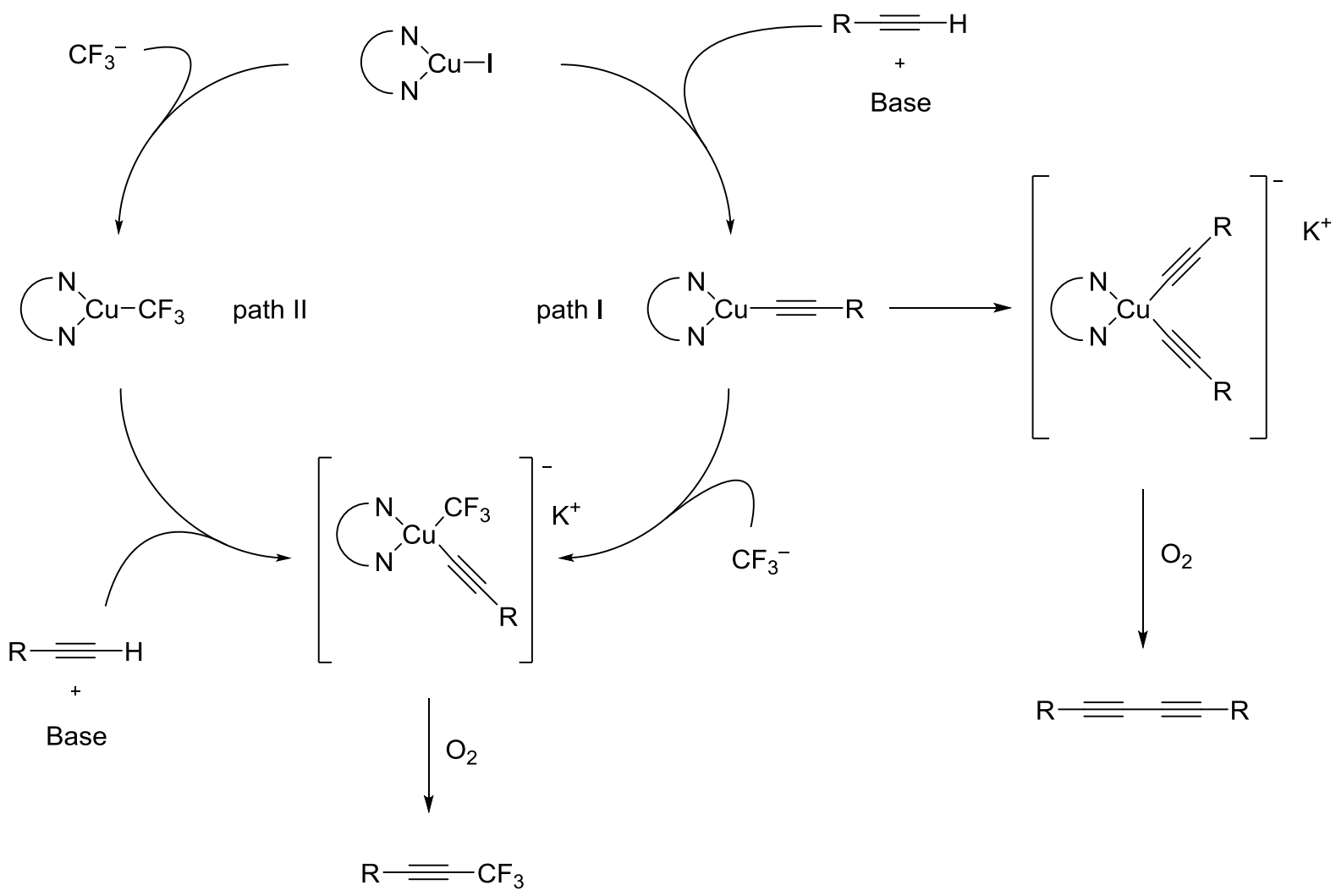

Scheme 6. Reaction mechanism for the copper-promoted oxidative trifluoromethylation of terminal alkynes with $\mathrm{Si}\left(\mathrm{CH}_{3}\right)_{3} \mathrm{CF}_{3}$ and 1,10-phenanthroline as proposed by Chu and Qing. ${ }^{[26 a]}$ 
Tresse et. al. also used $\mathrm{Si}\left(\mathrm{CH}_{3}\right)_{3} \mathrm{CF}_{3}$ for the copper-mediated oxidative trifluoromethylation of a wide range of alkynes and started to investigate the involved intermediates. ${ }^{[9 b]}$ By employing ${ }^{19} \mathrm{~F}-\mathrm{NMR}$ spectroscopy, they observed the formation of the trifluoromethyl cuprates $\left[\mathrm{Cu}\left(\mathrm{CF}_{3}\right)_{2}\right]^{-}$and $\left[\mathrm{Cu}\left(\mathrm{CF}_{3}\right)_{4}\right]^{-}$ upon treatment of $\mathrm{Cul}$ with $\mathrm{Si}\left(\mathrm{CH}_{3}\right)_{3} \mathrm{CF}_{3}, \mathrm{~N}, \mathrm{~N}, \mathrm{~N}^{\prime}, \mathrm{N}^{\prime}$-tetramethylethylene diamine (TMEDA), and potassium carbonate (Scheme 7). Still, the origin of these intermediates and the mechanism of the overall reaction remained unclear.

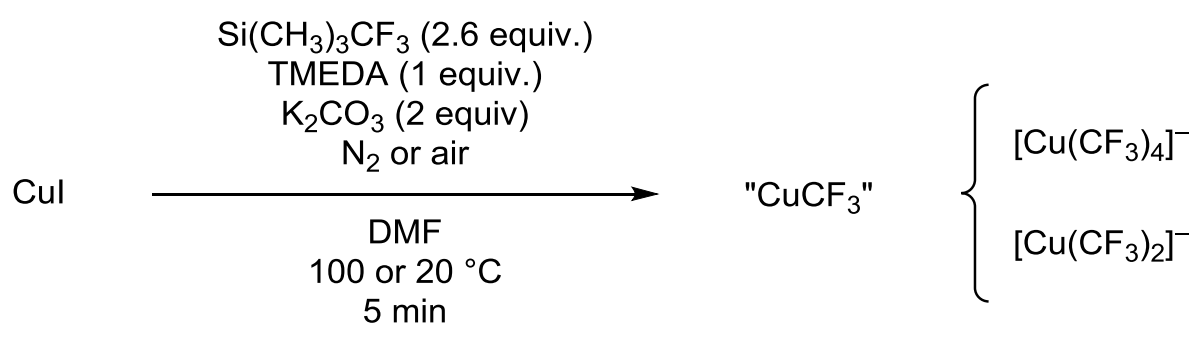

Scheme 7. Preparation of trifluoromethyl cuprates by Tresse et. al. ${ }^{[9 b]}$

Just as little progress has been made in the mechanistic elucidation of silver-mediated or -catalyzed coupling reactions. ${ }^{[33,37,39 a, 866,89]}$ In particular, the role of organoargentates in these transformations has received only little attention. ${ }^{[39 b]}$ Recently, however, Hardin and Ogle used rapid-injection NMR spectroscopy to study the reaction of LiAgMe2. $\mathrm{LiCl}$ with allyl iodide in THF. ${ }^{\left[{ }^{90]}\right.}$ They were able to observe the oxidative addition of the organyl iodide to the argentate, resulting in the formation of the organoargentate(III) $\left[\mathrm{RAgMe}_{3}\right]^{-}(\mathrm{R}=$ allyl). This $\mathrm{Ag}(\mathrm{III})$ species slowly released 1-butene via a reductive elimination.

\subsection{ESI Mass Spectrometry of Organometallates - Potential and Limitations}

Building upon pioneering work by the Lipshutz group, ${ }^{[91]}$ numerous studies have applied electrospray-ionization (ESI) mass spectrometry for the analysis of charged organometallics. ${ }^{[7,86 a, 92]}$ This method has proven to be a valuable tool for mechanistic investigations as it offers precise information about the stoichiometric composition of the present ionic species and can provide detailed insight into their unimolecular reactivity by gas-phase fragmentation experiments ${ }^{[93]} \mathrm{A}$ prerequisite for these experiments is the transfer of organometallic ions from the sample solutions into the gas phase. Electrospray ionization is well capable of this task, but it is mandatory to work under inert conditions to avoid decomposition of the sensitive organometallic species and to ensure constant experimental conditions. To this end, the ESI inlet system has to be flushed thoroughly with dry solvent prior to each mass spectrometric experiment.

However, it should be kept in mind that ESI mass spectrometry, like all mass spectrometric techniques, can only detect charged species. It is therefore necessary that the analytes are either $a$ priori charged species or at least form adducts with ions that are also present in the sample solution. A possible way to circumvent this shortcoming can be the use of charged tags that introduce a charge on otherwise neutral species. ${ }^{[92 \mathrm{~g}, 93 \mathrm{~d}, 94]}$ Moreover, the detected ions stem from charged nanodroplets that are generated during the ESI process (see also chapter 3.2), and the composition of these nanodroplets can differ from that of the sample solution itself. In particular, as shown by previous studies, the analyte concentration in these nanodroplets is higher than in the original sample solution, ${ }^{[95]}$ and their effective temperature may change, too. ${ }^{[96]}$ The increased concentration of 
analytes in the nanodroplets can result in a shift of equilibria that are already present in the sample solutions. In particular, a shift to higher aggregation states is possible. ${ }^{[74 a]}$ Therefore, the observed aggregates or the ratio of these aggreagates may not necessarily be identical to those in solution. Also, the observed signal intensities are not directly proportional to the concentrations of the respective species in the sample solutions, but depend on their concentration in the nanodroplets from where they are emitted into the gas phase, and, additionally, on the response factors of the respective ions. These response factors correlate with the surface activity of the analyte ions: the higher the surface activity, the higher the tendency to be ejected into the gas phase. ${ }^{[97]}$ Therefore, a quantitative analysis is not straightforward. However, quantitative statements may be possible if a suitable calibration can be performed. 
Parts of the following section ("2 Objectives") were taken from or are based on the publications given below.

The Role of Ate Complexes in the Copper-Mediated Trifluoromethylation of Alkynes Sebastian Weske, Ramona Schoop, Konrad Koszinowski, Chemistry - A European Journal, 2016, 22, 11310-11316.

DOI : 10.1002/chem.201601261

https://onlinelibrary.wiley.com/doi/full/10.1002/chem.201601261

Copyright Wiley-VCH Verlag GmbH \& Co. KGaA. Reproduced with permission.

Argentate(I) and (III) complexes as intermediates in silver-mediated cross-coupling reactions Sebastian Weske, Richard A. Hardin, Thomas Auth, Richard A. J. O'Hair, Konrad Koszinowski, Craig A. Ogle, Chemical Communications 2018, 54, 5086-5089.

DOI: $10.1039 / \mathrm{c} 8 \mathrm{cc} 01707 \mathrm{~g}$

https://pubs.rsc.org/en/content/articlelanding/2018/cc/c8cc01707g\#!divAbstract

Reproduced with permission from the Royal Society of Chemistry. 


\section{Objectives}

Despite the frequent use of magnesium organocuprates(I) in organic synthesis, the molecular composition of these reagents remains poorly understood. To achieve a better understanding of their speciation in solution, organocuprate reagents prepared from copper(I) precursors and Grignard reagents $\mathrm{RMgCl}\left(\mathrm{R}=\mathrm{Ph}\right.$, 2-thienyl, $\mathrm{Bu}$, and $\left.\mathrm{Me}_{3} \mathrm{SiCH}_{2}\right)$ in THF were to be analyzed by ESI mass spectrometric experiments. The influence of the copper precursor $\left(\mathrm{CuCl}, \mathrm{CuBr}, \mathrm{CuBr} \cdot \mathrm{Me}_{2} \mathrm{~S}\right.$, CuCN), the amounts of employed Grignard reagent $(2,3$, or 4 equivalents), and the reaction time was to be studied. In particular, the obtained results from the analysis of the magnesium cuprates had to be compared with the known behavior of their lithium-containing counterparts.

Organometallates(I) of the higher homologues silver and gold have been studied even less. In order to identify the ionic components of these reagents and to examine trends in the speciation and aggregation across group-11 organometallates, sample solutions prepared from the respective coinage-metal cyanides $\mathrm{MCN}(\mathrm{M}=\mathrm{Cu}, \mathrm{Ag}, \mathrm{Au})$ and $\mathrm{RLi}$ or $\mathrm{RMgCl}(\mathrm{R}=\mathrm{Ph}, \mathrm{Me})$ in THF were to be investigated by ESI mass spectrometry. Furthermore, comparing the fragmentation behavior of corresponding organometallate species upon collisional activation should provide insight into the influence of the kind of coinage metal on the unimolecular reactivity of the respective organometallates.

$\mathrm{Cu}(\mathrm{III})$ intermediates have long been postulated to be involved in $\mathrm{C}-\mathrm{C}$ bond forming reactions brought about by organocopper(I) reagents, and, eventually, several organocopper(III) species were detected and characterized. Recently, trifluoromethylcuprates(I) and (III) were observed in the coppermediated oxidative trifluoromethylation of alkynes employing a copper(I) halide and $\mathrm{Si}\left(\mathrm{CH}_{3}\right)_{3} \mathrm{CF}_{3}$. However, the origin of these intermediates and the mechanism of the overall reaction remained unclear. In the present work, ESI mass spectrometry and gas-phase fragmentation experiments were used to investigate the mechanism of these transformations in different solvents $\left(\mathrm{THF}, \mathrm{CH}_{2} \mathrm{Cl}_{2}\right.$, $\mathrm{CH}_{3} \mathrm{CN}$ ) as well as with and without added 1,10-phenanthroline.

Unlike organocuprates, organoargentates are not widely used in coupling reactions, although early work demonstrated the potential of silver to mediate these transformations. In particular, the role of organoargentates(I) and (III) as intermediates in these reactions has received only little attention. The present work sought to explore the formation of organoargentates(III) in oxidative addition reactions of dimethylargentate and organyl iodides $\mathrm{RI}(\mathrm{R}=\mathrm{Me}$, allyl, $\mathrm{Bu}, \mathrm{Ph})$ with $\mathrm{ESI}$ mass spectrometry, and to examine the elementary step of reductive elimination from these $\mathrm{Ag}$ (III) species by gas-phase fragmentation experiments. Comparing the reactivity of argentates(III) and cuprates(III) will provide mechanistic insights that improve the fundamental understanding of the role of highvalent transition metals in cross-coupling reactions.

The insight into the speciation of organocuprates, -argentates, and -aurates and the improved mechanistic understanding provided by this work will not only contribute to our knowledge about organometallic reagents in general, but should also facilitate the rational optimization of these reagents for their well-directed use in synthetic chemistry. 


\section{ESI Mass Spectrometry and Gas-Phase Fragmentation Experiments}

\subsection{General Aspects of Mass Spectrometry}

Mass spectrometry is an analytical technique for the study of ions in the gas phase. ${ }^{[98]}$ In a mass spectrometer, gas-phase ions, which are generated from a sample in an ion source, are separated according to their mass-to-charge $(\mathrm{m} / \mathrm{z})$ ratio in a mass analyzer and registered with their respective abundances in a detector. A plot of the relative signal intensity against the $\mathrm{m} / \mathrm{z}$ ratio yields a mass spectrum, which provides information about the charge and molecular mass of the analyte ions. Additionally, the isotopic patterns, which result from different isotopic compositions of elements with more than one isotope, can serve as a fingerprint for the identification of different ions. Further information can be obtained by deliberate fragmentation of particular ions in collision-induced dissociation (CID) experiments. ${ }^{[99]}$ To this end, isolated precursor ions are subjected to collisions with a collision gas. The thus produced fragment ions are also separated and detected according to their $\mathrm{m} / \mathrm{z}$ ratio. For this type of experiments, a mass spectrometer capable of performing two mass analysis steps is necessary. Such an instrument is called tandem (or $\mathrm{MS}^{2}$ ) mass spectrometer.

\subsection{Electrospray lonization}

Electrospray ionization (ESI) is a soft method for the generation of gas-phase ions at ambient pressure with usually little or no fragmentation of analyte ions during the ionization process. ${ }^{[97,100]}$ Therefore, it is well suited for the analysis of particularly sensitive compounds. The use of electrospray, which was already known in the coating of metal surfaces, as an ionization technique in mass spectrometry was first envisaged by Malcolm Dole in the 1960 s. $^{[101]}$ John B. Fenn further developed this technique and was awarded the Nobel prize for his achievements in 2002. ${ }^{[102]}$ During the ESI process, a sample solution containing the analyte is fed through a capillary, to which a high electric potential of several $\mathrm{kV}$ is applied (Scheme 8). ${ }^{[97,100,103]}$ This potential generates an electric field, which in turn leads to charge separation at the liquid surface at the tip of the capillary.

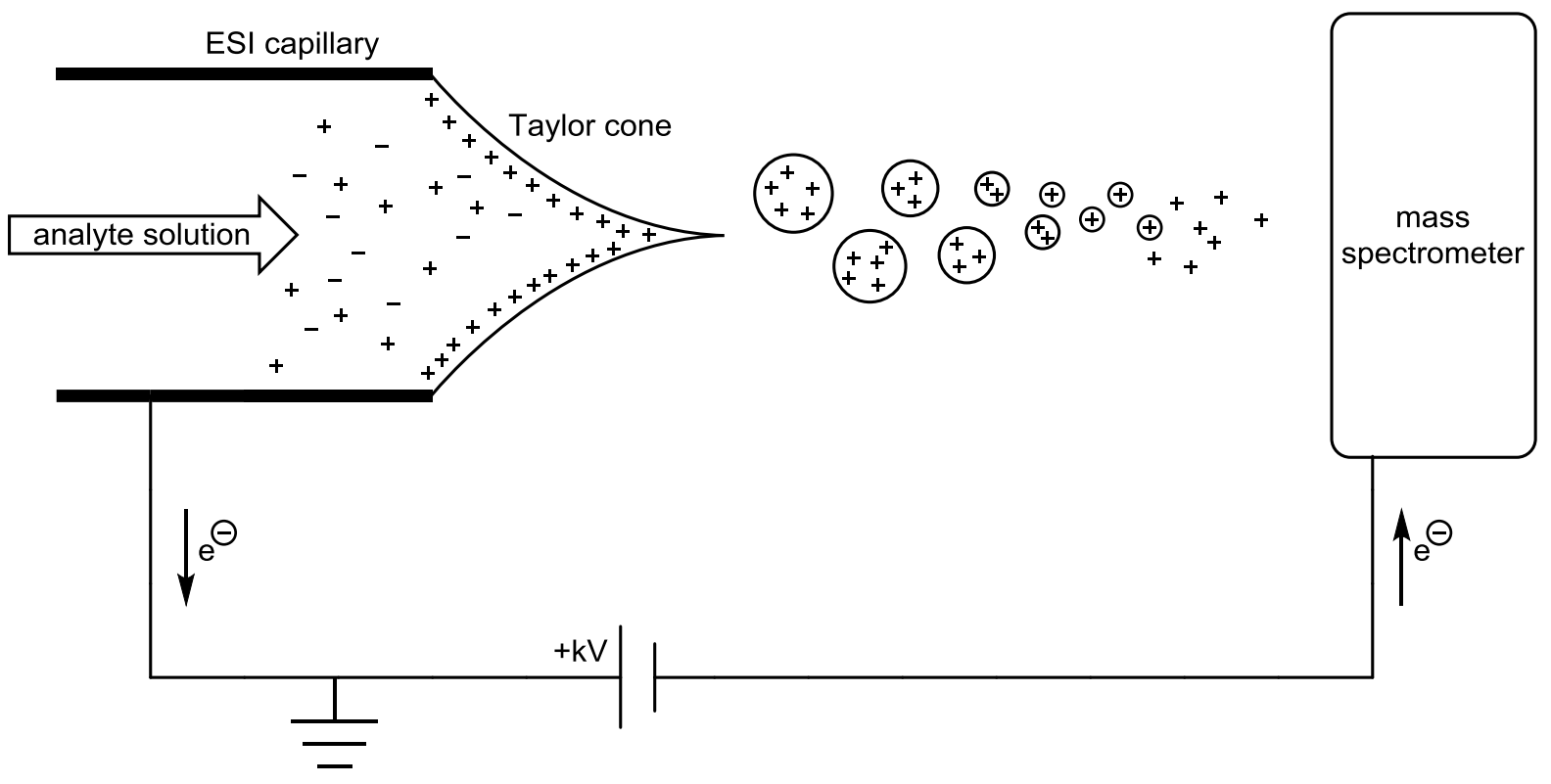

Scheme 8. Schematic depiction of the ESI process (positive-ion mode). ${ }^{[100 b]}$ 
As a result, a so-called Taylor cone ${ }^{[104]}$ is formed. As soon as the Coulombic repulsion of the charges at the surface equals the surface tension of the solution (the point which is known as the Rayleigh limit), a fine spray of small droplets with an excess charge is released from the tip of the Taylor cone. This process is usually supported by a coaxial flow of nebulizer gas. The charged droplets then move in the applied electric field towards the entrance of the mass spectrometer's vacuum system. On their way, the droplets shrink due to solvent evaporation (aided by a stream of heated dry gas), which results in an increase of their charge density. Eventually, the Coulombic repulsion at the droplet surface overcomes the surface tension and, thereby, causes the release of smaller droplets in a process called Coulomb fission. This sequence of evaporation and fission events occurs repeatedly until droplets with radii in the range of a few nanometers are produced. ${ }^{[100 b]}$ The formation of gasphase ions then proceeds from these nanodroplets according to one of the following models. The ion evaporation model applies for the transfer of preformed analyte ions with low molecular weight into the gas phase. ${ }^{[97,100 b]}$ When a nanodroplet reaches the Rayleigh limit due to solvent evaporation, the Coulombic repulsion causes the ejection of solvated ions from the droplet surface into the gas phase. The remaining few solvent molecules are subsequently lost in collisions of the solvated ions with background gas. ${ }^{[100 \mathrm{~b}]}$ The charged residue model describes the release of large and globular species (in particular natively folded proteins) into the gas phase. ${ }^{[97,100 b]}$ In this case, it is assumed that charged nanodroplets are formed that contain only one analyte molecule. The solvent completely evaporates and ions that were formerly residing on the surface of the droplet are transferred to the analyte. For unfolded proteins, however, the so-called chain-ejection model is proposed. ${ }^{[100 b]}$ The unfolded protein chains move to the droplet surface because their extended and hydrophobic character renders it unfavorable to stay in the inside of the droplet. They are then transferred to the gas phase in a step-by-step process.

\subsection{Mass Analyzer}

\subsubsection{Time-of-Flight Mass Analyzer}

In a time-of-flight (TOF) mass analyzer, a pulsed electrostatic field accelerates incoming ions, which then pass a field-free drift region of a given length before they reach the detector. ${ }^{[98,105]}$ During the acceleration step, all ions receive the same kinetic energy, which results in final ion velocities that depend on the mass and charge of the respective ions. These velocities stay constant during the flight through the drift region. As ions with different $m / z$ ratios are accelerated to different velocities, they need distinct times to travel through the drift region before they reach the detector. The determination of the $\mathrm{m} / \mathrm{z}$ ratios of the ions is then possible from the time-of-flight and the known values for the acceleration voltage and the travelled distance. ${ }^{[105]}$ However, before the acceleration step takes place, the ions possess certain initial distributions regarding position and velocity. As a consequence, ions with the same $\mathrm{m} / \mathrm{z}$ ratio exhibit slight deviations in their final kinetic energy, which in turn lead to different flight times and, thus, decrease the resolution of the mass spectrometer. To compensate for these effects, an ion mirror, or reflector, can be used, which reflects the incoming ions by means of an electric field. ${ }^{[105]}$ Ions of the same $m / z$ ratio but with different kinetic energies will penetrate the reflector to different depths before they are repelled. The resulting different flight paths of the ions within the reflector translate into differences in flight time, thereby effecting a correction of the initial deviation in kinetic energy. ${ }^{[105]}$ 


\subsubsection{Linear Quadrupole Mass Analyzer}

The linear quadrupole mass analyzer was developed by Paul and Steinwedel and consists of four parallel rod electrodes that are mounted in a square configuration. ${ }^{[98,106]}$ An electric potential is applied to the electrodes with each pair of opposite electrodes held at the same polarity. This potential is composed of a radio frequency (RF) voltage superimposed with a direct current (DC) voltage. Ions that enter the quadrupole along its z-axis (parallel to the rods) alternatively experience attractive and repulsive forces in the xy-plane due to the applied potential, leading to complex ion trajectories that can be unstable or stable. If the trajectory is unstable, the ions will hit the rods and discharge; but in case of a stable trajectory, the ions will pass the analyzer. Conditions for stable ion trajectories can be derived from a set of parameters obtained from the so-called Mathieu equations. ${ }^{[98,106,107]}$ In particular, these parameters depend on the values for the RF and DC voltage. Therefore, the stability of the trajectory for ions of a certain $\mathrm{m} / \mathrm{z}$ ratio depends on the chosen values for the RF and DC voltage. Continuously varying the the applied potentials allows for scanning across a range of $\mathrm{m} / \mathrm{z}$ ratios, because then only certain ions are able to travel through the analyzer at a given time. Alternatively, it is possible to hold the potentials at fixed values so that only ions within a particular $\mathrm{m} / \mathrm{z}$ ratio are permitted to pass the analyzer. This mode of operation is used for the isolation of precursor ions in $\mathrm{MS}^{2}$ experiments. In contrast, quadrupoles to which only an RF voltage is applied allow all ions to pass and are therefore widely used as ion guides or collision cells. ${ }^{[98]}$

\subsubsection{Three-dimensional Quadrupole Ion Trap}

A three-dimensional quadrupole ion trap is closely related to a linear quadrupole and, therefore, their operation principles are quite similar. ${ }^{[98,108]}$ Wolfgang Paul, who had already invented the linear quadrupole mass analyzer, received the Nobel prize for the development of the quadrupole ion trap in 1989. ${ }^{[109]}$ Such an ion trap consists of a ring electrode, which replaces a pair of opposite electrodes used in a linear quadrupole, and two endcap electrodes, which have openings in their centers that allow for the injection and ejection of ions. An electric potential composed of DC and RF voltages is applied to the ring electrode, while the endcaps are grounded. The resulting quadrupolar field forces ions to undergo periodic motions both in radial and axial direction and, thus, confines them within the ion trap. The frequencies of these oscillations are called secular frequencies. Again, a set of equations of the Mathieu type yields parameters from which the conditions for stable trajectories can be derived. Mass analysis is accomplished by consecutively removing ions of successive $\mathrm{m} / \mathrm{z}$ values from the ion trap in a process called resonant ejection. ${ }^{[98]}$ To this end, an auxiliary RF field with fixed amplitude and frequency is applied to the endcap electrodes. The axial secular frequency depends on the $m / z$ ratio of the respective ions and both the frequency and the amplitude of the RF voltage applied to the ring electrode. Ions can take up energy from the auxiliary field if their secular frequency matches the frequency of this field, resulting in ejection from the trap through the exit endcap. By continuous variation of the RF amplitude applied to the ring electrode, the axial secular frequencies of all ions present in the ion trap change likewise. Thus, ions with different $\mathrm{m} / \mathrm{z}$ ratios successively encounter resonance with the auxiliary field, resulting in their consecutive emission from the trap to the detector. The isolation of precursor ions for $\mathrm{MS}^{2}$ experiments is achieved by resonant ejection of all but the ions of interest. The isolated ions are then brought into resonance with the auxiliary field. Collisions of the excited precursor ions with helium gas present in the ion trap can cause fragmentation. The fragment ions are then subjected to mass analysis as described above. Alternatively, the sequence of isolation and fragmentation can be repeated once or several times with mass-selected fragment ions serving as precursor ions for the next turn (MS ${ }^{n}$ experiments). 


\subsection{Instrumental Setup}

\subsubsection{Bruker micrOTOF-Q II Mass Spectrometer}

The main instrument used for this work was a micrOTOF-Q II mass spectrometer (Bruker Daltonik, Bremen), ${ }^{[110]}$ which employs a combination of linear quadrupole and time-of-flight (TOF) mass analyzers for $\mathrm{MS}$ and $\mathrm{MS}^{2}$ experiments. In experiments with the time-of-flight instrument, the formation of gas-phase ions takes place by electrospray ionization in a spray chamber, which is connected by a metal-coated glass capillary to an ion transfer stage. The transfer stage consists of two ion funnels and a hexapole and is used for removal of drying gas and solvent as well as focusing of the ions, before they are transmitted to the so-called Q-q-stage. The Q-q-stage consists of two quadrupoles and provides the possibility to perform collision-induced dissociation (CID) experiments. In such experiments, the first quadrupole acts as a mass filter, where ions of interest are massselected by removing all other ions. The second quadrupole serves as a collision cell where the previously isolated precursor ions undergo collisions with a collision gas $\left(\mathrm{N}_{2}\right)$, which can result in the formation of fragment ions. In experiments without gas-phase fragmentation, the Q-q-stage acts as an additional ion-transfer stage. The ions are then ejected into a time-of-flight analyzer that includes a single reflector, and registered by a micro channel plate detector. All spectra shown in this work were recorded with the TOF-instrument, except otherwise noted.

\subsubsection{Bruker HCT Mass Spectrometer}

Additional experiments were performed with an HCT mass spectrometer (Bruker Daltonik, Bremen), ${ }^{[74 a, 92 k]}$ which uses a three-dimensional quadrupole ion trap as mass analyzer. In the ion trap instrument, similar to the time-of-flight instrument, the electrospray process occurs in a spray chamber, which is connected by a metal coated glass capillary to an ion transfer section. Within the transfer section, solvent and drying gas are removed, while the analyte ions are focused and transported to the ion trap. For this purpose, a skimmer, two octopoles, and two ion lenses are used. The ion trap is used both for MS and MS ${ }^{n}$ experiments. Detection of the ions is accomplished by a Daly-type detector that consists of a conversion dynode and an electron multiplier. 


\section{$4 \quad$ Results and Discussion}

\subsection{Association and Aggregation of Magnesium Organocuprates}

\subsubsection{ESI Mass Spectrometry of Magnesium Organocuprate Solutions and Gas-Phase Fragmentation Experiments}

Phenylcuprates. Negative-ion mode ESI mass spectra of magnesium phenylcuprate solutions that were prepared from $\mathrm{CuCl}$ and 2 equiv. of $\mathrm{PhMgCl}$ in THF (30 min reaction time) showed $\left[\mathrm{CuPh}_{2}\right]^{-}$as base peak (Figure 2). In addition, $\left[\mathrm{Cu}_{2} \mathrm{Ph}_{3}\right]^{-}$and $\left[\mathrm{Cu}_{3} \mathrm{Ph}_{4}\right]^{-}$were detected in lower signal intensity. The measurement was also repeated with cryospray ionization (CSI), a variant of ESI that actively cools the spray and, thus, supposedly achieves even softer ionization conditions. However, the resulting mass spectrum did not significantly differ from the normal ESI mass spectrum. Warming-up of the sample solution from $-78^{\circ} \mathrm{C}$ to room temperature did not result in notable changes either.

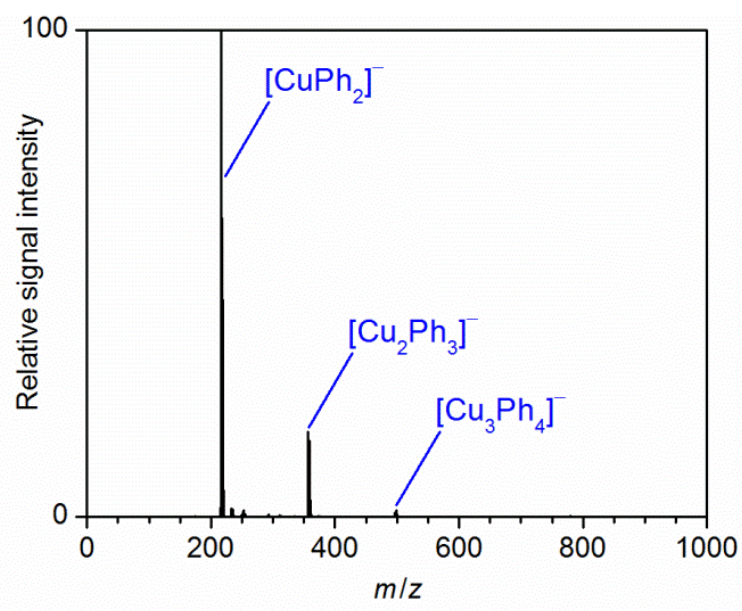

Figure 2. Negative-ion mode ESI mass spectrum of a solution of the products formed in the reaction of $\mathrm{CuCl}$ with $2 \mathrm{PhMgCl}$ in THF.

For further control experiments, sample solutions were prepared from $\mathrm{CuBr}$ or $\mathrm{CuCN}$ instead of $\mathrm{CuCl}$, with an excess of $\mathrm{PhMgCl}$ ( 3 or 4 equiv.), or with an extended reaction time of $60 \mathrm{~min}$. None of these changes had a significant effect. Performing the transmetallation in the presence of 2 equiv. of LiCl did not change the resulting ESI mass spectra either, except for the appearance of traces of $\left[\mathrm{LiCu}_{2} \mathrm{Ph}_{4}\right]^{-}$. The use of $\mathrm{CuBr} \cdot \mathrm{Me}_{2} \mathrm{~S}$ as copper source resulted in somewhat more pronounced changes of the ESI mass spectrum and increased the relative signal intensities of the polynuclear cuprates (Figure 3). Not only did the base peak now correspond to $\left[\mathrm{Cu}_{2} \mathrm{Ph}_{3}\right]^{-}$, but higher homologues of the type $\left[\mathrm{Cu}_{n} \mathrm{Ph}_{n+1}\right]^{-}$up to $n=6$ became visible. Among these larger aggregates, $\left[\mathrm{Cu}_{5} \mathrm{Ph}_{6}\right]^{-}$exhibited a much higher signal intensity than its neighboring peaks whereas that of $\left[\mathrm{Cu}_{4} \mathrm{Ph}_{5}\right]^{-}$was particularly low. Presumably, these pronounced differences reflect enhanced and reduced stabilities of $\left[\mathrm{Cu}_{5} \mathrm{Ph}_{6}\right]^{-}$ and $\left[\mathrm{Cu}_{4} \mathrm{Ph}_{5}\right]^{-}$, respectively. None of the observed cuprate anions showed the incorporation of $\mathrm{Me}_{2} \mathrm{~S}$. 


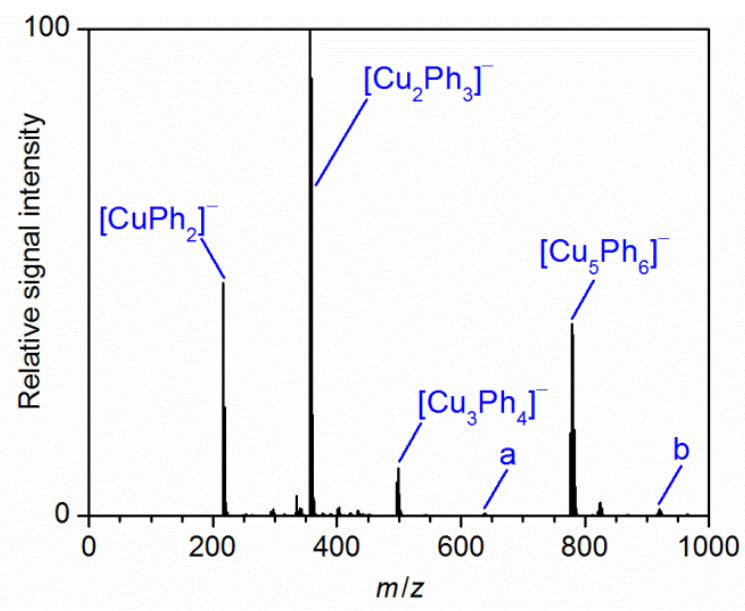

Figure 3. Negative-ion mode ESI mass spectrum of a solution of the products formed in the reaction of $\mathrm{CuBr} \cdot \mathrm{Me}_{2} \mathrm{~S}$ and $2 \mathrm{PhMgCl}$ in THF. a: $\left[\mathrm{Cu}_{4} \mathrm{Ph}_{5}\right]^{-}$, b: $\left[\mathrm{Cu}_{6} \mathrm{Ph}_{7}\right]^{-}$.

To gain further insight into the behavior of the phenylcuprates $\left[\mathrm{Cu}_{n} \mathrm{Ph}_{n+1}\right]^{-}$, their fragmentation in the gas phase was also studied. The smaller aggregates with $n \leq 3$ lost neutral CuPh units (Eq. 2a), whereas the larger ones exclusively released $\mathrm{Cu}_{4} \mathrm{Ph}_{4}$ (Eq. $2 \mathrm{~b}$ ). For the case of $\left[\mathrm{Cu}_{4} \mathrm{Ph}_{5}\right]^{-}$, the small abundance of this ion did not permit a conclusive fragmentation experiment.

$$
\begin{aligned}
& {\left[\mathrm{Cu}_{n} \mathrm{Ph}_{n+1}\right]^{-} \longrightarrow\left[\mathrm{Cu}_{n-1} \mathrm{Ph}_{n}\right]^{-}+\mathrm{CuPh} \quad n \leq 3} \\
& \longrightarrow\left[\mathrm{Cu}_{n-4} \mathrm{Ph}_{n-3}\right]^{-}+\mathrm{Cu}_{4} \mathrm{Ph}_{4} \quad n=5,6
\end{aligned}
$$

The positive-ion mode ESI mass spectra did not display any copper-containing peaks, but were dominated by the trinuclear magnesium cations $\left[\mathrm{Mg}_{3} \mathrm{Cl}_{3}(\mathrm{OMe})_{2}(\mathrm{THF})_{3}\right]^{+}$and $\left[\mathrm{Mg}_{3} \mathrm{Cl}_{3}(\mathrm{OMe})_{2}(\mathrm{THF})_{4}\right]^{+}$. These species are already known from ESI mass-spectrometric investigations of solutions of Grignard reagents. ${ }^{[92 n]}$ As shown in this previous work, the methoxy groups incorporated in these ions originate from residual traces of methanol, which was used for cleaning the ESI source and inlet system. To exclude any possible interference of this contaminant with the detected organocuprates, extra efforts were necessary to remove all residual traces of methanol (see Experimental Section). These measures completely eliminated the peaks of $\left[\mathrm{Mg}_{3} \mathrm{Cl}_{3}(\mathrm{OMe})_{2}(\mathrm{THF})_{x}\right]^{+}(x=3,4)$; instead, the methanol-free ions $\left[\mathrm{Mg}_{n} \mathrm{Cl}_{2 n-1}(\mathrm{THF})_{x}\right]^{+}(n=2,3 ; x=2-5)$ now prevailed (Figure 4). The negative-ion mode ESI mass spectra recorded under the same conditions did not significantly differ from those obtained without extra efforts aiming at the complete removal of the residual traces of methanol. This finding shows that the latter do not affect the observed organocuprate anions. As an additional control experiment, the system $\mathrm{CuCN} / 2 \mathrm{PhLi}$ in THF was also revisited. With the typical experimental conditions (without extra efforts aiming at the complete removal of the residual traces of methanol), it was possible to reproduce previous results ${ }^{[74]}$ and detect intact $\left[\mathrm{Li}_{n-1} \mathrm{Cu}_{n} \mathrm{R}_{2 n}\right]^{-}$anions $(n=1-3)$ and $\left[\mathrm{Li}_{2} \mathrm{CuPh}_{2}(\mathrm{THF})_{x}\right]^{+}$cations $(x=0-2)$, respectively. This finding lends further support to the adequacy of the present experiments. 


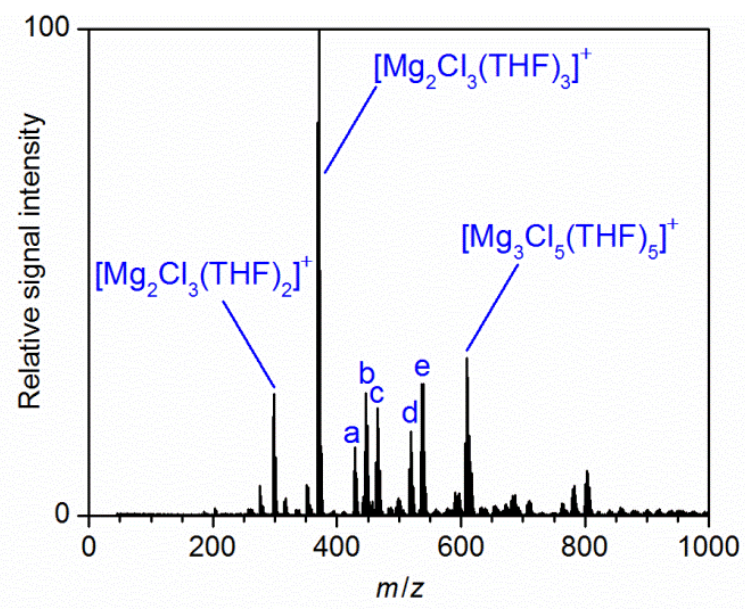

Figure 4. Positive-ion mode ESI mass spectrum of a solution of the products formed in the reaction of $\mathrm{CuCl}$ and $2 \mathrm{PhMgCl}$ in $\mathrm{THF}$ under rigorous exclusion of residual traces of methanol. a: $\left[\mathrm{Mg}_{3} \mathrm{Cl}_{3}(\mathrm{OH})_{2}(\mathrm{THF})_{3}\right]^{+}$, b: $\left[\mathrm{Mg}_{3} \mathrm{Cl}_{4}(\mathrm{OH})(\mathrm{THF})_{3}\right]^{+}, \quad$ c: $\left[\mathrm{Mg}_{3} \mathrm{Cl}_{5}(\mathrm{THF})_{3}\right]^{+}, \quad$ d: $\left[\mathrm{Mg}_{3} \mathrm{Cl}(\mathrm{OH})(\mathrm{THF})_{4}\right]^{+}$, e: $\left[\mathrm{Mg}_{3} \mathrm{Cl}_{5}(\mathrm{THF})_{4}\right]^{+}$.

Thienylcuprates. Thienylcuprates prepared from $\mathrm{CuCl}$ and 2 equiv. of $\mathrm{RMgCl}(\mathrm{R}=2$-thienyl) afforded negative-ion mode ESI mass spectra quite similar to those of the phenylcuprates with $\left[\mathrm{CuR}_{2}\right]^{-}$as the base peak and $\left[\mathrm{Cu}_{2} \mathrm{R}_{3}\right]^{-}$in minor abundance (Figure 5).

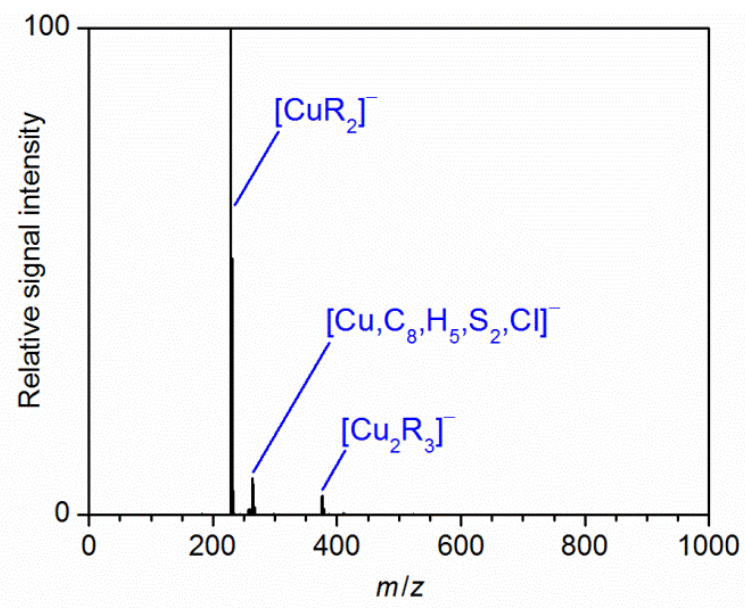

Figure 5. Negative-ion mode ESI mass spectrum of a solution of the products formed in the reaction of $\mathrm{CuCl}$ and $2 \mathrm{RMgCl}$ in THF ( $\mathrm{R}=2$-thienyl).

Upon gas-phase fragmentation, both ions lost neutral CuR (Eq. 3). However, for mononuclear $\left[\mathrm{CuR}_{2}\right]^{-}$, the preferred fragmentation pathway resulted in the elimination of thiophene (Eq. 4).

$$
\begin{aligned}
& {\left[\mathrm{Cu}_{n} \mathrm{R}_{n+1}\right]^{-} \longrightarrow\left[\mathrm{Cu}_{n-1} \mathrm{R}_{n}\right]^{-}+\mathrm{CuR} \quad n \leq 1,2} \\
& {\left[\mathrm{CuR}_{2}\right]^{-} \longrightarrow[\mathrm{CuR}-\mathrm{H}]^{-}+\mathrm{RH}}
\end{aligned}
$$

Additionally, a peak with a sum formula of $\left[\mathrm{Cu}_{1} \mathrm{C}_{8}, \mathrm{H}_{5}, \mathrm{~S}_{2}, \mathrm{Cl}\right]^{-}$was observed in low signal intensity (Figure 5). For its structure, the two alternatives $\left[\left(\mathrm{R}_{2}-\mathrm{H}\right) \mathrm{CuCl}\right]^{-}$and $[\mathrm{RCu}(\mathrm{R}+\mathrm{Cl}-\mathrm{H})]^{-}$were considered. In the first structure, the copper center binds to one dimerized thienyl substituent and one chlorine atom, whereas in the second it bears two separate thienyl residues, one of which contains a chlorine 
substituent. Upon gas-phase fragmentation, $\left[\mathrm{Cu}, \mathrm{C}_{8}, \mathrm{H}_{5}, \mathrm{~S}_{2}, \mathrm{Cl}\right]^{-}$afforded, among other ions, $\left[\mathrm{R}_{2}-\mathrm{H}\right]^{-}$ (Eq. 5), but no $[R]^{-}$or $\left.[\mathrm{R}+\mathrm{Cl}-\mathrm{H})\right]^{-}$. This finding indicates that the ion in question corresponds to $\left[\left(\mathrm{R}_{2}-\mathrm{H}\right) \mathrm{CuCl}\right]^{-}$.

$$
\left[\mathrm{Cu}, \mathrm{C}_{8}, \mathrm{H}_{5}, \mathrm{~S}_{2}, \mathrm{Cl}\right]^{-} \longrightarrow\left[\mathrm{R}_{2}-\mathrm{H}\right]^{-}+\mathrm{CuCl}
$$

Butylcuprates. The treatment of $\mathrm{CuCl}$ with 2 equiv. of $\mathrm{BuMgCl}$ furnished solutions, which quickly turned black when they were allowed to warm up to room temperature (Figure 5, left). ESI-mass spectrometric analysis of freshly prepared sample solutions detected butylcuprates $\left[\mathrm{Cu}_{n} \mathrm{Bu}_{n+1}\right]^{-}$ $(n=1-5)$, of which the dinuclear ion $\left[\mathrm{Cu}_{2} \mathrm{Bu}_{3}\right]^{-}$displayed the highest signal intensity (Figure 5 , right). Very similar mass spectra were obtained with the CSI source.
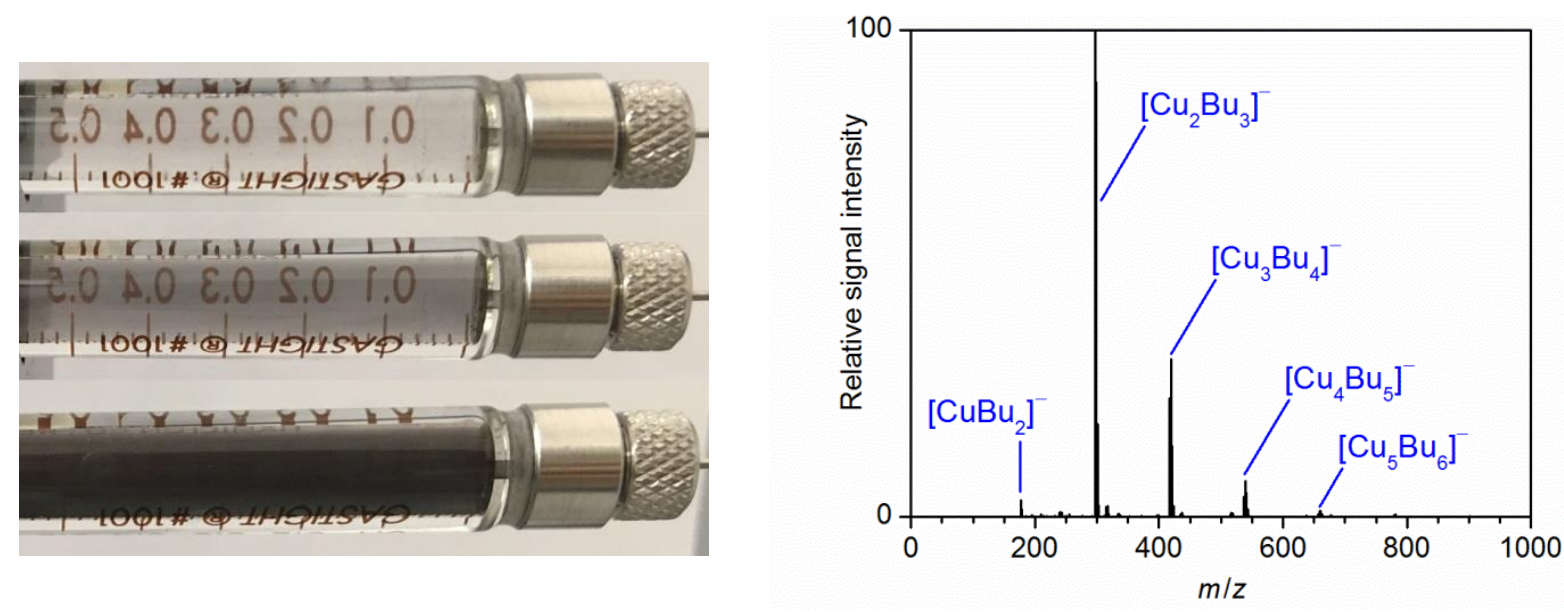

Figure 5. Left: Photographs of the $\mathrm{CuCl} / 2 \mathrm{BuMgCl}$ sample solutions in THF at 0,3 , and 6 min after preparation (top to bottom). Right: Negative-ion mode ESI mass spectrum of a solution of the products formed in the reaction of $\mathrm{CuCl}$ with $2 \mathrm{BuMgCl}$ in THF.

Gas-phase fragmentation of the polynuclear cuprates $\left[\mathrm{Cu}_{n} \mathrm{Bu}_{n+1}\right]^{-}(n=2-4)$ resulted in the release of neutral CuBu units and butene (Eqs. $6 a$ and 6b, see Figure 6 for $n=2$ and 4). The second fragmentation channel obviously corresponds to a $\beta$-hydrogen elimination. Both reactions also occurred in a consecutive manner. Due to their low signal intensity, fragmentation experiments of $\left[\mathrm{CuBu}_{2}\right]^{-}$and $\left[\mathrm{Cu}_{5} \mathrm{Bu}_{6}\right]^{-}$were not feasible.

$$
\begin{array}{rlrl}
{\left[\mathrm{Cu}_{n} \mathrm{Bu}_{n+1}\right]^{-}} & \longrightarrow\left[\mathrm{Cu}_{n-1} \mathrm{Bu}_{n}\right]^{-}+\mathrm{CuBu} & n & =2-4 \\
& \longrightarrow\left[\mathrm{Cu}_{n} \mathrm{Bu}_{n} \mathrm{H}\right]^{-}+\mathrm{C}_{4} \mathrm{H}_{8} & n & =2-4
\end{array}
$$

Control experiments performed under the rigorous exclusion of residual traces of methanol (see above) again detected methanol-free cations, whereas the negative-ion mode ESI mass spectra still found butylcuprate aggregates of the type $\left[\mathrm{Cu}_{n} \mathrm{Bu}_{n+1}\right]^{-}, n=3$ and 4 . In addition, the ions $\left[\mathrm{MgCu}_{2} \mathrm{Bu}_{2}(\mathrm{OH})_{3}\right]^{-}$and ions $\left[\mathrm{Mg}_{2} \mathrm{Cu}_{2} \mathrm{Bu}(\mathrm{OH})_{5} \mathrm{Cl}\right]^{-}$appeared as new species and pointed to the occurrence of partial hydrolysis reactions. 

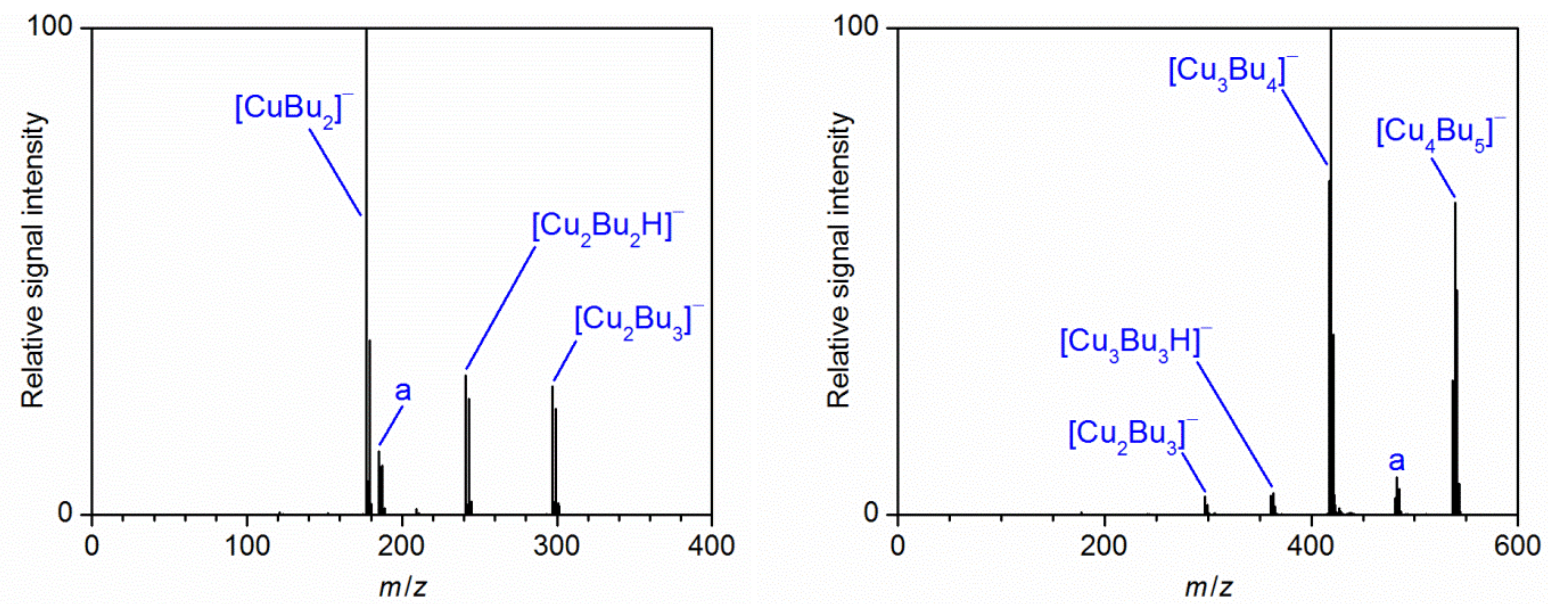

Figure 6. Left: Mass spectrum of mass-selected $\left[\mathrm{Cu}_{2} \mathrm{Bu}_{3}\right]^{-}$and its fragment ions produced upon collision-induced dissociation at $E_{\mathrm{LAB}}=10 \mathrm{eV}$. a: $\left[\mathrm{Cu}_{2} \mathrm{BuH}_{2}\right]^{-}$. Right: Mass spectrum of mass-selected $\left[\mathrm{Cu}_{4} \mathrm{Bu}_{5}\right]^{-}$and its fragment ions produced upon collision-induced dissociation at $E_{\mathrm{LAB}}=10 \mathrm{eV}$. a: $\left[\mathrm{Cu}_{4} \mathrm{Bu}_{4} \mathrm{H}\right]^{-}$.

(Trimethylsilyl)methylcuprates. The transmetallation of $\mathrm{CuCl}$ with 2 equiv. of $\mathrm{RMgCl}\left(\mathrm{R}=\mathrm{Me}_{3} \mathrm{SiCH}_{2}\right)$ produced solutions, whose ESI mass spectra again showed cuprates of the type $\left[\mathrm{Cu}_{n} \mathrm{R}_{n+1}\right]^{-}(n=1-5)$ (Figure 7). Of these aggregates, those with $n=2$ and 3 exhibited the highest signal intensity. Upon collisional activation, the loss of single CuR units was observed for the $\left[\mathrm{Cu}_{n} \mathrm{R}_{n+1}\right]^{-}$ions with $n=2-4$ (Eq. 7), whereas the larger aggregate $\left[\mathrm{Cu}_{5} \mathrm{R}_{6}\right]^{-}$cleaved off neutral $\mathrm{Cu}_{3} \mathrm{R}_{3}$ and $\mathrm{Cu}_{4} \mathrm{R}_{4}$ (Eqs. $8 \mathrm{a}$ and $8 \mathrm{~b}$ ).

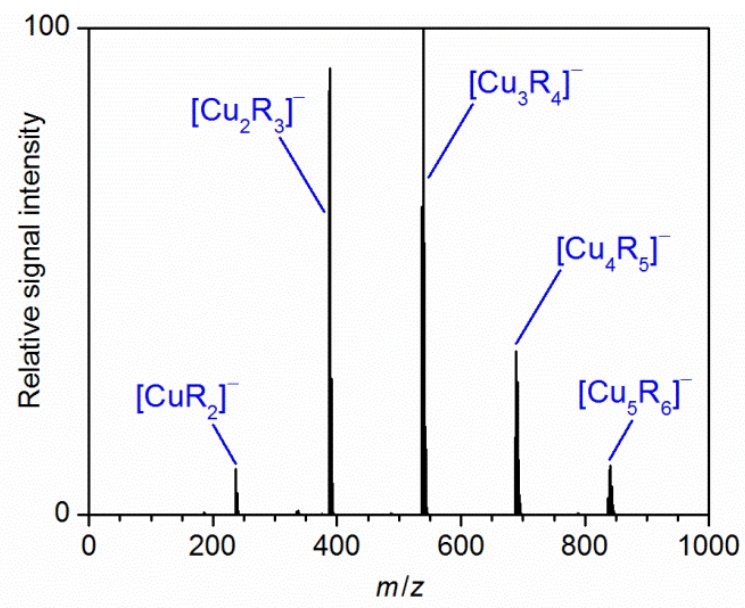

Figure 7. Negative-ion mode ESI mass spectrum of a solution of the products formed in the reaction of $\mathrm{CuCl}$ and $2 \mathrm{RMgCl}$ in THF $\left(\mathrm{R}=\mathrm{Me}_{3} \mathrm{SiCH}_{2}\right)$.

$$
\begin{aligned}
{\left[\mathrm{Cu}_{n} \mathrm{R}_{n+1}\right]^{-} } & \longrightarrow\left[\mathrm{Cu}_{n-1} \mathrm{R}_{n}\right]^{-}+\mathrm{CuR} \quad n=2-4 \\
{\left[\mathrm{Cu}_{5} \mathrm{R}_{6}\right]^{-} } & \longrightarrow\left[\mathrm{Cu}_{2} \mathrm{R}_{3}\right]^{-}+\mathrm{Cu}_{3} \mathrm{R}_{3} \\
& \longrightarrow\left[\mathrm{CuR}_{2}\right]^{-}+\mathrm{Cu}_{4} \mathrm{R}_{4}
\end{aligned}
$$

A peculiar reactivity was observed for the case of mononuclear $\left[\mathrm{CuR}_{2}\right]^{-}$, which exclusively afforded the ion [CuR(Me)] $]^{-}$(Eq. 9 and Figure 8). This fragmentation apparently corresponded to a $\beta$-methylelimination and gave $\mathrm{Me}_{2} \mathrm{Si}=\mathrm{CH}_{2}$ as a neutral byproduct. While such simple silenes undergo fast 
cyclodimerization in solution, such bimolecular reactions do not occur in the diluted gas phase, where the formation of silenes is well documented. ${ }^{[111]}$

$$
\left[\mathrm{CuR}_{2}\right]^{-} \longrightarrow[\mathrm{CuR}(\mathrm{Me})]^{-}+\mathrm{C}_{3} \mathrm{H}_{8} \mathrm{Si}
$$

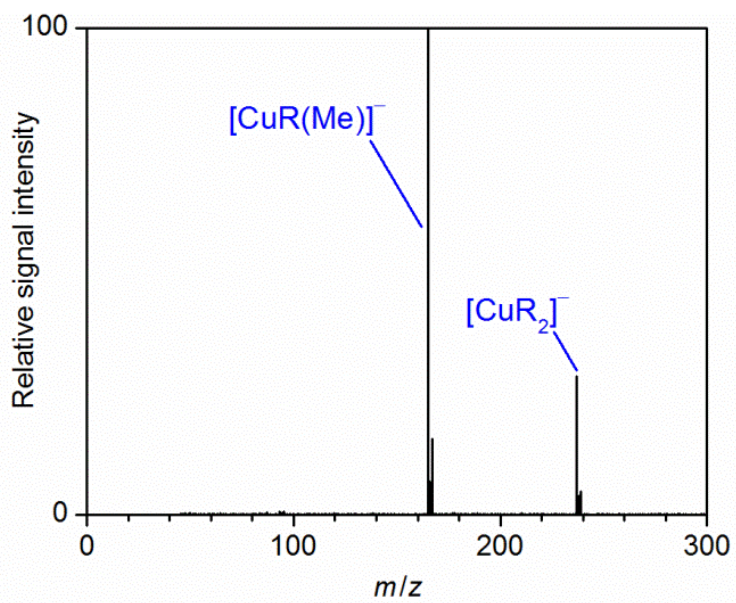

Figure 8. Mass spectrum of mass-selected $\left[\mathrm{CuR}_{2}\right]^{-}\left(\mathrm{R}=\mathrm{Me}_{3} \mathrm{SiCH}_{2}\right)$ and its fragment ions produced upon collision-induced dissociation at $E_{\mathrm{LAB}}=20 \mathrm{eV}$.

\subsubsection{Speciation and Aggregation of Magnesium Organocuprates}

The present findings clearly show that solutions of magnesium cuprates contain anions of the type $\left[\mathrm{Cu}_{n} \mathrm{R}_{n+1}\right]^{-}$. Variation of the organyl substituent $\mathrm{R}$, the counter-ion of the copper precursor $\mathrm{CuX}$, or the addition of dimethyl sulfide has only limited effects and mainly influences the degree of aggregation of the $\left[\mathrm{Cu}_{n} \mathrm{R}_{n+1}\right]^{-}$anions. In this context, it is important to remember that the aggregation states observed by ESI mass spectrometry do not necessarily equal those of the cuprates present in solution, because the increased effective concentrations during the ESI process favor the formation of higher aggregates (see chapter 1.4).Despite this complication, the observed distribution of the ESI signal intensities points to a particular stability of the $\left[\mathrm{Cu}_{5} \mathrm{Ph}_{6}\right]^{-}$aggregate. The enhanced stability of this anion is fully consistent with the formation of $\left[\mathrm{Cu}_{5} \mathrm{R}_{6}\right]^{-}$anions $(\mathrm{R}=\mathrm{Ph}, 2$-thienyl) in the solid state. ${ }^{[41,46,47]}$ In analogy to the formation of $\left[\mathrm{Li}_{2} \mathrm{Cu}_{3} \mathrm{R}_{6}\right]^{-}$from anionic $\left[\mathrm{CuR}_{2}\right]^{-}$and neutral $\mathrm{Li}_{2} \mathrm{Cu}_{2} \mathrm{R}_{4}$ (see chapter 1.3.2), these aggregates can be understood as adducts of linear $\left[\mathrm{CuR}_{2}\right]^{-}$anions with neutral $\left[\mathrm{Cu}_{4} \mathrm{R}_{4}\right]$ tetramers. The latter are also known from X-ray crystallography and adopt cyclic structures as well. ${ }^{[41,47,112,113]}$ As both the anionic and the neutral component are relatively stable, it is not surprising that their combination appears to afford anionic aggregates more stable than alternative ones. The putative composition of the $\left[\mathrm{Cu}_{5} \mathrm{R}_{6}\right]^{-}$aggregates from $\left[\mathrm{CuR}_{2}\right]^{-}$and $\left[\mathrm{Cu}_{4} \mathrm{R}_{4}\right]$ subunits is directly supported by the gas-phase fragmentation experiments. The inferred origin of the $\left[\mathrm{Cu}_{5} \mathrm{R}_{6}\right]^{-}$ anions from $\left[\mathrm{CuR}_{2}\right]^{-}$and $\left[\mathrm{Cu}_{4} \mathrm{R}_{4}\right]$ and, more generally, of $\left[\mathrm{Cu}_{n} \mathrm{R}_{n+1}\right]^{-}$from $\left[\mathrm{CuR}_{2}\right]^{-}$and $[\mathrm{CuR}]_{n-1}$, also implies that the relative abundances of mono- and polynuclear cuprates contain information on the ratio between copper tied up in anionic and neutral species, respectively. While the obtained data does not permit a rigorous quantitative analysis (see above), the prominence of polynuclear cuprates suggests that, at least for the alkylcuprates, most of the copper is present in the form of neutral organocopper species. 
The $\left[\mathrm{Cu}_{n} \mathrm{R}_{n+1}\right]^{-}$complexes observed in the present study moreover closely resemble $\left[\mathrm{Cu}_{2} \mathrm{Mes}_{3}\right]^{-}$, which had previously been found as the anionic component of crystals produced upon the reaction of CuMes with MesMgBr. ${ }^{[114]}$ In addition, the absence of any halide in the detected cuprates agrees with the results of a previous report on magnesium methylcuprates formed in the reactions of $\mathrm{CuX}(\mathrm{X}=\mathrm{Cl}$, $\mathrm{Br}, \mathrm{I})$ or MeCu with MeMgX in THF. ${ }^{[115]}$ Furthermore, this study provided evidence of the monomeric and dimeric nature of the probed methylcuprates. The formation of cuprates in different aggregation states is in full accordance with the current findings.

A conspicuous feature of the inspected magnesium cuprate solutions is the almost complete absence of any magnesium-containing species in the negative-ion mode ESI mass spectra. Instead of forming anionic magnesates ${ }^{[92 n]}$ or being incorporated in the cuprate anions, magnesium forms bi- and trinuclear cations. This partitioning of copper and magnesium reflects the different electropositivity of the two metals and their abilities to stabilize negative and positive charges, respectively. Very similar behavior has been previously observed for transmetallation reactions between iron, ${ }^{[920,5]}$ cobalt, ${ }^{[92 r]}$ palladium, ${ }^{[116]}$ or zinc compounds ${ }^{[117]}$ with Grignard reagents.

\subsubsection{Stoichiometry and Stability of Magnesium Organocuprates}

Another notable aspect of the observed $\left[\mathrm{Cu}_{n} \mathrm{R}_{n+1}\right]^{-}$species is their stoichiometry, which does not agree with the 1:2 ratio of the $\mathrm{CuX}$ and $\mathrm{RMgCl}$ reactants. This deviation indicates the occurrence of decomposition reactions, in which organyl residues are consumed. Previous work has already established the limited stability of magnesium methylcuprate reagents at room temperature. ${ }^{[115]}$ For the case of the butylcuprates, decomposition reactions could be observed directly. The darkening of the sample solutions upon warming up points to the formation of colloidal copper(0). The alleged reduction of the copper must be accompanied by the release of the organyl residues. Insight into the microscopic mechanism of these decomposition reactions is afforded by the gas-phase fragmentation experiments. For the butylcuprates, these experiments revealed a relatively high tendency toward $\beta$-hydrogen elimination. Although these reactions themselves do not change the oxidation state of copper, the resulting hydride species may well undergo consecutive processes, which lead to a reduction. The fact that the butylcuprates showed the highest propensity to produce colloidal copper and were the only systems prone to $\beta$-hydrogen eliminations indeed suggests a connection between these two findings. The absence of any observable hydride complexes in the sample solutions might moreover indicate that such species decompose quite fast.

Another decomposition pathway operates for the (trimethylsilyl)methylcuprates, which lack any $\beta$ hydrogen atoms. The fragmentation of the mononuclear complex results in a $\beta$-methyl elimination. Although this reaction type has been observed before, the far majority of known cases involves early transition metals. ${ }^{[118,119]}$ The present findings suggest that $\beta$-methyl eliminations can also operate for complexes of late transition metals, provided that no energetically more favorable reactions, such as $\beta$-hydrogen eliminations, are feasible.

\subsubsection{Comparison of Magnesium Organocuprates with Lithium Organocuprates}

The behavior of the magnesium cuprates can also be compared with that of their well-studied lithium counterparts. In the negative-ion mode ESI mass spectra of THF solutions of lithium cuprates $\mathrm{LiCuR}_{2} \cdot \mathrm{LiX}(\mathrm{X}=\mathrm{CN}, \mathrm{Cl}, \mathrm{Br}, \mathrm{I})$, heteronuclear complexes of the type $\left[\mathrm{Li}_{n-1} \mathrm{Cu}_{n} \mathrm{R}_{2 n}\right]^{-}$predominate. ${ }^{[74,86 a]}$ Likewise, numerous crystal structures of lithium cuprates reveal direct interactions between the cuprate anion and its lithium counter-ion. ${ }^{[41,73 a]}$ What is the reason for the different affinities of the 
cuprates to $\mathrm{Li}^{+}$on the one hand and $\mathrm{MgX}^{+}$on the other? Quantum chemical calculations carried out by Thomas Auth in the Koszinowski group for the phenylcuprates showed that the absence of heterononuclear complexes containing magnesium does not result from an intrinsically low stability of the latter. ${ }^{[120]}$ In fact, isolated $\left[\mathrm{MgClCu}_{2} \mathrm{Ph}_{4}\right]^{-}$is predicted to be relatively more stable than $\left[\mathrm{LiCu}_{2} \mathrm{Ph}_{4}\right]^{-}$. However, the examination of solutions of $\mathrm{LiCuPh} 2 \cdot \mathrm{LiCl}$ and $\mathrm{MgClCuPh} \cdot \mathrm{MgCl}_{2}$ in THF by quantum chemical calculations revealed, that the situation changes completely if the solvation shell and counter-ions are included in the analysis. In this case, the magnesium-containing heteronuclear aggregates were calculated to be relatively less stable than their lithium-containing counterparts. ${ }^{[120]}$ This reversal of the relative stabilities chiefly originates from the different stabilities of the corresponding counter-ions. For the magnesium cuprates, the formation of heteronuclear aggregates is accompanied by the energetically costly breakage of solvated $\left[\mathrm{Mg}_{2} \mathrm{Cl}_{3}\right]^{+}$cations. ${ }^{[120]}$ The considerable thermodynamic stability of $\left[\mathrm{Mg}_{2} \mathrm{Cl}_{3}\right]^{+}$is also evident from several crystal structures obtained from $\mathrm{THF}^{[121]}$ and from its observation in the present positive-ion mode ESI-mass spectrometric experiments under rigorous exclusion of methanol (Figure 4). In contrast, the formation of the analogous lithium-containing cuprates does not suffer from a comparable energetic penalty because of the easy availability of free $\left[\mathrm{Li}(\mathrm{THF})_{4}\right]^{+}$ions in THF. ${ }^{[120]}$ Thus, the stability of the counter-ions controls the speciation of the organocuprate anions.

Unlike the magnesium cuprates, most of their lithium counterparts have stoichiometries that exactly match the 1:2 ratio of the CuX and LiR reactants. Furthermore, solutions of $\mathrm{LiCuBu}_{2} \cdot \mathrm{LiX}$ and all other probed lithium cuprates proved to be stable at room temperature. ${ }^{[74,86 a]}$ Possibly, the higher stability of the lithium cuprates results from their enhanced tendency toward ion pairing. To test this hypothesis, the gas phase fragmentation of the $\left[\mathrm{Cu}_{n} \mathrm{Bu}_{n+1}\right]^{-}$species was compared with that of $\left[\mathrm{Li}_{2} \mathrm{Cu}_{3} \mathrm{Bu}_{6}\right]^{-}$. Previous experiments had shown that the heteronuclear complex undergoes $\beta$-hydrogen elimination to a much smaller extent than now observed for their $\mathrm{Cu}_{n} \mathrm{Bu}_{n+1}{ }^{-}$analogues. ${ }^{[74 a]}$ This result supports the inferred higher stability of the lithium-containing cuprates. Presumably, the interaction with the lithium counter-ions restricts the conformational flexibility of the cuprates and prevents them from accessing geometries on the way toward decomposition reactions. Interestingly, the presence of $\mathrm{LiCl}$ during the transmetallation of $\mathrm{CuCl}$ with $\mathrm{PhMgCl}$ afforded only minor quantities of lithium-containing cuprates. Apparently, the addition of $\mathrm{LiCl}$ to the sample solution does not provide significant amounts of free $\mathrm{Li}^{+}$ions available for the incorporation into heteronuclear lithium cuprates. Thus, the experimental findings support the results of the quantum chemical calculations, which predicted $\mathrm{LiCl}$ to form preferentially the $\mathrm{Li}_{2} \mathrm{Cl}_{2}$ dimer in THF in accordance with experimental results. $^{[122]}$

Most likely, the different microscopic compositions of magnesium and lithium cuprates also translate into different reactivities. For reactions involving Lewis acids for the activation of the electrophilic substrates, such as conjugate addition reactions (see chapter 1.3.4), lithium cuprates usually appear to be the reagent of choice because they combine both the nucleophilic $\left[\mathrm{CuR}_{2}\right]^{-}$moiety and the Lewis-acidic $\mathrm{Li}^{+}$in one molecular entity (at least in $\mathrm{Et}_{2} \mathrm{O}$ ). ${ }^{[72,73 \mathrm{a}]}$ In line with this analysis, Michael-type additions commonly make use of lithium cuprates. ${ }^{123}$ In contrast, magnesium cuprates may be a viable alternative for reactions that do not require a Lewis-acidic activation of the electrophilic substrates, such as cross-coupling reactions. Even in these cases, care must be taken to avoid the unwanted thermal decomposition of the cuprate reagent. 


\subsection{From Organocuprates to -aurates: Trends in Transition Metal Chemistry}

\subsubsection{ESI Mass Spectrometry of Group-11 Organometallate Solutions}

Phenylmetallates. Negative-ion mode ESI mass spectra of sample solutions that were prepared from 1 equiv. of $\mathrm{MCN}(\mathrm{M}=\mathrm{Cu}, \mathrm{Ag}, \mathrm{Au})$ and 2 equiv. of PhLi in THF showed coinage-metal ate complexes with the general formula $\left[\mathrm{Li}_{n-1} \mathrm{M}_{n} \mathrm{Ph}_{2 n}\right]^{-}(n=1-3$; Figures 9-11). In spectra of the cuprate and argentate solutions, the mononuclear species $\left[\mathrm{MPh}_{2}\right]^{-}$was observed as the base peak, and $\left[\mathrm{Li}_{2} \mathrm{M}_{3} \mathrm{Ph}_{6}\right]^{-}$and $\left[\mathrm{LiM}_{2} \mathrm{Ph}_{4}\right]^{-}$were detected with intermediate or low signal intensity, respectively. For $M=A u$, the base peak corresponded to $\left[\mathrm{Li}_{2} \mathrm{Au}_{3} \mathrm{Ph}_{6}\right]^{-}$, but $[\mathrm{AuPh}]^{-}$and $\left[\mathrm{LiAu}_{2} \mathrm{Ph}_{4}\right]^{-}$also appeared in large abundance. Additionally, $\left[\mathrm{AuPh}_{4}\right]^{-}$was detected, which is an $\mathrm{Au}(\mathrm{III})$-species and most likely stems from a contamination of the employed $\mathrm{AuCN}$ with $\mathrm{Au}(\mathrm{CN})_{3}$ (Figure 11).
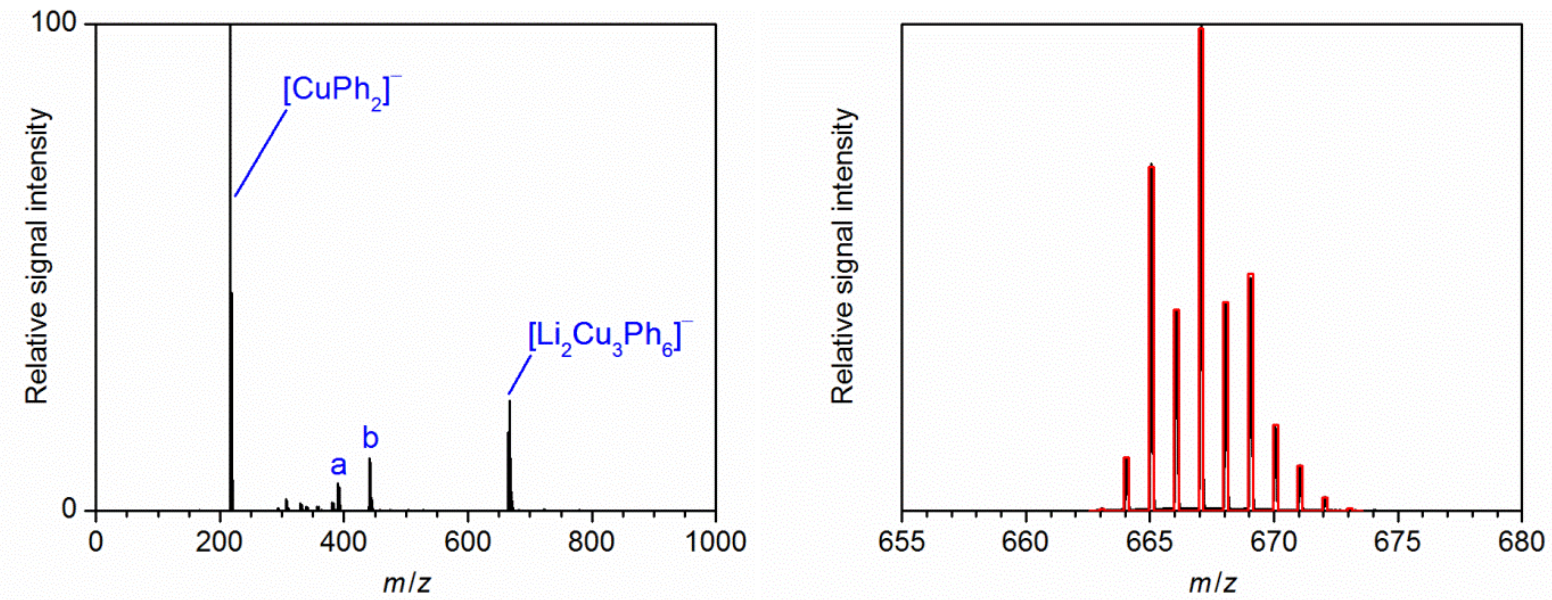

Figure 9. Left: Negative-ion mode ESI mass spectrum of a solution of the products formed in the reaction of $\mathrm{CuCN}$ with $2 \mathrm{PhLi}$ in THF. a: $\left[\mathrm{LiCu}_{2} \mathrm{Ph}_{3}(\mathrm{CN})\right]^{-}$, b: $\left[\mathrm{LiCu}_{2} \mathrm{Ph}_{4}\right]^{-}$. Right: Measured (black) and simulated (red) isotopic pattern of $\left[\mathrm{Li}_{2} \mathrm{Cu}_{3} \mathrm{Ph}_{6}\right]^{-}$.
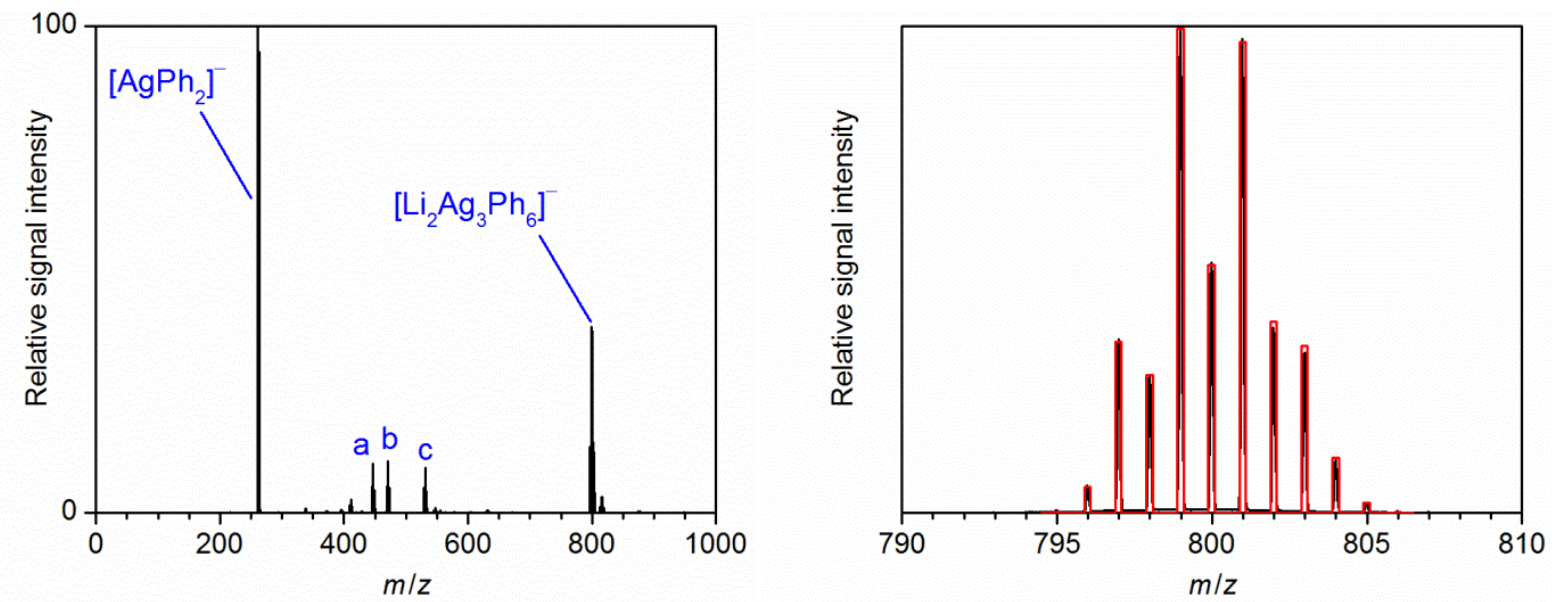

Figure 10. Left: Negative-ion mode ESI mass spectrum of a solution of the products formed in the reaction of AgCN with $2 \mathrm{PhLi}$ in THF. a: $\left[\mathrm{Ag}_{2} \mathrm{Ph}_{3}\right]^{-}$, b: $\left[\mathrm{LiAg}_{2} \mathrm{Ph}_{3}(\mathrm{OH})\right]^{-}$, c: $\left[\mathrm{LiAg}_{2} \mathrm{Ph}_{4}\right]^{-}$. Right: Measured (black) and simulated (red) isotopic pattern of $\left[\mathrm{Li}_{2} \mathrm{Ag}_{3} \mathrm{Ph}_{6}\right]^{-}$. 

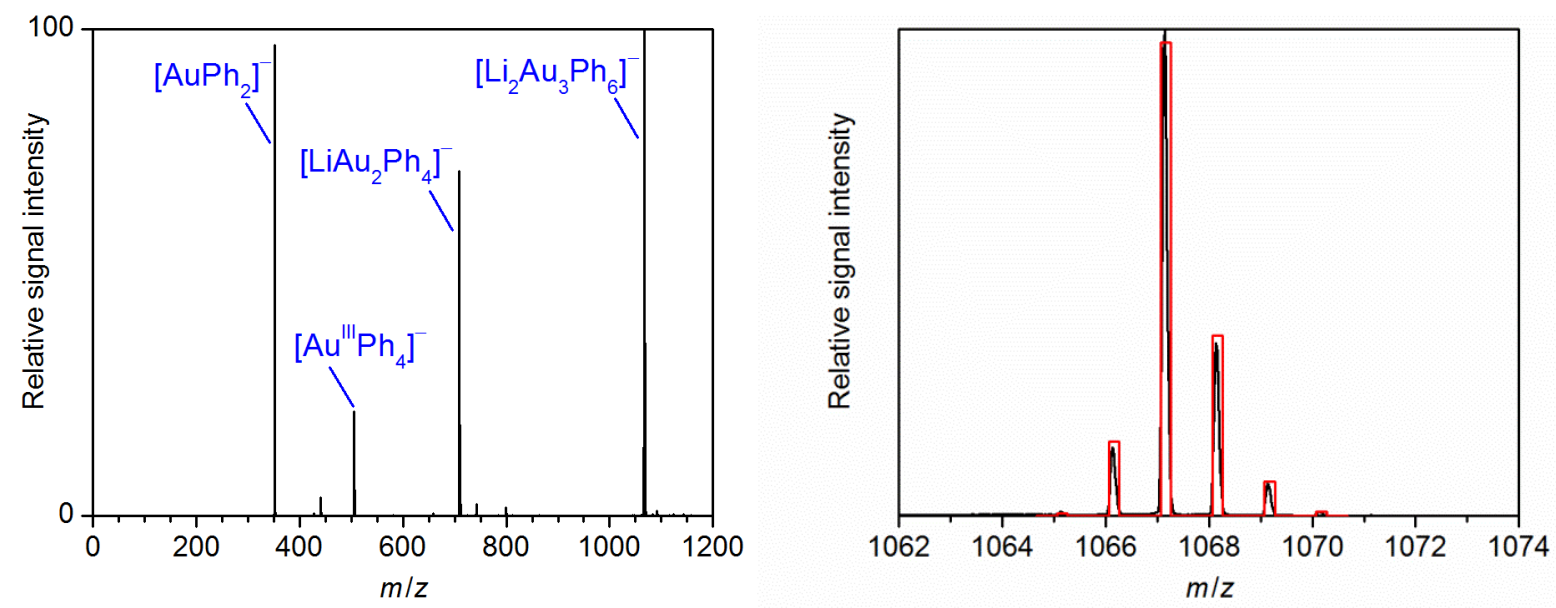

Figure 11. Left: Negative-ion mode ESI mass spectrum of a solution of the products formed in the reaction of AuCN with 2 PhLi in THF. Right: Measured (black) and simulated (red) isotopic pattern of $\left[\mathrm{Li}_{2} \mathrm{Au}_{3} \mathrm{Ph}_{6}\right]^{-}$.

The treatment of a mixture of 0.5 eq of $M^{1} C N$ and 0.5 eq of $M^{2} C N\left(M^{1}, M^{2}=C u, A g, A u ; M^{1} \neq M^{2}\right)$ with 2 equiv. of PhLi in THF furnished solutions whose mass spectra featured the already known ions as well as additional signals for ate complexes with two different coinage metals $\left(\left[\mathrm{LiM}^{1} \mathrm{M}^{2} \mathrm{Ph}_{4}\right]^{-}\right.$, $\left.\left[\mathrm{Li}_{2} \mathrm{M}_{2}^{1} \mathrm{M}^{2} \mathrm{Ph}_{6}\right]^{-},\left[\mathrm{Li}_{2} \mathrm{M}^{1} \mathrm{M}_{2}^{2} \mathrm{Ph}_{6}\right]^{-}\right)$. The transmetallation of a mixture of all three coinage-metal cyanides (0.33 equiv. each) with 2 equiv. of PhLi in THF also produced [ $\left.\mathrm{Li}_{2} \mathrm{CuAgAuPh}_{6}\right]^{-}$(Figure 12). Beyond organometallates that exclusively contained organyl residues, ions bearing cyanide or hydroxide ligands were also present in minor amounts. These species presumably originate from partial hydrolysis reactions. Apart from species of the type $\left[\mathrm{MPh}_{2}\right]^{-}$, the dinuclear $\left[\mathrm{Ag}_{2} \mathrm{Ph}_{3}\right]^{-}$was the only other lithium-free species that could be observed in mass spectra of sample solutions prepared from PhLi (Figure 10).
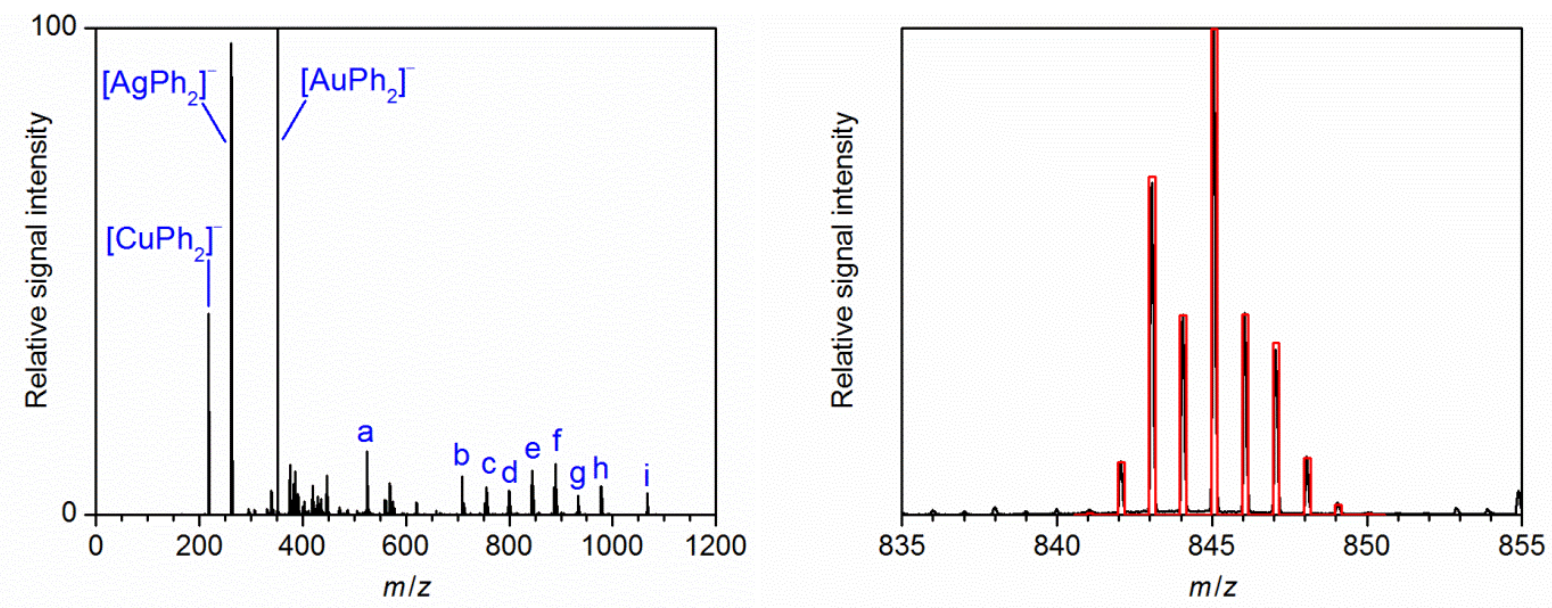

Figure 12. Left: Negative-ion mode ESI mass spectrum of a solution of the products formed in the reaction of CuCN, AgCN, and AuCN (0.33 equiv. each) with $2 \mathrm{PhLi}$ in THF. a: [LiCuAuPh$\left.{ }_{3}(C N)\right]^{-}$, b: $\left[\mathrm{LiAu}_{2} \mathrm{Ph}_{4}\right]^{-}+\left[\mathrm{Li}_{2} \mathrm{Cu}_{2} \mathrm{AgPh}_{6}\right]^{-}$, c: $\left[\mathrm{Li}_{2} \mathrm{CuAg}_{2} \mathrm{Ph}_{6}\right]^{-}$, d: presumably overlapping signals of $\left[\mathrm{Li}_{2} \mathrm{Ag}_{3} \mathrm{Ph}_{6}\right]^{-}$and $\left[\mathrm{Li}_{2} \mathrm{Cu}_{2} \mathrm{AuPh}_{6}\right]^{-}$, e: $\left[\mathrm{Li}_{2} \mathrm{CuAgAuPh}_{6}\right]^{-}$, f: $\left[\mathrm{Li}_{2} \mathrm{Ag}_{2} \mathrm{AuPh}_{6}\right]^{-}$, g: $\left[\mathrm{Li}_{2} \mathrm{CuAu}_{2} \mathrm{Ph}_{6}\right]^{-}$, h: $\left[\mathrm{Li}_{2} \mathrm{AgAu}_{2} \mathrm{Ph}_{6}\right]^{-}$, i: $\left[\mathrm{Li}_{2} \mathrm{Au}_{3} \mathrm{Ph}_{6}\right]^{-}$. Right: Measured (black) and simulated (red) isotopic pattern of [LiCuAgAuPh$\left.]_{6}\right]^{-}$.

Sample solutions prepared from 1 equiv. of $\mathrm{MCN}$ and 2 equiv. of $\mathrm{PhMgCl}$ in $\mathrm{THF}$ also yielded negative-ion mode ESI mass spectra showing coinage metal ate complexes. The mononuclear ions 
$\left[\mathrm{CuPh}_{2}\right]^{-}$and $\left[\mathrm{AuPh}_{2}\right]^{-}$dominated the mass spectra of the respective cuprate and aurate solutions, while the heterobimetallic complex $\left[\mathrm{MgAg}_{2} \mathrm{Ph}_{2}(\mathrm{CN})_{2} \mathrm{Cl}\right]^{-}$was the base peak in spectra of argentate solutions. Further heterobimetallic species incorporating magnesium and silver or gold, respectively, were found with low intensity, but only if $\mathrm{OH}^{-}, \mathrm{CN}^{-}, \mathrm{Cl}^{-}$, or a combination of these inorganic ligands were also part of the complex. Heterobimetallic species that contained solely organic residues could not be detected. Additionally, the homometallic phenylmetallates $\left[\mathrm{Cu}_{2} \mathrm{Ph}_{3}\right]^{-},\left[\mathrm{AgPh}_{2}\right]^{-}$and $\left[\mathrm{Ag}_{2} \mathrm{Ph}_{3}\right]^{-}$ were observed, but only with moderate to low intensities.

Methylmetallates. Organometallate solutions prepared from 1 equiv. of $\mathrm{MCN}(\mathrm{M}=\mathrm{Cu}, \mathrm{Ag}, \mathrm{Au})$ and 2 equiv. of MeLi in THF afforded negative-ion mode ESI mass spectra that showed ate complexes similar to those of the phenylmetallates. The lithium-containing species $\left[\mathrm{Li}_{2} \mathrm{M}_{3} \mathrm{Me}_{6}\right]^{-}$was present for all three coinage metals and represented the base peak for $M=A g$ and Au. Spectra of aurate solutions also showed high amounts of $\left[\mathrm{AuMe}_{2}\right]^{-}$and $\left[\mathrm{LiAu}_{2} \mathrm{Me}_{3}(\mathrm{CN})\right]^{-}$. A related cyanide-containing ion, $\left[\mathrm{LiCu}_{2} \mathrm{Me}_{2}(\mathrm{CN})_{2}\right]^{-}$, exhibited the highest signal intensity in spectra of methylcuprate solutions. Similar to the phenylmetallates, methylaurates with the general sum formula $\left[\mathrm{Li}_{n-1} \mathrm{Au}_{n} \mathrm{Me}_{2 n}\right]^{-}$could be observed for $n=1-4$ and 6 (Figure 13). Additionally, a higher number of the homometallic ions $\left[\mathrm{M}_{n} \mathrm{Me}_{n+1}\right]^{-}$became visible for $\mathrm{M}=\mathrm{Cu}(n=2,3)$ and $\mathrm{M}=\mathrm{Ag}(n=1-4)$, albeit with lower intensities. Beyond the already mentioned $\left[\mathrm{LiCu}_{2} \mathrm{Me}_{2}(\mathrm{CN})_{2}\right]^{-}$and $\left[\mathrm{LiAu}_{2} \mathrm{Me}_{3}(\mathrm{CN})\right]^{-}$, ions, in which some of the methyl groups were exchanged for hydroxy- or cyanide ligands, were present with different intensities in all spectra of solutions prepared from MCN and MeLi. The presence of these species, also in higher abundance, points to more pronounced hydrolysis reactions of the methylmetallates compared with their phenyl counterparts. The gold(III)-species [AuMe $]_{4}^{-}$was also present and, just as in the case of $\left[\mathrm{AuPh}_{4}\right]^{-}$, probably resulted from a contamination of the gold precursor with $\mathrm{Au}(\mathrm{CN})_{3}$.
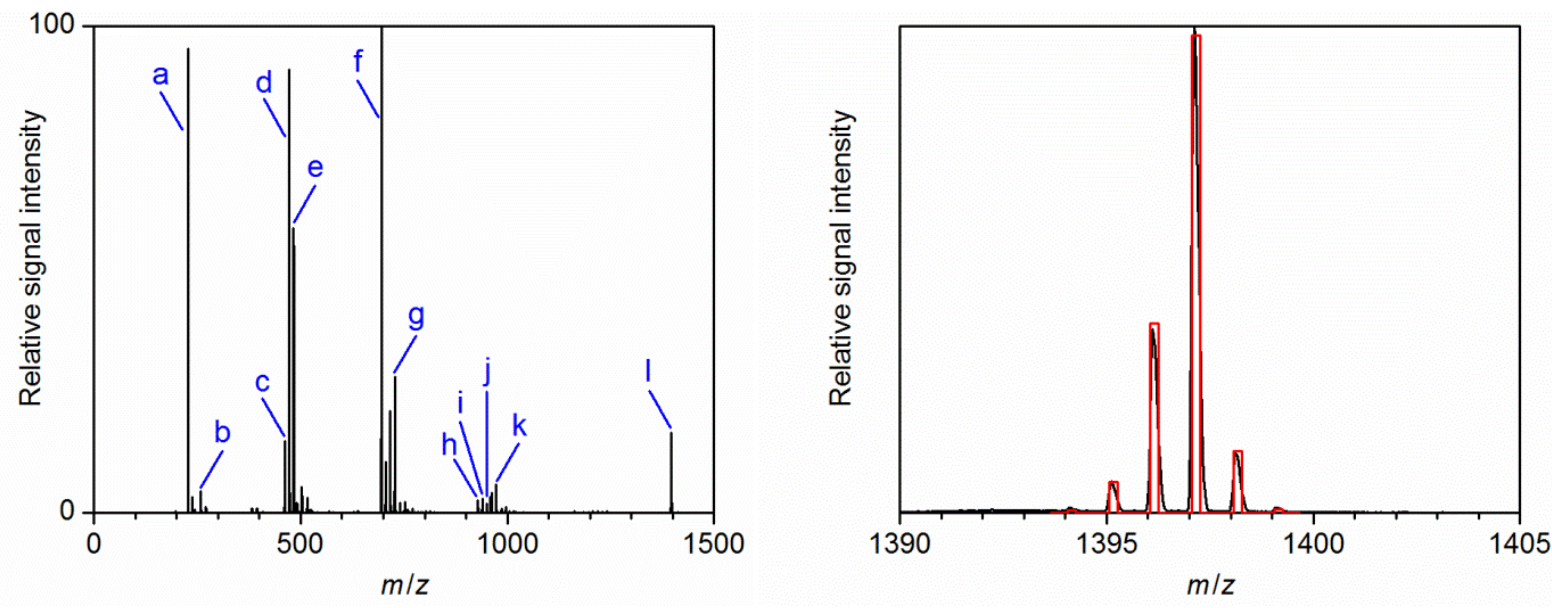

Figure 13. Left: Negative-ion mode ESI mass spectrum of a solution of the products formed in the reaction of AuCN with $2 \mathrm{MeLi}$ in THF. a: $\left[\mathrm{AuMe}_{2}\right]^{-}$, b: $\left[\mathrm{AuMe}_{4}\right]^{-}$, c: $\left[\mathrm{LiAu}_{2} \mathrm{Me}_{4}\right]^{-}$, d: $\left[\mathrm{LiAu}_{2} \mathrm{Me}_{3}(\mathrm{CN})\right]^{-}$, e: $\left[\mathrm{LiAu}_{2} \mathrm{Me}_{2}(\mathrm{CN})_{2}\right]^{-}$, f: $\left[\mathrm{Li}_{2} \mathrm{Au}_{3} \mathrm{Me}_{6}\right]^{-}$, g: $\left[\mathrm{Li}_{2} \mathrm{Au}_{3} \mathrm{Me}_{3}(\mathrm{CN})_{3}\right]^{-}$, h: $\left.\left[\mathrm{Li}_{3} \mathrm{Au}_{4} \mathrm{Me}_{8}\right]^{-}+{ }^{-} \mathrm{Li}_{3} \mathrm{Au}_{4} \mathrm{Me}_{7}(\mathrm{OH})\right]^{-}$, i: $\quad\left[\mathrm{Li}_{3} \mathrm{Au}_{4} \mathrm{Me}_{7}(\mathrm{CN})\right]^{-}+\left[\mathrm{Li}_{3} \mathrm{Au}_{4} \mathrm{Me}_{6}(\mathrm{CN})(\mathrm{OH})\right]^{-}, \mathrm{j}:\left[\mathrm{Li}_{3} \mathrm{Au}_{4} \mathrm{Me}_{6}(\mathrm{CN})_{2}\right]^{-}+\left[\mathrm{Li}_{3} \mathrm{Au}_{4} \mathrm{Me}_{5}(\mathrm{CN})_{2}(\mathrm{OH})\right]^{-}$, k: $\left[\mathrm{Li}_{3} \mathrm{Au}_{4} \mathrm{Me}_{4}(\mathrm{CN})_{4}\right]^{-}+\left[\mathrm{Li}_{3} \mathrm{Au}_{4} \mathrm{Me}_{3}(\mathrm{CN})_{4}(\mathrm{OH})\right]^{-}$, I: $\left[\mathrm{Li}_{5} \mathrm{Au}_{6} \mathrm{Me}_{12}\right]^{-}$. The peaks centered at $\mathrm{m} / \mathrm{z} 706$ and $\mathrm{m} / \mathrm{z} 717$ correspond to $\left[\mathrm{Li}_{2} \mathrm{Au}_{3} \mathrm{Me}_{5}(\mathrm{CN})\right]^{-}$and $\left[\mathrm{Li}_{2} \mathrm{Au}_{3} \mathrm{Me}_{4}(\mathrm{CN})_{2}\right]^{-}$, respectively. Right: Measured (black) and simulated (red) isotopic pattern of $\left[\mathrm{Li}_{5} \mathrm{Au}_{6} \mathrm{Me}_{12}\right]^{-}$.

Negative-ion mode ESI mass spectra of sample solutions prepared from 1 equiv. of MCN and 2 equiv. of $\mathrm{MeMgCl}$ in THF predominantly exhibited heterobimetallic organometallates that always included hydroxide, cyanide, or chloride ligands. Similar to the phenylmetallates prepared from $\mathrm{PhMgCl}$, no 
heterobimetallic species bearing only organic ligands could be identified. Except for the cyanidecontaining ions $\left[\mathrm{Cu}_{2} \mathrm{Me}(\mathrm{CN})_{2}\right]^{-}$and $\left[\mathrm{Au}_{2} \mathrm{Me}_{2}(\mathrm{CN})\right]^{-}$, no further magnesium-free species were detected. In addition, spectra of the methylmetallates solutions prepared from $\mathrm{MeMgCl}$ suffered from generally lower signal intensities. Here, hydrolysis was apparently a major issue.

Cationic Species. Positive-ion mode ESI mass spectra of sample solutions that were prepared by treating 1 equiv. of $\mathrm{MCN}(\mathrm{M}=\mathrm{Cu}, \mathrm{Ag}, \mathrm{Au})$ with 2 equiv. of PhLi in THF afforded two types of ions: heterobimetallic cations of the type $\left[\mathrm{Li}_{2} \mathrm{MPh}_{2}(\mathrm{THF})_{x}\right]^{+}(\mathrm{M}=\mathrm{Cu}, \mathrm{Ag}, \mathrm{Au}, x=0-2)$, as well as the homometallic lithium monomers and dimers $\left[\mathrm{Li}_{2}(\mathrm{CN})\left(\mathrm{Bu}_{2} \mathrm{O}\right)\right]^{+},\left[\mathrm{Li}_{2}(\mathrm{CN})(\mathrm{THF})_{2}\right]^{+},\left[\mathrm{Li}\left(\mathrm{Bu}_{2} \mathrm{O}\right)(\mathrm{THF})\right]^{+}$, and $\left[\mathrm{Li}_{2}(\mathrm{CN})\left(\mathrm{Bu}_{2} \mathrm{O}\right)(\mathrm{THF})\right]^{+}$(see Figure 14 for the case of $\mathrm{M}=\mathrm{Au}$ ). (Please note: $\mathrm{Bu}_{2} \mathrm{O}$ stems from the PhLi reagent used for the sample preparation, which was purchased as $\mathrm{Bu}_{2} \mathrm{O}$-solution.) The signal intensities of the present species varied, however, $\left[\mathrm{Li}_{2} \mathrm{MPh}_{2}(\mathrm{THF})_{2}\right]^{+}(\mathrm{M}=\mathrm{Cu}, \mathrm{Ag}, \mathrm{Au})$ always appeared among the most intense ions. Furthermore, the $\mathrm{Bu}_{2} \mathrm{O}$-containing ions $\left[\mathrm{Li}_{2} \mathrm{AgPh}_{2}\left(\mathrm{Bu}_{2} \mathrm{O}\right)(\mathrm{THF})\right]^{+}$and $\left[\mathrm{Li}_{2} \mathrm{AuPh}_{2}\left(\mathrm{Bu}_{2} \mathrm{O}\right)(\mathrm{THF})\right]^{+}$as well as the higher aggregate $\left[\mathrm{Li}_{3} \mathrm{Au}_{2} \mathrm{Ph}_{4}(\mathrm{THF})\right]^{+}$were observed. Likewise, sample solutions prepared by treating a mixture of two coinage-metal cyanides with phenyl lithium produced positive-ion mode mass spectra that included the heterobimetallic cations of both employed coinage metals, together with the homometallic lithium species. As an exception, spectra of sample solutions stemming from mixtures of $\mathrm{AgCN}$ and $\mathrm{AuCN}$ only showed the gold-containing heterobimetallic cations as well as the lithium monomers and dimers. This particular result was also obtained for solutions prepared by transmetallation of a mixture of all three coinage metals with phenyl lithium. Positive-ion mode ESI mass spectra of sample solutions that were prepared from 1 equiv. of $M C N(M=C u, A g, A u)$ and 2 equiv. of MeLi in THF always showed cations with the general sum formula $\left[\mathrm{Li}_{2} \mathrm{MMe}(\mathrm{CN})(\mathrm{THF})_{x}\right]^{+}(\mathrm{M}=\mathrm{Cu}, \mathrm{Ag}, \mathrm{Au} ; x=1,2)$. The ion with $x=2$ was the main species in all cases. Additionally, the silver- and gold-containing ions $\left[\mathrm{Li}_{3} \mathrm{Ag}(\mathrm{CN})_{2}(\mathrm{OH})(\mathrm{THF})_{x}\right]^{+}(x=0,1)$ and $\left[\mathrm{Li}_{2} \mathrm{AuMe}_{2}(\mathrm{THF})_{x}\right]^{+}(x=1,2)$ were identified.

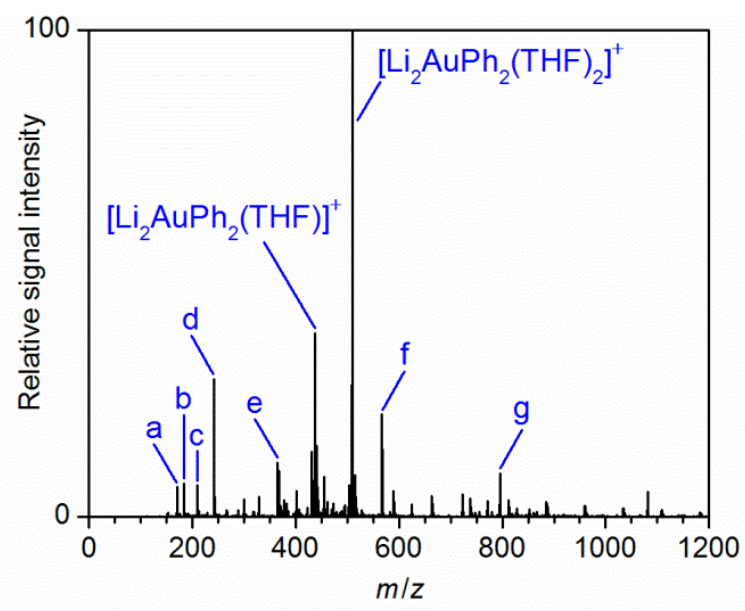

Figure 14. Positive-ion mode ESI mass spectrum of a solution of the products formed in the reaction

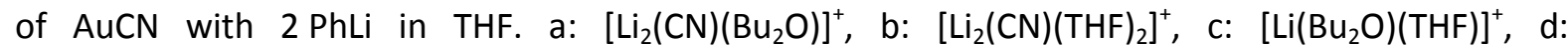
$\left[\mathrm{Li}_{2}(\mathrm{CN})\left(\mathrm{Bu}_{2} \mathrm{O}\right)(\mathrm{THF})\right]^{+}$, e: $\left[\mathrm{Li}_{2} \mathrm{AuPh}_{2}\right]^{+}, \mathrm{f}:\left[\mathrm{Li}_{2} \mathrm{AuPh}_{2}\left(\mathrm{Bu}_{2} \mathrm{O}\right)(\mathrm{THF})\right]^{+}, \mathrm{g}:\left[\mathrm{Li}_{3} \mathrm{Au}_{2} \mathrm{Ph}_{4}(\mathrm{THF})\right]^{+}$.

Sample solutions prepared from $\mathrm{MCN}$ and Grignard reagents exhibited $\left[\mathrm{Mg}_{3} \mathrm{Cl}_{3}(\mathrm{OMe})_{2}(\mathrm{THF})_{x}\right]^{+}$ $(x=3,4)$ upon positive-ion mode ESI mass spectrometric analysis. The methoxy residues in these species originate from methanol that was used for flushing the ESI inlet system of the spectrometer. ${ }^{[92 n]}$ It has been shown that its presence and the formation of these magnesium species does not interfere with the formation of the anionic ate complexes (see chapter 4.1). 


\subsubsection{Gas-Phase Fragmentation Experiments of Group-11 Organometallates}

Fragmentation of $\left[\mathrm{Li}_{2} \mathrm{M}_{3} \mathrm{R}_{6}\right]^{-}$. Upon collision-induced dissociation (CID) of $\left[\mathrm{Li}_{2} \mathrm{M}_{3} \mathrm{Ph}_{6}\right]^{-}(\mathrm{M}=\mathrm{Cu}, \mathrm{Ag}$, $\mathrm{Au}$ ), the loss of neutral $\mathrm{Li}_{2} \mathrm{M}_{2} \mathrm{Ph}_{4}$ led to the formation of $\left[\mathrm{MPh}_{2}\right]^{-}$(see Figure 15, left, for the case of $M=A u)$. Gas-phase fragmentation of the analogous species $\left[\mathrm{Li}_{2} \mathrm{M}_{2}^{1} \mathrm{M}^{2} \mathrm{Ph}_{6}\right]^{-}$and $\left[\mathrm{Li}_{2} \mathrm{M}^{1} \mathrm{M}_{2}{ }_{2} \mathrm{Ph}_{6}\right]^{-}\left(\mathrm{M}^{1}\right.$, $M^{2}=C u, A g, A u ; M^{1} \neq M^{2}$ ) also resulted in the release of mononuclear fragment ions, $\left[M^{1} \mathrm{Ph}_{2}\right]^{-}$and $\left[\mathrm{M}^{2} \mathrm{Ph}_{2}\right]^{-}$, corresponding to the loss of $\mathrm{Li}_{2} \mathrm{M}_{2}{ }_{2} \mathrm{Ph}_{4}, \mathrm{Li}_{2} \mathrm{M}_{2}^{1} \mathrm{Ph}_{4}$, and $\mathrm{Li}_{2} \mathrm{M}^{1} \mathrm{M}^{2} \mathrm{Ph}_{4}$ (see Figure 15, right, for the case of $\mathrm{M}^{1}=\mathrm{Cu}, \mathrm{M}^{2}=\mathrm{Ag}$ ). The fragment ion with the coinage metal that was present two times in the precursor ion always appeared with roughly twice the intensity of the other fragment ion. Similarly, $\left[\mathrm{Li}_{2} \mathrm{CuAgAuPh}\right]_{6}^{-}$formed $\left[\mathrm{MPh}_{2}\right]^{-}(\mathrm{M}=\mathrm{Cu}, \mathrm{Ag}, \mathrm{Au})$ in approximately equal amounts in $\mathrm{CID}$ experiments, accompanied by the release of $\mathrm{Li}_{2} \mathrm{AgAuPh}_{4}, \mathrm{Li}_{2} \mathrm{CuAuPh}_{4}$, and $\mathrm{Li}_{2} \mathrm{CuAgPh}_{4}$ (Figure 16).
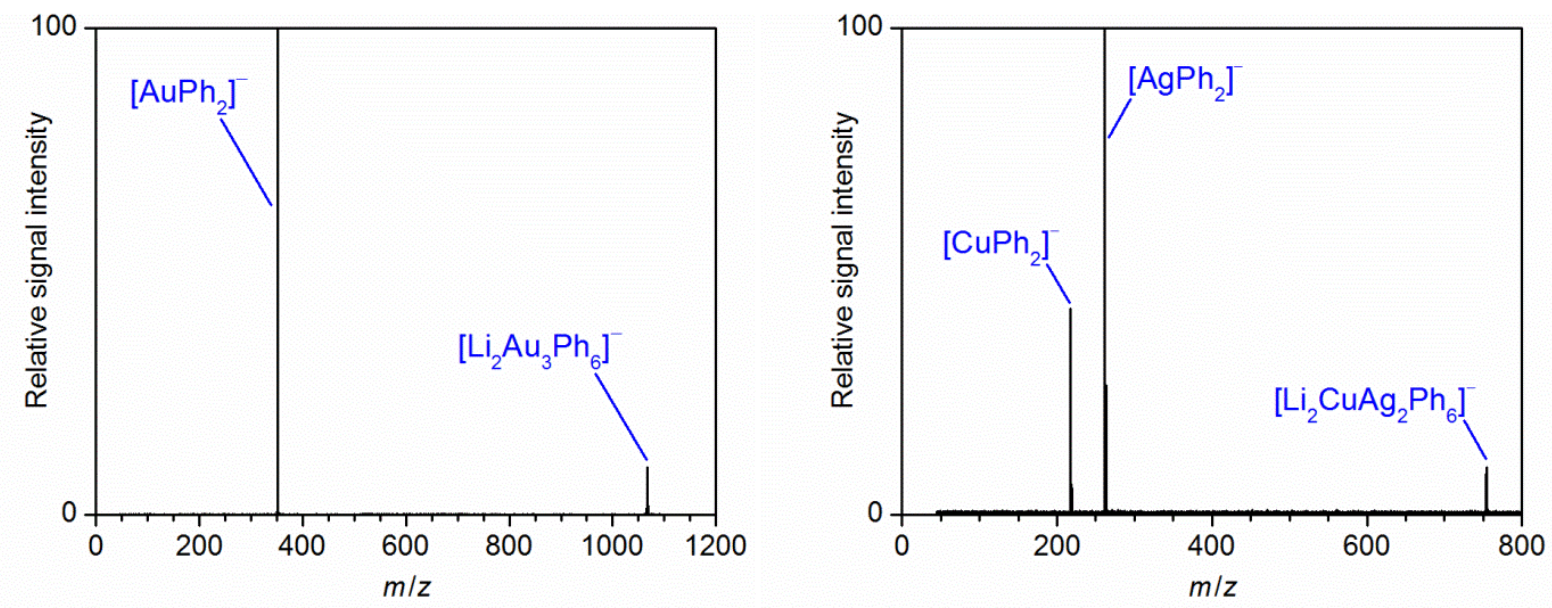

Figure 15. Left: Mass spectrum of mass-selected $\left[\mathrm{Li}_{2} \mathrm{Au}_{3} \mathrm{Ph}_{6}\right]^{-}$and its fragment ions produced upon collision-induced dissociation at $E_{\mathrm{LAB}}=10 \mathrm{eV}$. Right: Mass spectrum of mass-selected $\left[\mathrm{Li}_{2} \mathrm{CuAg}_{2} \mathrm{Ph}_{6}\right]^{-}$ and its fragment ions produced upon collision-induced dissociation at $E_{\mathrm{LAB}}=10 \mathrm{eV}$.

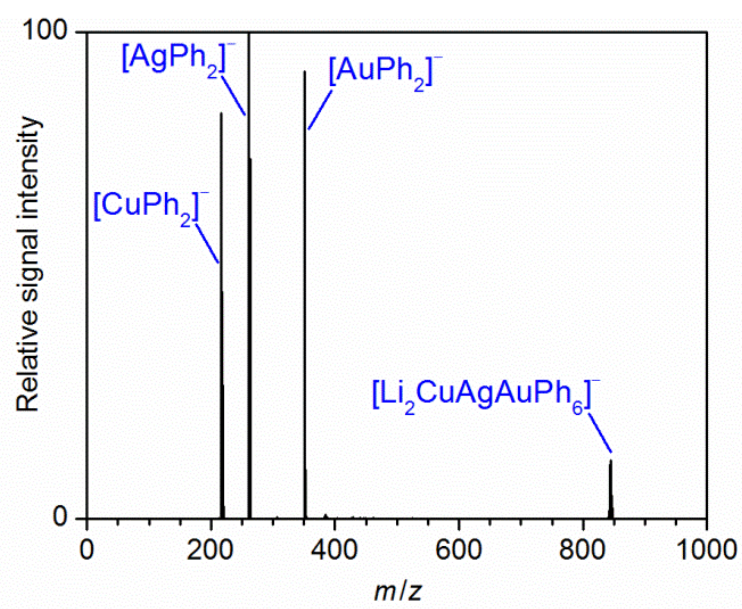

Figure 16. Mass spectrum of mass-selected $\left[\mathrm{Li}_{2} \mathrm{CuAgAuPh}{ }_{6}\right]^{-}$and its fragment ions produced upon collision-induced dissociation at $E_{\mathrm{LAB}}=10 \mathrm{eV}$.

Likewise, collisional activation of the related methyl metallates $\left[\mathrm{Li}_{2} \mathrm{M}_{3} \mathrm{Me}_{6}\right]^{-}(\mathrm{M}=\mathrm{Cu}, \mathrm{Ag}, \mathrm{Au})$ yielded the mononuclear fragment ions $\left[\mathrm{MMe}_{2}\right]^{-}$by elimination of $\mathrm{Li}_{2} \mathrm{M}_{2} \mathrm{Me}_{4}$ (see Figure 17 for $\mathrm{M}=\mathrm{Ag}$ and $M=A u$, and Eq. 10a). This type of dissociation was one of the main fragmentation channels of $\left[\mathrm{Li}_{2} \mathrm{Ag}_{3} \mathrm{Me}_{6}\right]^{-}$and $\left[\mathrm{Li}_{2} \mathrm{Au}_{3} \mathrm{Me}_{6}\right]^{-}$. However, only very little amounts of $\left[\mathrm{CuMe}_{2}\right]^{-}$were produced in the 
fragmentation of $\left[\mathrm{Li}_{2} \mathrm{Cu}_{3} \mathrm{Me}_{6}\right]^{-}$. Instead, the latter favored the release of $\left[\mathrm{Cu}_{2} \mathrm{Me}_{3}\right]^{-}$(Eq. 10b). The homologous silver-species $\left[\mathrm{Ag}_{2} \mathrm{Me}_{3}\right]^{-}$was also generated in high abundance as ionic fragment of $\left[\mathrm{Li}_{2} \mathrm{Ag}_{3} \mathrm{Me}_{6}\right]^{-}$(Eq. 10b). Additionally, the heterobimetallic fragment ions $\left[\mathrm{LiM}_{2} \mathrm{Me}_{4}\right]^{-}(\mathrm{M}=\mathrm{Cu}, \mathrm{Ag}, \mathrm{Au})$ could be identified as well, albeit with different intensities: it was observed with high intensity in the fragmentation of $\left[\mathrm{Li}_{2} \mathrm{Au}_{3} \mathrm{Me}_{6}\right]^{-}$and appeared with medium and low intensity in CID experiments of $\left[\mathrm{Li}_{2} \mathrm{Cu}_{3} \mathrm{Me}_{6}\right]^{-}$and $\left[\mathrm{Li}_{2} \mathrm{Ag}_{3} \mathrm{Me}_{6}\right]^{-}$, respectively (Eq. 10c).
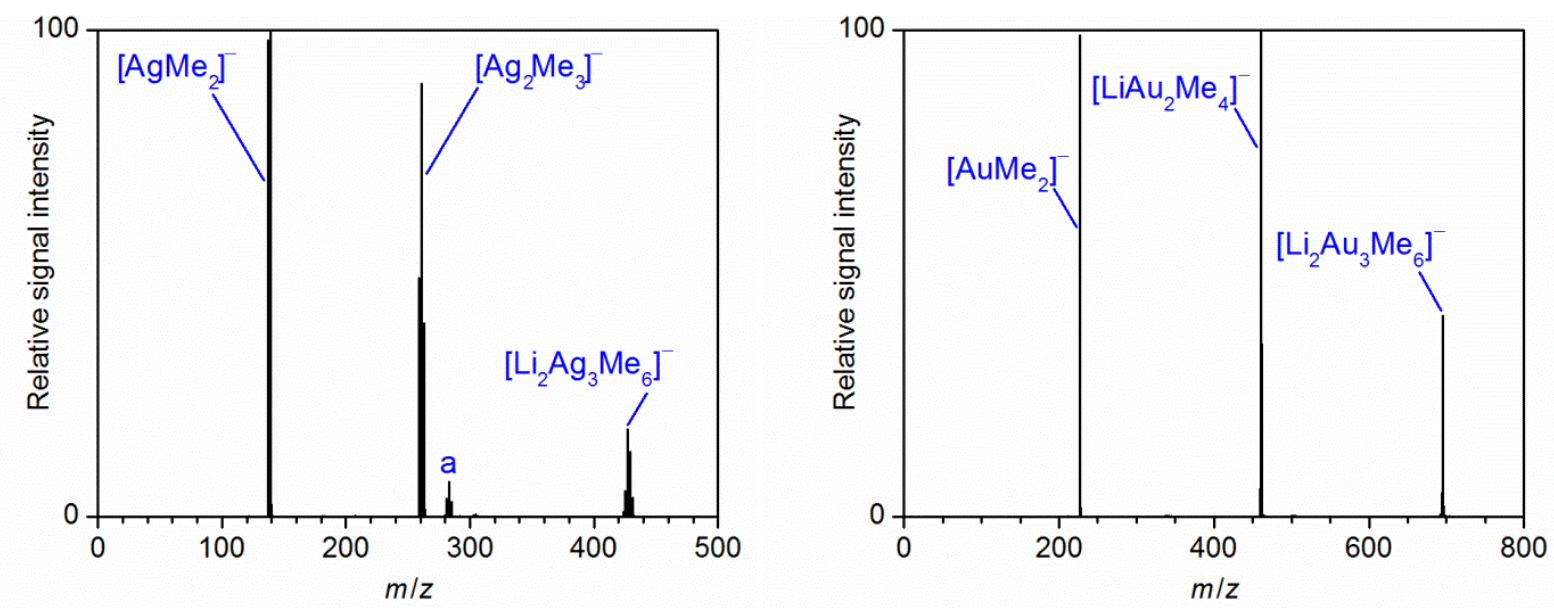

Figure 17. Left: Mass spectrum of mass-selected $\left[\mathrm{Li}_{2} \mathrm{Ag}_{3} \mathrm{Me}_{6}\right]^{-}$and its fragment ions produced upon collision-induced dissociation at $E_{\mathrm{LAB}}=10 \mathrm{eV}$. a: $\left[\mathrm{LiAg}_{2} \mathrm{Me}_{4}\right]^{-}$Right: Mass spectrum of mass-selected $\left[\mathrm{Li}_{2} \mathrm{Au}_{3} \mathrm{Me}_{6}\right]^{-}$and its fragment ions produced upon collision-induced dissociation at $E_{\mathrm{LAB}}=10 \mathrm{eV}$.

$$
\begin{aligned}
{\left[\mathrm{Li}_{2} \mathrm{M}_{3} \mathrm{Me}_{6}\right]^{-} } & \longrightarrow\left[\mathrm{MMe}_{2}\right]^{-}+\mathrm{Li}_{2} \mathrm{M}_{2} \mathrm{Me}_{4} \\
& \longrightarrow\left[\mathrm{M}_{2} \mathrm{Me}_{3}\right]^{-}+\mathrm{Li}_{2} \mathrm{MMe}_{3} \\
& \longrightarrow\left[\mathrm{LiM}_{2} \mathrm{Me}_{4}\right]^{-}+\mathrm{LiMMe}_{2}
\end{aligned}
$$

$$
\begin{aligned}
& M=C u, A g, A u \\
& M=C u, A g \\
& M=C u, A g, A u
\end{aligned}
$$

Fragmentation of [ $\left[\mathrm{LiM}_{2} \mathrm{R}_{4}\right]^{-}$. Gas-phase fragmentation experiments of $\left[\mathrm{LiM}_{2} \mathrm{Ph}_{4}\right]^{-}(\mathrm{M}=\mathrm{Cu}, \mathrm{Ag}, \mathrm{Au})$ primarily featured the formation of the mononuclear species $\left[\mathrm{MPh}_{2}\right]^{-}$. The CID spectra of $\left[\mathrm{LiCu}_{2} \mathrm{Ph}_{4}\right]^{-}$ and $\left[\mathrm{LiAg}_{2} \mathrm{Ph}_{4}\right]^{-}$also showed $\left[\mathrm{Cu}_{2} \mathrm{Ph}_{3}\right]^{-}$and $\left[\mathrm{Ag}_{2} \mathrm{Ph}_{3}\right]^{-}$as well as $[\mathrm{LiAgPh}]^{-}$, respectively, but $\left[\mathrm{Cu}_{2} \mathrm{Ph}_{3}\right]^{-}$ and $\left[\mathrm{LiAgPh}_{3}\right]^{-}$were only detected in trace amounts. The mixed metallates $\left[\mathrm{LiM}^{1} \mathrm{M}^{2} \mathrm{Ph}_{4}\right]^{-}\left(\mathrm{M}^{1}\right.$, $M^{2}=C u, A g, A u ; M^{1} \neq M^{2}$ ) similarly fragmented into the mononuclear ate complexes $\left[\mathrm{M}^{1} \mathrm{Ph}_{2}\right]^{-}$and $\left[\mathrm{M}^{2} \mathrm{Ph}_{2}\right]^{-}$. While always both of these ions were formed, the species with lower $m / z$ ratio prevailed in fragmentation spectra of [ $\left.\mathrm{LiCuAuPh}_{4}\right]^{-}$and [ $\left.\mathrm{LiAgAuPh}_{4}\right]^{-}$(Figure 18). In contrast, the formation of the heavier fragment ion was preferred in the case of $\left[\mathrm{LiCuAgPh}_{4}\right]^{-}$, which additionally produced [CuAgPh $]_{3}^{-}$(Figure 19). CID experiments of $\left[\mathrm{LiAu}_{2} \mathrm{Me}_{4}\right]^{-}$proceeded analogously and afforded solely $\left[\mathrm{AuMe}_{2}\right]^{-}$. Fragmentation of the copper and silver homologues $\left[\mathrm{Li}_{2} \mathrm{CuMe}_{4}\right]^{-}$and $\left[\mathrm{LiAg}_{2} \mathrm{Me}_{4}\right]^{-}$was not possible due to the absence of these species in the respective ESI mass spectra. 

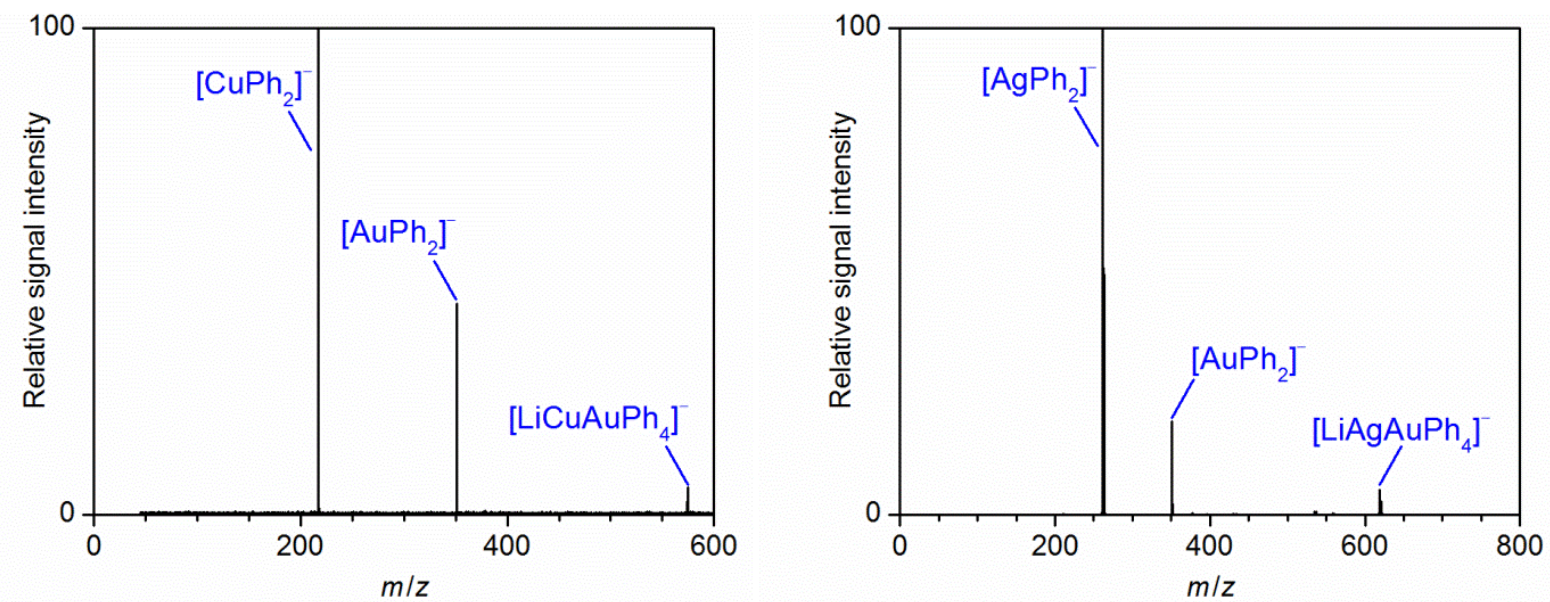

Figure 18. Left: Mass spectrum of mass-selected [LiCuAuPh$\left.]_{4}\right]^{-}$and its fragment ions produced upon collision-induced dissociation at $E_{\mathrm{LAB}}=15 \mathrm{eV}$. Right: Mass spectrum of mass-selected [LiAgAuPh$\left.]_{4}\right]^{-}$ and its fragment ions produced upon collision-induced dissociation at $E_{\mathrm{LAB}}=15 \mathrm{eV}$.

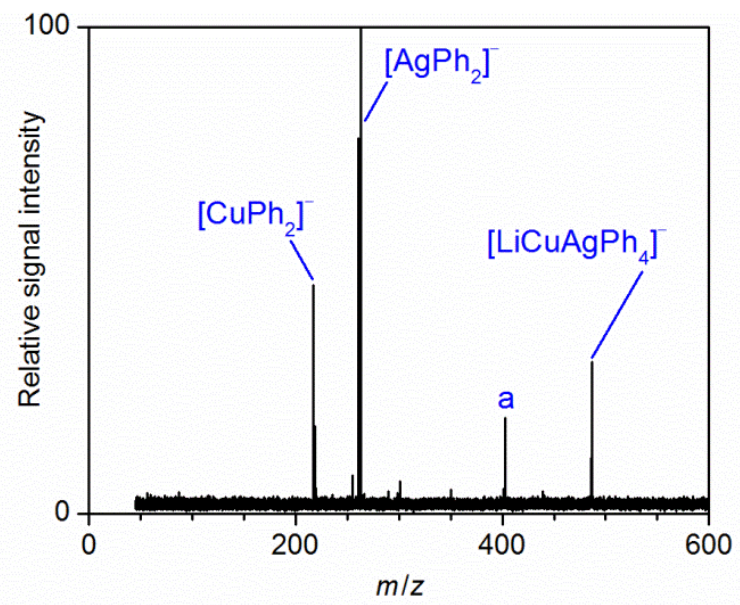

Figure 19. Mass spectrum of mass-selected [ $\left.\mathrm{LiCuAgPh}_{4}\right]^{-}$and its fragment ions produced upon collision-induced dissociation at $E_{\mathrm{LAB}}=12.5 \mathrm{eV}$. a: $\left[\mathrm{CuAgPh}_{3}\right]^{-}$.

Fragmentation of $\left[\mathrm{MR}_{2}\right]^{-}$. The gas-phase fragmentation behavior of the mononuclear complexes $\left[\mathrm{MR}_{2}\right]^{-}(\mathrm{M}=\mathrm{Cu}, \mathrm{Ag}, \mathrm{Au} ; \mathrm{R}=\mathrm{Ph}, \mathrm{Me})$ exhibited more pronounced differences. While $\left[\mathrm{CuPh}_{2}\right]^{-}$afforded the phenyl anion $\mathrm{Ph}^{-}$(Figure 20, left), no fragment ions could be detected in the fragmentation of $\left[\mathrm{AgPh}_{2}\right]^{-}$. However, the signal intensity of the latter decreased upon increasing the collision energy. In contrast, $\left[\mathrm{AuPh}_{2}\right]^{-}$showed several fragmentation pathways: in addition to the phenyl anion, $\mathrm{Ph}^{-}$, the $\mathrm{CID}$ spectrum included $\mathrm{Au}^{-},[\mathrm{AuPh}]^{-}$, and $[\mathrm{AuPh}(\mathrm{H})]^{-}$(Figure 20, right). 

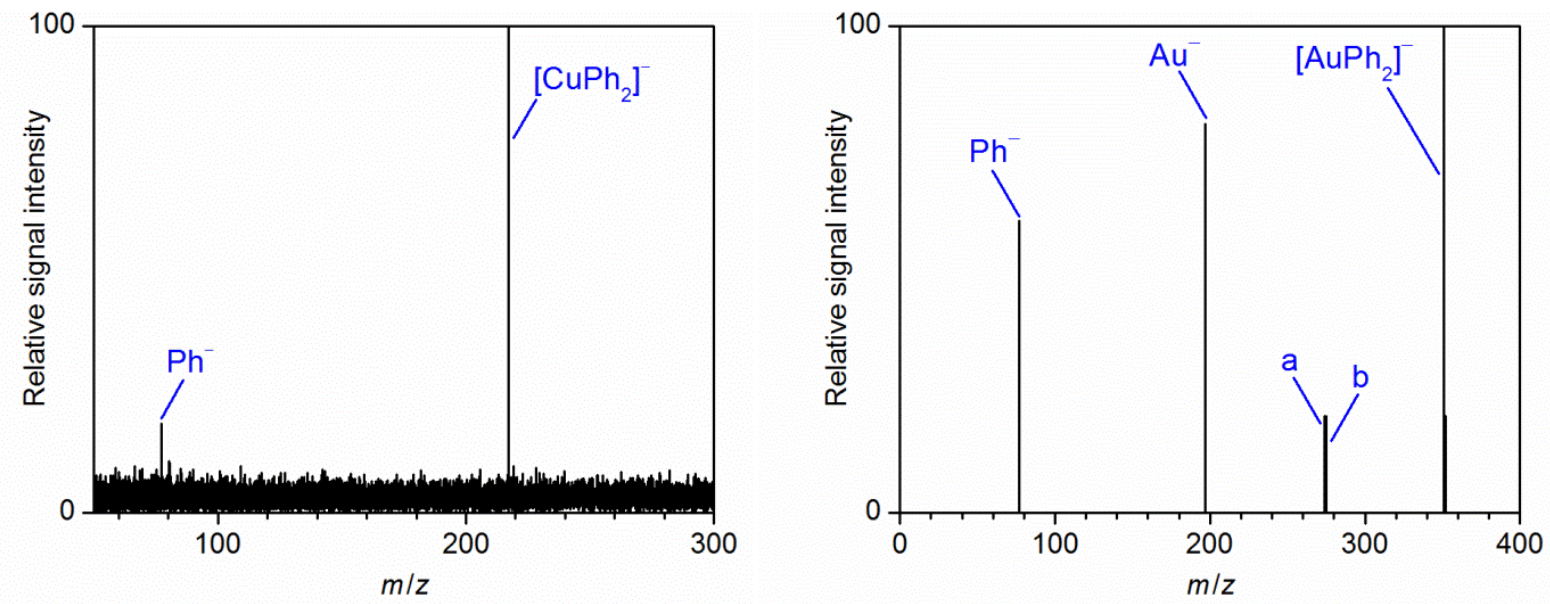

Figure 20. Left: Mass spectrum of mass-selected $\left[\mathrm{CuPh}_{2}\right]^{-}$and its fragment ions produced upon collision-induced dissociation at $E_{\mathrm{LAB}}=30 \mathrm{eV}$. Right: Mass spectrum of mass-selected $\left[\mathrm{AuPh}_{2}\right]^{-}$and its fragment ions produced upon collision-induced dissociation at $E_{\mathrm{LAB}}=30 \mathrm{eV}$. a: $[\mathrm{AuPh}]^{-}, \mathrm{b}:[\mathrm{AuPh}(\mathrm{H})]^{-}$.

Of the mononuclear methylmetallates, only the silver complex $\left[\mathrm{AgMe}_{2}\right]^{-}$produced fragment ions, namely $\mathrm{Ag}^{-}$and $[\mathrm{AgMe}]^{-}$(Figure 21). [AuMe $]^{-}$did not yield any ionic fragments upon collisional activation, and $\left[\mathrm{CuMe}_{2}\right]^{-}$was not present in the regular ESI mass spectrum.

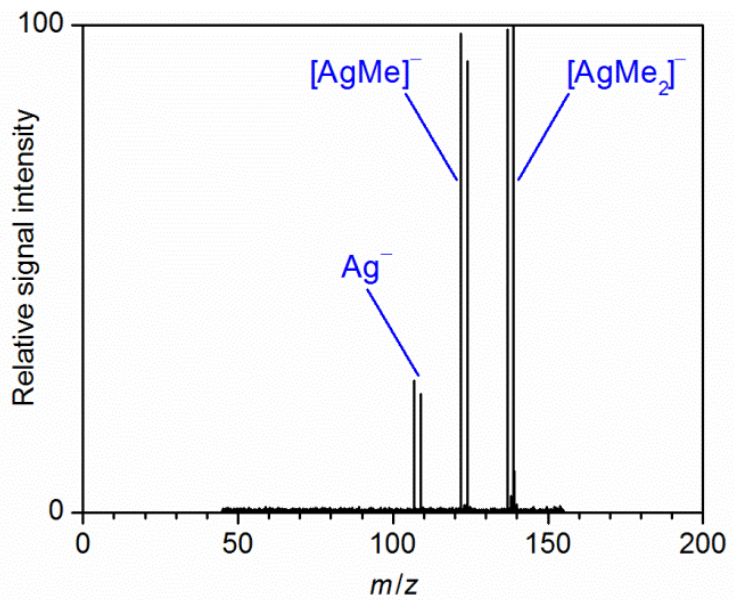

Figure 21. Mass spectrum of mass-selected $\left[\mathrm{AgMe}_{2}\right]^{-}$and its fragment ions produced upon collisioninduced dissociation at $E_{\mathrm{LAB}}=10 \mathrm{eV}$.

Fragmentation of $\left[\mathrm{MR}_{4}\right]^{-}$. Gas-phase fragmentation of $\left[A u R_{4}\right]^{-}(R=P h, M e)$ led to the formation of $\left[\mathrm{AuR}_{2}\right]^{-}$in both cases (Figure 22). This corresponds to the reductive elimination of biphenyl or ethane, respectively. 

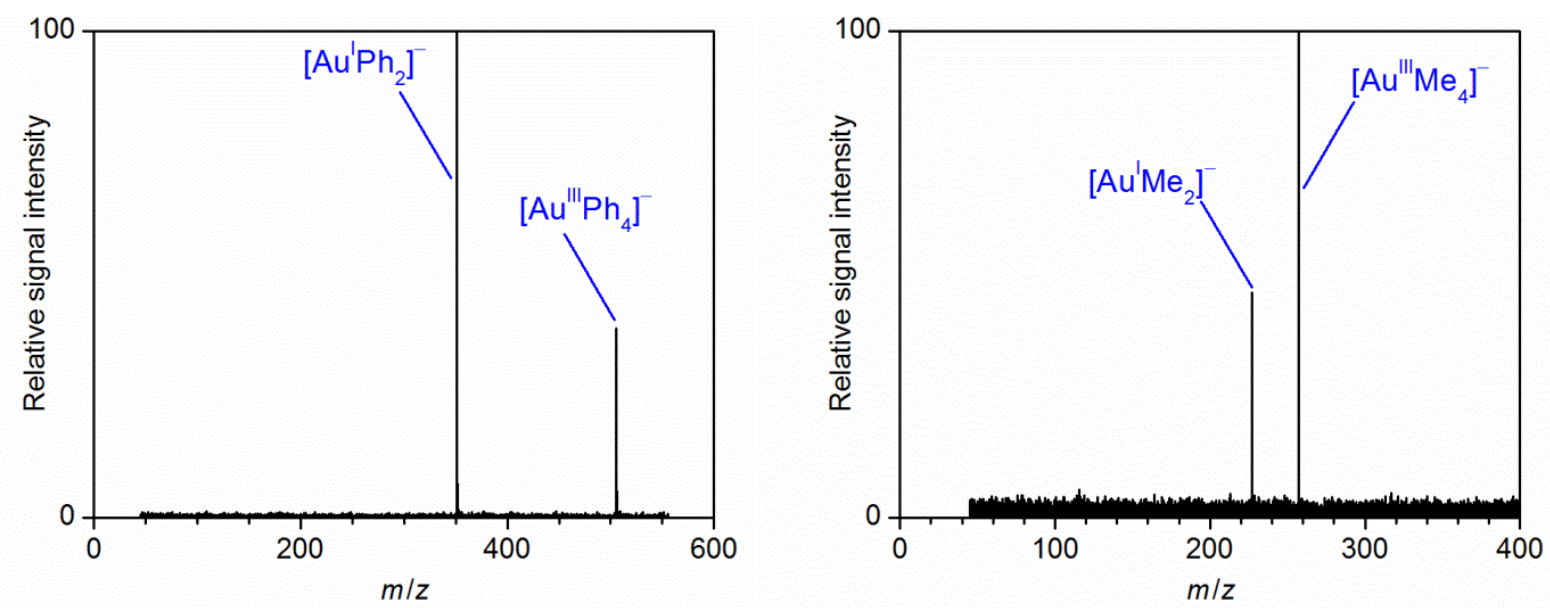

Figure 22. Left: Mass spectrum of mass-selected $\left[\mathrm{AuPh}_{4}\right]^{-}$and its fragment ions produced upon collision-induced dissociation at $E_{\mathrm{LAB}}=15 \mathrm{eV}$. Right: Mass spectrum of mass-selected $\left[\mathrm{AuMe}_{4}\right]^{-}$and its fragment ions produced upon collision-induced dissociation at $E_{\mathrm{LAB}}=10 \mathrm{eV}$.

\subsubsection{Formation of Organometallate Anions}

The detection of organometallates with the general formula $\left[\mathrm{Li}_{n-1} \mathrm{M}_{n} \mathrm{R}_{2 n}\right]^{-}(\mathrm{M}=\mathrm{Cu}, \mathrm{Ag}, \mathrm{Au} ; \mathrm{R}=\mathrm{Ph}, \mathrm{Me}$; $n=1-3$ ) in the present experiments is completely in line with previous reports on lithium cyanocuprates and Gilman cuprates. ${ }^{[74 a, c]}$ The gold species $\left[\mathrm{Li}_{3} \mathrm{Au}_{4} \mathrm{Me}_{8}\right]^{-}$and $\left[\mathrm{Li}_{5} \mathrm{Au}_{6} \mathrm{Me}_{12}\right]^{-}$even extend the range to $n=4$ and 6 . Moreover, the mixed metallates $\left[\operatorname{LiM}^{1} \mathrm{M}^{2} \mathrm{Ph}_{4}\right]^{-},\left[\mathrm{Li}_{2} \mathrm{M}_{2}^{1} \mathrm{M}^{2} \mathrm{Ph}_{6}\right]^{-}$, $\left[\mathrm{Li}_{2} \mathrm{M}^{1} \mathrm{M}_{2}^{2} \mathrm{Ph}_{6}\right]^{-}$, and $\left[\mathrm{Li}_{2} \mathrm{CuAgAuPh}_{6}\right]^{-}$also resemble the aforementioned formula for $n=2$ and 3 . These findings point to close similarities between copper, silver, and gold in the formation of organometallates. The occurrence of $\left[\mathrm{Li}_{n-1} \mathrm{Cu}_{n} \mathrm{R}_{2 n}\right]^{-}$anions in mass spectra of lithium cyanocuprate solutions has been rationalized in terms of association/dissociation equilibria. ${ }^{[74]}$ In particular, species of the general type $\left[\mathrm{Li}_{2} \mathrm{Cu}_{3} \mathrm{R}_{6}\right]^{-}$were regarded as adducts of the ionic organocuprate monomer $\left[\mathrm{CuR}_{2}\right]^{-}$ and the neutral organocuprate homodimer $\mathrm{Li}_{2} \mathrm{Cu}_{2} \mathrm{R}_{4},{ }^{[74]}$ which have been identified as the predominant species in ethereal cyanocuprate solutions. ${ }^{[69,73,124]}$ Gschwind and coworkers proposed an equilibrium between the two latter species (Scheme 4). ${ }^{[42 c, 69,73 a, c, 124]}$ and suggested a shift of the equilibrium towards the solvent-separated ion pairs in THF. If the increase in concentration during the ESI process is taken into account, ${ }^{[95]}$ a shift to the dimeric species and further association to higher ionic aggregates such as $\left[\mathrm{Li}_{2} \mathrm{Cu}_{3} \mathrm{Ph}_{6}\right]^{-}$appears quite likely, thus explaining their observation in mass spectrometric experiments. The appearance of the corresponding aggregates $\left[\mathrm{Li}_{n-1} \mathrm{Ag}_{n} \mathrm{R}_{2 n}\right]^{-}$ $(n=2,3)$ and $\left[\mathrm{Li}_{n-1} \mathrm{Au}_{n} \mathrm{R}_{2 n}\right]^{-}(n=2-4,6)$ thus indicates, that similar association/dissociation equilibria apply to organoargentates and -aurates as well.

The observation of mixed phenylmetallates reveals the operation of analogous equilibria between mononuclear phenylmetallates, homodimers bearing different coinage metals, and higher aggregates. In particular, the formation of $\left[\mathrm{Li}_{2} \mathrm{M}_{2}^{1} \mathrm{M}^{2} \mathrm{Ph}_{6}\right]^{-}$and $\left[\mathrm{Li}_{2} \mathrm{M}^{1} \mathrm{M}_{2}^{2} \mathrm{Ph}_{6}\right]^{-}$can be rationalized by association of mononuclear phenylmetallates of one coinage metal and the neutral homodimer of another coinage metal (Eqs. 11a and 11b). Dissociation of the thus formed mixed metallates then yields the mixed neutral dimer $\mathrm{Li}_{2} \mathrm{M}^{1} \mathrm{M}^{2} \mathrm{Ph}_{4}$ (Eqs. 12a and $12 \mathrm{~b}$ ), which in turn can form $\left[\mathrm{LiM}^{1} \mathrm{M}^{2} \mathrm{Ph}_{4}\right]^{-}$ (Eq. 13). In phenylmetallate solutions prepared from all three coinage metal, association of the mixed neutral dimer with the diphenylmetallate of the respective third coinage metal, $\left[\mathrm{M}^{3} \mathrm{Ph}_{2}\right]^{-}$, affords $\left[\mathrm{Li}_{2} \mathrm{M}^{1} \mathrm{M}^{2} \mathrm{M}^{3} \mathrm{Ph}_{6}\right]^{-}$, i.e. $\left[\mathrm{Li}_{2} \mathrm{CuAgAuPh}\right]_{6}^{-}$(Eq. 14). 


$$
\begin{aligned}
& {\left[\mathrm{M}^{1} \mathrm{Ph}_{2}\right]^{-}+\mathrm{Li}_{2} \mathrm{M}_{2}^{2} \mathrm{Ph}_{4} \rightleftharpoons\left[\mathrm{Li}_{2} \mathrm{M}^{1} \mathrm{M}_{2}^{2} \mathrm{Ph}_{6}\right]^{-}} \\
& {\left[\mathrm{M}^{2} \mathrm{Ph}_{2}\right]^{-}+\mathrm{Li}_{2} \mathrm{M}_{2}^{1} \mathrm{Ph}_{4} \rightleftharpoons\left[\mathrm{Li}_{2} \mathrm{M}_{2}^{1} \mathrm{M}^{2} \mathrm{Ph}_{6}\right]^{-}} \\
& {\left[\mathrm{Li}_{2} \mathrm{M}^{1} \mathrm{M}_{2}{ }_{2} \mathrm{Ph}_{6}\right]^{-} \rightleftharpoons\left[\mathrm{M}^{2} \mathrm{Ph}_{2}\right]^{-}+\mathrm{Li}_{2} \mathrm{M}^{1} \mathrm{M}^{2} \mathrm{Ph}_{4}} \\
& {\left[\mathrm{Li}_{2} \mathrm{M}_{2}^{1} \mathrm{M}^{2} \mathrm{Ph}_{6}\right]^{-} \rightleftharpoons\left[\mathrm{M}^{1} \mathrm{Ph}_{2}\right]^{-}+\mathrm{Li}_{2} \mathrm{M}^{1} \mathrm{M}^{2} \mathrm{Ph}_{4}} \\
& \mathrm{Li}_{2} \mathrm{M}^{1} \mathrm{M}^{2} \mathrm{Ph}_{4} \rightleftharpoons \mathrm{Li}^{+}+\left[\mathrm{LiM}^{1} \mathrm{M}^{2} \mathrm{Ph}_{4}\right]^{-} \\
& \mathrm{Li}_{2} \mathrm{M}^{1} \mathrm{M}^{2} \mathrm{Ph}_{4}+\left[\mathrm{M}^{3} \mathrm{Ph}_{2}\right]^{-} \rightleftharpoons\left[\mathrm{Li}^{2} \mathrm{M}^{1} \mathrm{M}^{2} \mathrm{M}^{3} \mathrm{Ph}_{6}\right]^{-}
\end{aligned}
$$

Furthermore, the sum formulas of $\left[\mathrm{Li}_{2} \mathrm{Cu}_{3} \mathrm{Ph}_{6}\right]^{-}$and $\left[\mathrm{Li}_{2} \mathrm{Ag}_{3} \mathrm{Ph}_{6}\right]^{-}$agree with those of pentanuclear organocuprates (Figure 1 ) and argentates that have been found in the solid state, ${ }^{[44,58]}$ which suggests that the species identified by ESI mass spectrometry and by X-ray crystallography may be identical. Even more, these two solid-state anions adopt structures that are remarkably similar, which prompts the assumption of a structural motif common for all species of the type $\left[\mathrm{Li}_{2} \mathrm{M}_{3} \mathrm{R}_{6}\right]^{-}$found in the present study. The occurrence of lithium-free organometallates like $\left[\mathrm{Ag}_{2} \mathrm{Ph}_{3}\right]^{-}$and $\left[\mathrm{M}_{n} \mathrm{Me}_{n+1}\right]^{-}(n=2$, 3 for $\mathrm{M}=\mathrm{Cu}$, and $n=2-4$ for $\mathrm{M}=\mathrm{Ag}$ ) is also not surprising. Homometallic organocuprates of the type $\left[\mathrm{Cu}_{n} \mathrm{R}_{n+1}\right]^{-}$have been observed before in mass spectrometric experiments of Normant cuprates and were discussed as decomposition products (see chapter 4.1). Accordingly, their appearance here also implies the operation of degradation processes.

Coinage-metal ate complexes could also be observed in ESI mass spectra upon addition of Grignard reagents to coinage-metal cyanides in THF. In particular, the mass spectra of phenyl cuprate and aurate solutions prepared from $\mathrm{CuCN}$ or $\mathrm{AuCN}$ with $2 \mathrm{PhMgCl}$ were largely dominated by the respective monomeric species $\left[\mathrm{MPh}_{2}\right]^{-}$. This result is in full agreement with the outcome of mass spectrometric analysis of magnesium phenylcuprates prepared from $\mathrm{CuCl}$ instead of $\mathrm{CuCN}$ (see chapter 4.1). Mass spectra of magnesium phenylargentates prepared from $\mathrm{AgCN}$ and $\mathrm{PhMgCl}$ also showed $\left[\mathrm{AgPh}_{2}\right]^{-}$and additionally $\left[\mathrm{Ag}_{2} \mathrm{Ph}_{3}\right]^{-}$. However, the base peak corresponded to $\left[\mathrm{MgAg}_{2} \mathrm{Ph}_{2}(\mathrm{CN})_{2} \mathrm{Cl}\right]^{-}$. The high abundance of this species, together with the presence of $\left[\mathrm{MgAg}_{2} \mathrm{Ph}_{2}(\mathrm{CN})_{2}(\mathrm{OH})\right]^{-}$can be attributed to hydrolysis reactions. Despite this complication, the formation of coinage-metal ate complexes from $\mathrm{MCN}$ and $\mathrm{PhMgCl}$ apparently results in similar species for copper, silver, and gold. However, in the case of $\mathrm{R}=\mathrm{Me}$, hydrolysis was a major issue for all three coinage metals, and no complexes bearing exclusively organic ligands were observed.

\subsubsection{Formation of Cationic Species}

Positive-ion mode ESI mass spectra of organometallate solutions that were prepared from MCN and organolithium reagents showed two types of cations. On the one hand, the inorganic lithium species $\left[\mathrm{Li}(\text { solv })_{n}\right]^{+}$and $\left[\mathrm{Li}_{2}(\mathrm{CN})(\text { solv })_{n}\right]^{+}$(solv $\left.=\mathrm{THF}, \mathrm{Bu}_{2} \mathrm{O} ; n=1,2\right)$ were observed. These results are consistent with the mass-spectrometric analysis of Gilman and cyanocuprates in $\mathrm{THF} \mathrm{Et}_{2} \mathrm{O}$, and further ethereal solvents, in which these or similar species were found. ${ }^{[74]}$ In these solutions, the presence of free, solvated lithium cations is a direct consequence of the equilibrium between the neutral homodimer $\mathrm{Li}_{2} \mathrm{Cu}_{2} \mathrm{R}_{2}$ and the mononuclear cuprate $\left[\mathrm{CuR}_{2}\right]^{-}$, as suggested by Gschwind and coworkers (Scheme 4). ${ }^{[42,69,73 a, c, 124]}$ Putau and Koszinowski further rationalized the formation of $\left[\mathrm{Li}_{2}(\mathrm{CN})(\text { solv })_{n}\right]^{+}$by additional association/dissociation equilibria (Eq. 15). ${ }^{[74 b]}$ In the present work, the observation of $\left[\mathrm{Li}(\mathrm{solv})_{n}\right]^{+}$and $\left[\mathrm{Li}_{2}(\mathrm{CN})(\text { solv })_{n}\right]^{+}$in ESI mass spectra of organocuprate, -argentate and -aurate solutions points to the operation of similar equilibria as a feature that is common to all of these reagents. 


$$
\left[\mathrm{Li}(\text { solv })_{n}\right]^{+}+2 \mathrm{CN}^{-} \rightleftharpoons \mathrm{Li}(\mathrm{CN})(\text { solv })_{n}+\mathrm{CN}^{-} \rightleftharpoons\left[\mathrm{Li}(\mathrm{CN})_{2}(\text { solv })_{n}\right]^{-}
$$

On the other hand, the heterobimetallic cations $\left[\mathrm{Li}_{2} \mathrm{MPh}_{2}(\text { solv })_{n}\right]^{+}\left(\mathrm{M}=\mathrm{Cu}, \mathrm{Ag}, \mathrm{Au}\right.$; solv $=\mathrm{THF}, \mathrm{Bu}_{2} \mathrm{O}$; $n=0-2)$ and $\left[\mathrm{Li}_{2} \mathrm{AuMe}_{2}(\mathrm{THF})_{n}\right]^{+}(n=1,2)$ were found in positive-ion mode ESI mass spectra of sample solutions prepared from MCN and PhLi or MeLi, respectively. Previously published studies of mass spectrometric experiments also found organometallic cations of this type in mass spectra of cyanocuprates $^{[74 b]}$ and Gilman cuprates ${ }^{[74 c]}$. However, the earlier experiments detected these species only in small quantities, but in the present work, cations of this type were among the most intense species in the spectra. Slight differences in sample preparation and the use of different mass spectrometers might - at least in part - account for these different findings, but still, the exact reason for this discrepancy remains unclear. Nonetheless, the question arises of how the formation of $\left[\mathrm{Li}_{2} \mathrm{MR}_{2}(\text { solv })_{n}\right]^{+}$can be rationalized. In addition to the already discussed dissociation of the homodimer, yielding monomeric cuprates and lithium cations, a further possibility is conceivable, in which a neutral homodimer dissociates into the monomeric $\left[\mathrm{MR}_{2}\right]^{-}$and the heterobimetallic cation $\left[\mathrm{Li}_{2} \mathrm{MR}_{2}(\mathrm{THF})_{n}\right]^{+}$(Eq. 16), thus providing a straightforward explanation for the presence of the latter. The (probably stepwise) association of two lithium cations and one monomeric metallate might also account for the formation of $\left[\mathrm{Li}_{2} \mathrm{MR}_{2}(\mathrm{THF})_{n}\right]^{+}$(Eq. 17).

$$
\begin{aligned}
& \mathrm{Li}_{2} \mathrm{M}_{2} \mathrm{R}_{4}(\text { solv })_{x} \rightleftharpoons\left[\mathrm{MR}_{2}\right]^{-}+\left[\mathrm{Li}_{2} \mathrm{MR}_{2}(\mathrm{THF})_{n}\right]^{+} \\
& 2\left[\mathrm{Li}(\text { solv })_{x}\right]^{+}+\left[\mathrm{MR}_{2}\right]^{-} \rightleftharpoons\left[\mathrm{Li}(\text { solv })_{x}\right]^{+}+\mathrm{LiMR}_{2}(\text { solv })_{n} \rightleftharpoons\left[\mathrm{Li}_{2} \mathrm{MR}_{2}(\text { solv })_{n}\right]^{+}
\end{aligned}
$$

The related species $\left[\mathrm{Li}_{2} \mathrm{MMe}(\mathrm{CN})(\mathrm{THF})_{n}\right]^{+}(\mathrm{M}=\mathrm{Cu}, \mathrm{Ag}, \mathrm{Au}, n=1,2)$, which dominated spectra of solutions that were prepared from coinage-metal cyanides and methyl lithium, are most likely the result of partial hydrolysis of the aforementioned species followed by a replacement of $\mathrm{OH}^{-}$by $\mathrm{CN}^{-}$.

\subsubsection{Gas-Phase Reactivity of Organocuprates, -argentates, and -aurates}

$\left[\mathrm{Li}_{2} \mathbf{M}_{3} \mathbf{R}_{6}\right]^{-}$. The gas-phase fragmentation of the pentanuclear complexes $\left[\mathrm{Li}_{2} \mathrm{M}_{3} \mathrm{Ph}_{6}\right]^{-}$consistently proceeded by loss of neutral $\mathrm{Li}_{2} \mathrm{M}_{2} \mathrm{Ph}_{4}$ and led to the formation of the respective mononuclear $\left[\mathrm{MPh}_{2}\right]^{-}$species, regardless of the kind of coinage metal that was included, or if one, two, or all three coinage metals were present in the precursor ion. The preference for this dissociation pathway is in full accordance with the previously observed behavior of a range of similar cuprates $\left[\mathrm{Li}_{2} \mathrm{Cu}_{3} \mathrm{R}_{6}\right]^{-}$ $\left(\mathrm{R}=\mathrm{Me}, \mathrm{Et},{ }^{n} \mathrm{Bu},{ }^{5} \mathrm{Bu}, \mathrm{Ph}\right)$ in $\mathrm{CID}$ experiments ${ }^{[74 \mathrm{a}]}$ and apparently constitutes the preferred mode of fragmentation for $\left[\mathrm{Li}_{2} \mathrm{M}_{3} \mathrm{Ph}_{6}\right]^{-}$species in general. As already discussed above, the formation of $\left[\mathrm{Li}_{2} \mathrm{M}_{3} \mathrm{Ph}_{6}\right]^{-}$can be rationalized as association of the mononuclear ate complex $\left[\mathrm{MPh}_{2}\right]^{-}$and the neutral homodimer $\mathrm{Li}_{2} \mathrm{M}_{2} \mathrm{Ph}_{4}$. The observed dissociation of $\left[\mathrm{Li}_{2} \mathrm{M}_{3} \mathrm{Ph}_{6}\right]^{-}$into exactly these two species lends further support to this interpretation as it represents exactly the reversed formation reaction. In fragmentation experiments of $\left[\mathrm{Li}_{2} \mathrm{M}_{2}^{1} \mathrm{M}^{2} \mathrm{Ph}_{6}\right]^{-}$and $\left[\mathrm{Li}_{2} \mathrm{M}^{1} \mathrm{M}_{2}{ }_{2} \mathrm{Ph}_{6}\right]^{-}$, the fragment ion including the coinage metal that was present two times in the parent ion always appeared with higher intensity than the other fragment ion. The intensity ratio of these two fragment ions was approximately 2:1 in each case, except for $\left[\mathrm{Li}_{2} \mathrm{CuAu}_{2} \mathrm{Ph}_{6}\right]^{-}$and $\left[\mathrm{Li}_{2} \mathrm{AgAu}_{2} \mathrm{Ph}_{6}\right]^{-}$, where the ratio was somewhat closer to unity. Fragmentation of $\left.\left[\mathrm{Li}_{2} \mathrm{CuAgAuPh}\right]_{6}\right]^{-}$resulted in the formation of $\left[\mathrm{CuPh}_{2}\right]^{-},\left[\mathrm{AgPh}_{2}\right]^{-}$, and $\left[\mathrm{AuPh}_{2}\right]^{-}$ in approximately equal amounts. These results point to a rather statistical fragmentation of the mixed pentanuclear metallates, which does not depend on the nature of the included coinage metals, and, beyond this, further support the assumption of a common structure of $\left[\mathrm{Li}_{2} \mathrm{M}_{3} \mathrm{Ph}_{6}\right]^{-}$and the associated mixed species. 
Additional dissociation channels were observed upon collisional activation of the analogous methylmetallates $\left[\mathrm{Li}_{2} \mathrm{M}_{3} \mathrm{Me}_{6}\right]^{-}$. Again, fragmentation of $\left[\mathrm{Li}_{2} \mathrm{Ag}_{3} \mathrm{Me}_{6}\right]^{-}$and $\left[\mathrm{Li}_{2} \mathrm{Au}_{3} \mathrm{Me}_{6}\right]^{-}$afforded high amounts of the respective mononuclear ions $\left[\mathrm{MMe}_{2}\right]^{-}$by release of the corresponding neutral fragment $\mathrm{Li}_{2} \mathrm{M}_{2} \mathrm{Me}_{4}$, but now, $\left[\mathrm{Ag}_{2} \mathrm{Me}_{3}\right]^{-}$and $\left[\mathrm{LiAu}_{2} \mathrm{Me}_{4}\right]^{-}$were also detected. Even more, fragmentation of $\left[\mathrm{Li}_{2} \mathrm{Cu}_{3} \mathrm{Me}_{6}\right]^{-}$afforded both $\left[\mathrm{Cu}_{2} \mathrm{Me}_{3}\right]^{-}$and $\left[\mathrm{LiCu}_{2} \mathrm{Me}_{4}\right]^{-}$, but only traces of [CuMe $]^{-}$. However, a previous $\mathrm{CID}$ experiment on $\left[\mathrm{Li}_{2} \mathrm{Cu}_{3} \mathrm{Me}_{6}\right]^{-}$by Putau and Koszinowski produced $\left[\mathrm{CuMe}_{2}\right]^{-}$and $\left[\mathrm{Cu}_{2} \mathrm{Me}_{3}\right]^{-}$ as fragment ions, ${ }^{[74 a]}$ thus resembling the fragmentation pattern of $\left[\mathrm{Li}_{2} \mathrm{Ag}_{3} \mathrm{Me}_{6}\right]^{-}$. The discrepancy between the present findings and the results obtained by Putau and Koszinowski may be attributed to the use of different mass spectrometers. In particular, the fragmentation experiments in the study of Putau and Koszinowski were performed in a three-dimensional ion trap, while the time-of-flight instrument used in the present study employs a linear quadrupole as collision cell. Nevertheless, changing the organyl ligand $R$ from phenyl to methyl in $\left[\mathrm{Li}_{2} \mathrm{M}_{3} \mathrm{R}_{6}\right]^{-}$species apparently provides access to further dissociation channels, which now depend more strongly on the present coinage metal. While the $\left[\mathrm{Li}_{2} \mathrm{M}_{3} \mathrm{Ph}_{6}\right]^{-}$anions have the possibility of lithium-phenyl $\pi$-binding, this kind of interaction is not possible in $\left[\mathrm{Li}_{2} \mathrm{M}_{3} \mathrm{Me}_{6}\right]^{-}$species. Perhaps, this $\pi$-binding reduces the influence of the individual metal-carbon bond strengths between the ipso-carbon atoms of the phenyl groups and $\mathrm{Cu}, \mathrm{Ag}$, or $\mathrm{Au}$, respectively, in $\left[\mathrm{Li}_{2} \mathrm{M}_{3} \mathrm{Ph}_{6}\right]^{-}$, thereby resulting in a uniform fragmentation behavior. In contrast the influence of the respective bond strengths becomes more decisive for the outcome of unimolecular fragmentation reactions in $\left[\mathrm{Li}_{2} \mathrm{M}_{3} \mathrm{Me}_{6}\right]^{-}$anions that lack the possibility of $\pi$-binding. Additionally, the lower steric demand of the methyl groups in $\left[\mathrm{Li}_{2} \mathrm{M}_{3} \mathrm{Me}_{6}\right]^{-}$might increase their conformational flexibility compared to their phenyl analogues, thereby allowing the ions to assume geometries from which the additional fragmentation pathways can emanate.

$\left[\mathrm{LiM}_{2} \mathbf{R}_{4}\right]^{-}$. The formation of the mononuclear species $\left[\mathrm{MPh}_{2}\right]^{-}$also dominated the gas-phase fragmentation of the trinuclear complexes $\left[\mathrm{LiM}_{2} \mathrm{Ph}_{4}\right]^{-}$. The mixed metallates $\left[\mathrm{LiM}^{1} \mathrm{M}^{2} \mathrm{Ph}_{4}\right]^{-}$likewise afforded $\left[\mathrm{M}^{1} \mathrm{Ph}_{2}\right]^{-}$and $\left[\mathrm{M}^{2} \mathrm{Ph}_{2}\right]^{-}$. Of the corresponding methyl metallates, only $\left[\mathrm{LiAu}_{2} \mathrm{Me}_{4}\right]^{-}$was present in the regular mass spectra, but its copper homologue $\left[\mathrm{LiCu}_{2} \mathrm{Me}_{4}\right]^{-}$has been studied in previous experiments. ${ }^{[74 a]}$ Similar to the phenyl complexes, both methyl metallates yielded the monomeric ate complexes $\left[\mathrm{CuMe}_{2}\right]^{-}$and $\left[\mathrm{AuMe}_{2}\right]^{-}$. In addition, the binuclear fragment ions $\left[\mathrm{Cu}_{2} \mathrm{Ph}_{3}\right]^{-}$, $\left.\left[\mathrm{Ag}_{2} \mathrm{Ph}_{3}\right]^{-},[\mathrm{CuAgPh}]_{3}\right]^{-}$could be detected in different amounts. Their formation corresponds to the elimination of PhLi from the precursor ion and has been observed upon gas-phase fragmentation of $\left[\mathrm{LiCu}_{2} \mathrm{Me}_{4}\right]^{-}$before. ${ }^{[74 a]}$ These fragments belong to the $\left[\mathrm{M}_{2} \mathrm{R}_{3}\right]^{-}$type of ions, which also appeared in CID experiments of $\left[\mathrm{Li}_{2} \mathrm{M}_{3} \mathrm{Me}_{6}\right]^{-}$species (see above). Thus, the fragmentation of $\left[\mathrm{LiM}_{2} \mathrm{R}_{4}\right]^{-}$species not only proceeds similarly for all three coinage metals but also closely resembles the behavior of the higher aggregates $\left[\mathrm{Li}_{2} \mathrm{M}_{3} \mathrm{R}_{6}\right]^{-}$.

However, deviating from the mixed pentanuclear complexes $\left[\mathrm{Li}_{2} \mathrm{M}_{2}^{1} \mathrm{M}^{2} \mathrm{Ph}_{6}\right]^{-}$and $\left[\mathrm{Li}_{2} \mathrm{M}^{1} \mathrm{M}_{2}{ }_{2} \mathrm{Ph}_{6}\right]^{-}$, the ratio of the product ions afforded by fragmentation of $\left[\mathrm{LiM}^{1} \mathrm{M}^{2} \mathrm{Ph}_{4}\right]^{-}$clearly does not show a statistical distribution of 1:1, but points to a more pronounced influence of the present coinage metals: apparently, the ratio of the product ion formation is now modulated by the nature of $\mathrm{M}^{1}$ and $M^{2}$. As the release of a particular $\left[\mathrm{M}^{1} \mathrm{Ph}_{2}\right]^{-}$fragment ion is always accompanied by the elimination of the respective lithium-containing neutral fragment $\mathrm{LiM}^{2} \mathrm{Ph}_{2}$ and vice versa, the resulting intensity ratios may be attributed to different lithium-affinities of $\left[\mathrm{M}^{1} \mathrm{Ph}_{2}\right]^{-}$and $\left[\mathrm{M}^{2} \mathrm{Ph}_{2}\right]^{-}$, which should directly depend on the incorporated coinage metal. For example, if $\left[\mathrm{M}^{1} \mathrm{Ph}_{2}\right]^{-}$has a higher affinity to $\mathrm{Li}^{+}$than $\left[\mathrm{M}^{2} \mathrm{Ph}_{2}\right]^{-}$, the dissociation of $\left[\mathrm{LiM}^{1} \mathrm{M}^{2} \mathrm{Ph}_{4}\right]^{-}$should preferentially lead to $\mathrm{LiM}^{1} \mathrm{Ph}_{2}$ and $\left[\mathrm{M}^{2} \mathrm{Ph}_{2}\right]^{-}$. Specifically, the formation of $\left[\mathrm{CuPh}_{2}\right]^{-}$or $\left[\mathrm{AgPh}_{2}\right]^{-}$, respectively, is preferred over the generation of 
$\left[\mathrm{AuPh}_{2}\right]^{-}$in fragmentation experiments of [ $\left.\mathrm{LiCuAuPh}_{4}\right]^{-}$and $\left[\mathrm{LiAgAuPh}_{4}\right]^{-}$(Figure 18). Accordingly, the elimination of $\mathrm{LiAuPh}_{2}$ is favored over the release of $\mathrm{LiCuPh}_{2}$ and $\mathrm{LiAgPh}_{2}$. In turn, the fragmentation of [ $\left.\mathrm{LiCuAgPh}_{4}\right]^{-}$prefers the fragmentation that affords $\left[\mathrm{AgPh}_{2}\right]^{-}$and $\mathrm{LiCuPh}_{2}$ over the dissociation that yields $\left[\mathrm{CuPh}_{2}\right]^{-}$and $\mathrm{LiAgPh}_{2}$. (Figure 19). As a consequence thereof, it is possible to arrange the mononuclear phenylcuprates according to their respective lithium affinity, which increases in the order $\left[\mathrm{AgPh}_{2}\right]^{-}<\left[\mathrm{CuPh}_{2}\right]^{-}<\left[\mathrm{AuPh}_{2}\right]^{-}$. This situation can be considered an example of Cooks' kinetic method, which allows the determination of relative ion affinities from the intensity ratio of fragment ions formed in the competitive dissociation of ion-bound heterodimers that were mass-selected and subjected to gas-phase fragmentation experiments. ${ }^{[125]}$

$\left[\mathrm{MR}_{2}\right]^{-}$. In contrast to the pentanuclear and trinuclear species $\left[\mathrm{Li}_{2} \mathrm{M}_{3} \mathrm{Ph}_{6}\right]^{-}$and $\left[\mathrm{LiM}_{2} \mathrm{Ph}_{4}\right]^{-}$, which showed a qualitatively consistent fragmentation behavior, the gas-phase reactivity of the mononuclear ate complexes $\left[\mathrm{MPh}_{2}\right]^{-}$exhibited fundamental differences for copper, silver, and gold. The release of phenyl anions, $\mathrm{Ph}^{-}$, was observed upon collisional activation of $\left[\mathrm{CuPh}_{2}\right]^{-}$and $\left[\mathrm{AuPh}_{2}\right]^{-}$. This corresponds to the loss of $\mathrm{MPh}(\mathrm{M}=\mathrm{Cu}, \mathrm{Au})$ and parallels the elimination of neutral CuR fragments that was observed in CID experiments of $\left[\mathrm{Cu}_{n} \mathrm{R}_{n+1}\right]^{-}$species as well (see chapter 4.1.1). Additionally, $\left[\mathrm{AuPh}_{2}\right]^{-}$also expelled naked gold anions (sic) as well as $[\mathrm{AuPh}]^{-}$and $[\mathrm{AuPh}(\mathrm{H})]^{-}$. The generation of $\mathrm{Au}^{-}$ions from the linear $\left[\mathrm{AuPh}_{2}\right]^{-}$complex can formally be regarded as reductive elimination of biphenyl. For a process like this, however, the transition structure would have to feature a highly bent geometry, which should be energetically unfavorable, thus rendering this fragmentation mechanism rather unlikely. It seems more probable, that a subsequent loss of two phenyl radicals accounts for the formation of $\mathrm{Au}^{-}$. The assumption of such a stepwise formation is supported by the presence of $[\mathrm{AuPh}]^{-}$in the fragmentation spectrum, which presumably originates from the parent $\left[\mathrm{AuPh}_{2}\right]^{-}$ion through loss of a phenyl radical, and might undergo further loss of the remaining phenyl group via homolytic dissociation, resulting in the formation of $\mathrm{Au}^{-}$. Moreover, the identification of the hydride-containing fragment ion $[\mathrm{AuPh}(\mathrm{H})]^{-}$indicates a process in which benzyne is released as neutral species.

Unexpectedly, collisional activation of $\left[\mathrm{AgPh}_{2}\right]^{-}$, did not produce any observable fragment ions, but only resulted in the decrease of the precursor-ion intensity (at a collision energy of $E_{\mathrm{LAB}}=10 \mathrm{eV}$, the signal intensity of the precursor ion had dropped to approximately $50 \%$ of the initial value at $\left.E_{\mathrm{LAB}}=0 \mathrm{eV}\right)$. However, the corresponding methyl argentate $\left[\mathrm{AgMe}_{2}\right]^{-}$afforded $[\mathrm{AgMe}]^{-}$and $\mathrm{Ag}^{-}$as fragment ions at the same collision energy $\left(E_{\mathrm{Lab}}=10 \mathrm{eV}\right)$. This dissociation pattern partially resembles that of $\left[\mathrm{AuPh}_{2}\right]^{-}$and probably proceeds in a stepwise fashion as well (see above). Rijs and O'Hair performed CID experiments on the mixed argentate [MeAgPh] ${ }^{-[92 f]}$ Their fragmentation spectrum showed $[\mathrm{AgPh}]^{-}$as the main fragment ion, which corresponds to the loss of a methyl radical, and only traces of the phenyl anion. These findings are not in disagreement with the present result that a methyl radical can be expelled from $\left[\mathrm{AgMe}_{2}\right]^{-}$upon collisional activation, but $\left[\mathrm{AgPh}_{2}\right]^{-}$does not lose a phenyl radical at the same collision energy. Still, the question remains why the fragmentation of $\left[\mathrm{AgPh}_{2}\right]^{-}$into the phenyl anion and neutral AgPh was not observed, as could have been expected from the CID experiments on $\left[\mathrm{CuPh}_{2}\right]^{-}$and $\left[\mathrm{AuPh}_{2}\right]^{-}$. In a further gas-phase study, $\left[\mathrm{AgPh}_{2}\right]^{-}$has been found to undergo electron detachment in photodetachment action spectroscopy experiments. ${ }^{[126]}$ Of course, laser irradiation and collisional activation are two fundamental different processes. But the observation of electron detachment from $\left[\mathrm{AgPh}_{2}\right]^{-}$upon irradiation at least opens up the possibility, that diphenylargentate could possibly also lose an electron upon collisional activation, thereby accounting for the absence of any fragment ions in CID experiments. This explanation might also be 
invoked for the case of $\left[\mathrm{AuMe}_{2}\right]^{-}$, which also did not exhibit any observable fragmentation in CID experiments. However, it should be noted, that a hypothetically formed methyl anion $(\mathrm{m} / \mathrm{z} 15)$ would not be detectable due to the low-mass cut-off of the spectrometer.

Comparison and Trends. As can be seen from the results of the CID experiments, the neutral fragments released in deaggregation of $\left[\mathrm{Li}_{2} \mathrm{M}_{3} \mathrm{R}_{6}\right]^{-}$and $\left[\mathrm{LiM}_{2} \mathrm{R}_{4}\right]^{-}$always included lithium. Apparently, the lithium-containing structure of these higher aggregates facilitates the elimination of neutral species that either can be regarded as ion pairs of lithium cations and organometallates (especially $\mathrm{Li}_{2} \mathrm{M}_{2} \mathrm{R}_{4}$ and $\mathrm{LiMR}_{2}$ ) or correspond to RLi. In particular, the release of RLi corresponds to a transmetallation reaction that is reverse to that used for the generation of the cuprates. Thus, the structure of $\left[\mathrm{Li}_{2} \mathrm{M}_{3} \mathrm{R}_{6}\right]^{-}$and $\left[\mathrm{LiM}_{2} \mathrm{R}_{4}\right]^{-}$determines their unimolecular reactivity, thereby reducing the influence of the individual coinage metal centers. In contrast, the outcome of collisional activation of the mononuclear $\left[\mathrm{MR}_{2}\right]^{-}$heavily depends on the nature of the present coinage metal. Obviously, $\left[\mathrm{MR}_{2}\right]^{-}$anions cannot dissociate by deaggregation processes, so their unimolecular gas-phase reactivity is solely governed by the coinage metal $\mathrm{M}$.

$\left[\mathrm{AuR}_{4}\right]^{-}$. CID experiments of the Au' ${ }^{\prime \prime \prime}$-containing ions $\left[\mathrm{AuPh}_{4}\right]^{-}$and $\left[\mathrm{AuMe}_{4}\right]^{-}$resulted in the formation of the corresponding $\mathrm{Au}^{\prime}$-species, $\left[\mathrm{AuPh}_{4}\right]^{-}$and $\left[\mathrm{AuMe}_{4}\right]^{-}$, and elimination of biphenyl and ethane, respectively. In contrast to the fragmentation reactions of $\left[\mathrm{AuPh}_{2}\right]^{-}$and $\left[\mathrm{AgMe}_{2}\right]^{-}$, which probably proceed as subsequent losses of phenyl and methyl radicals (see above), reductive elimination reactions are quite likely for $\left[\mathrm{AuR}_{4}\right]^{-}$ions, as this reactivity has been observed before for organoaurates(III) ${ }^{[8, b, h,, 36,127]}$ as well as for tetraalkylcuprates(III) ${ }^{[86]}$ and tetraalkylargentates(III) ${ }^{[90]}$. 
The following section ("4.3 The Role of Ate Complexes in the Copper-Mediated Trifluoromethylation of Alkynes") was taken from the publication given below.

The following figures were added from the supporting information of this publication: 23 (right), 24 (left), 25, 27-31.

The Role of Ate Complexes in the Copper-Mediated Trifluoromethylation of Alkynes Sebastian Weske, Ramona Schoop, Konrad Koszinowski, Chemistry - A European Journal, 2016, 22, 11310-11316.

DOI : 10.1002/chem.201601261

https://onlinelibrary.wiley.com/doi/full/10.1002/chem.201601261

Copyright Wiley-VCH Verlag GmbH \& Co. KGaA. Reproduced with permission. 


\subsection{The Role of Ate Complexes in the Copper-Mediated Trifluoromethylation of Alkynes}

\subsubsection{In-Situ Formed Homoleptic Cuprate Complexes}

Trifluoromethyl-cuprate solutions were prepared by adding $\mathrm{Si}\left(\mathrm{CH}_{3}\right)_{3} \mathrm{CF}_{3}$ to a suspension of $\mathrm{Cul}$ and $\mathrm{KF}$ in THF and analyzed by ESI mass spectrometry. Besides $\left[\mathrm{CuI}_{2}\right]^{-}$and $\mathrm{I}_{3}^{-}$, the resulting negative-ion mode ESI mass spectra showed the homoleptic $\mathrm{Cu}(\mathrm{I})$ complex $\left[\mathrm{Cu}\left(\mathrm{CF}_{3}\right)_{2}\right]^{-}$in small and its $\mathrm{Cu}(\mathrm{III})$ counterpart $\left[\mathrm{Cu}\left(\mathrm{CF}_{3}\right)_{4}\right]^{-}$in larger abundance (Figure 23), ${ }^{[128]}$ in full accordance with the ${ }^{19} \mathrm{~F}-\mathrm{NMR}$ spectroscopic experiments of Tresse et al. ${ }^{[9 b]}$ Gas-phase fragmentation of $\left[\mathrm{Cu}\left(\mathrm{CF}_{3}\right)_{2}\right]^{-}$led to the loss of difluorocarbene and the formation of $\left[\mathrm{Cu}\left(\mathrm{CF}_{3}\right) \mathrm{F}\right]^{-}$(Eq. 18, Figure 24, left). Analogous behavior had previously been observed for $\left[\left(\mathrm{CF}_{3} \mathrm{CO}_{2}\right) \mathrm{CuCF}_{3}\right]^{-}$. ${ }^{[93 e]}$ Fragmentation of $\left[\mathrm{Cu}\left(\mathrm{CF}_{3}\right)_{4}\right]^{-}$afforded both $\left[\mathrm{Cu}\left(\mathrm{CF}_{3}\right)_{3}\right]^{-}$and $\left[\mathrm{Cu}\left(\mathrm{CF}_{3}\right)_{2}\right]^{-}$(Eqs. 19a and 19b, Figure 24, right).

$$
\begin{aligned}
{\left[\mathrm{Cu}\left(\mathrm{CF}_{3}\right)_{2}\right]^{-} } & \longrightarrow\left[\mathrm{Cu}\left(\mathrm{CF}_{3}\right) \mathrm{F}\right]^{-}+\mathrm{CF}_{2} \\
{\left[\mathrm{Cu}\left(\mathrm{CF}_{3}\right)_{4}\right]^{-} } & \longrightarrow\left[\mathrm{Cu}\left(\mathrm{CF}_{3}\right)_{3}\right]^{-}+\mathrm{CF}_{3} \\
& \longrightarrow\left[\mathrm{Cu}\left(\mathrm{CF}_{3}\right)_{2}\right]^{-}+\mathrm{CF}_{3} \mathrm{CF}_{3}
\end{aligned}
$$

The energy dependence of these two fragmentation channels suggested that the latter did not predominantly result from a secondary fragmentation of the former, but that it mainly originated from the direct expulsion of the homo-coupling product $\mathrm{CF}_{3} \mathrm{CF}_{3}$. Such reductive eliminations are wellknown for $\mathrm{Cu}(\mathrm{III})$ complexes. ${ }^{[86 a]}$ Minor amounts of $\left[\mathrm{Cu}\left(\mathrm{CF}_{3}\right) \mathrm{F}\right]^{-}$observed upon fragmentation of $\left[\mathrm{Cu}\left(\mathrm{CF}_{3}\right)_{4}\right]^{-}$presumably resulted from the consecutive decomposition of the primary fragment ion $\left[\mathrm{Cu}\left(\mathrm{CF}_{3}\right)_{2}\right]^{-}$. Positive-ion mode ESI MS did not detect any copper-containing species. However, the spectra showed adducts of sodium and potassium with 9-octadecenamide (oleamide, $\mathrm{C}_{17} \mathrm{H}_{33} \mathrm{CONH}_{2}$, see Figure 25). Oleamide is a slip agent, which was reported to leach from laboratory plasticware into solvents. ${ }^{[129]}$
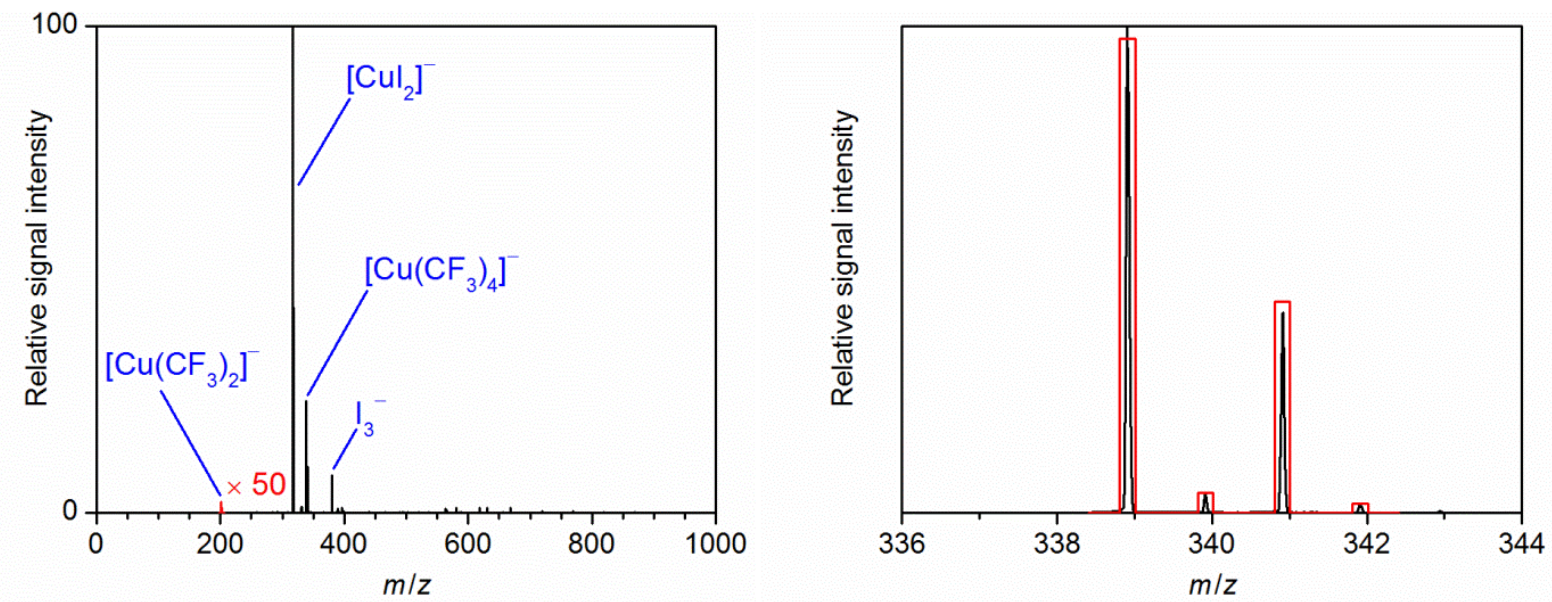

Figure 23. Left: Negative-ion mode ESI mass spectrum of a solution of the products formed in the reaction of Cul with $\mathrm{KF}$ and $\mathrm{Si}\left(\mathrm{CH}_{3}\right)_{3} \mathrm{CF}_{3}$ in THF. Signal intensities displayed in the mass range from $\mathrm{m} / \mathrm{z}$ 195-205 are enlarged by a factor of 50. Right: Measured (black) and simulated (red) isotopic pattern of $\left[\mathrm{Cu}\left(\mathrm{CF}_{3}\right)_{4}\right]^{-}$observed upon negative-ion mode ESI of a solution of $\mathrm{Cul}, \mathrm{KF}$, and $\mathrm{Si}\left(\mathrm{CH}_{3}\right)_{3} \mathrm{CF}_{3}$ in THF. 

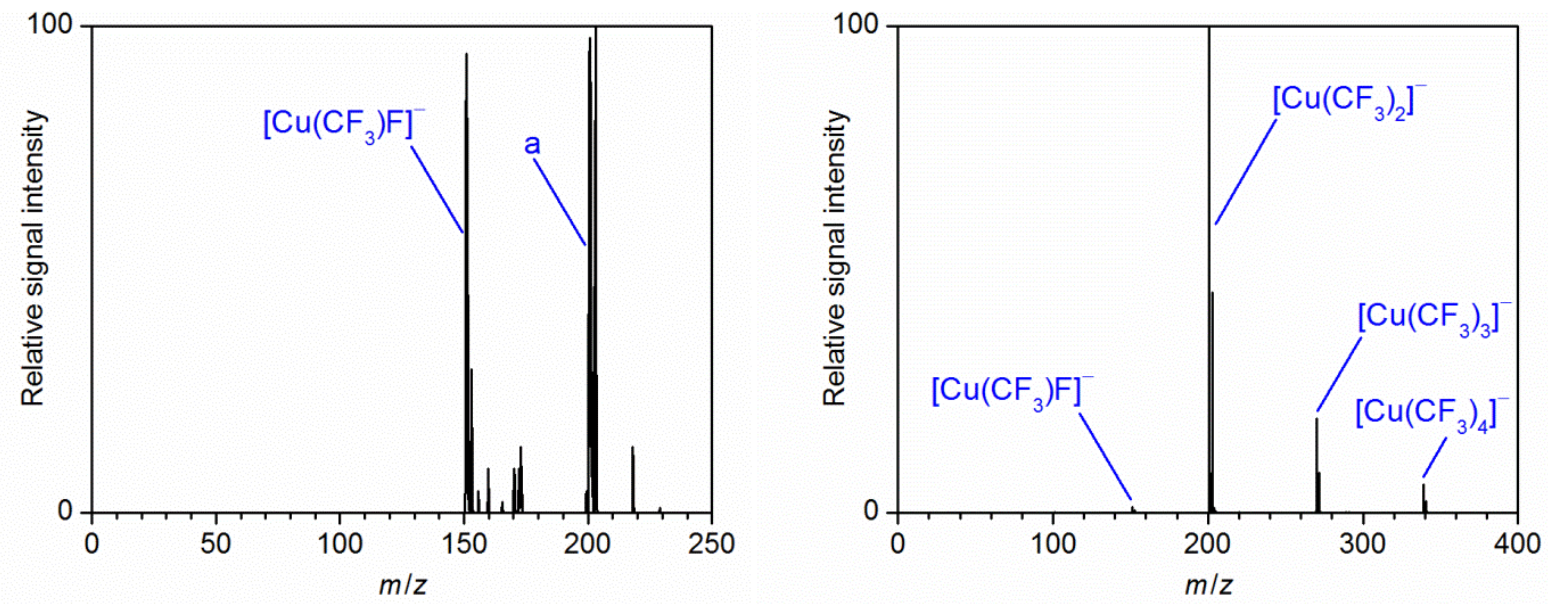

Figure 24. Left: Mass spectrum of mass-selected $\left[\mathrm{Cu}\left(\mathrm{CF}_{3}\right)_{2}\right]^{-}$and its fragment ions produced upon collision-induced dissociation $\left(V_{\mathrm{EXC}}=0.60 \mathrm{~V}\right.$, recorded with the quadrupole-ion trap instrument). $\left[\mathrm{Cu}\left(\mathrm{CF}_{3}\right)_{2}\right]^{-}$in turn was obtained by collision-induced dissociation of mass selected $\left[\mathrm{Cu}\left(\mathrm{CF}_{3}\right)_{4}\right]^{-}$ $\left(V_{\mathrm{EXC}}=0.40 \mathrm{~V}\right.$, spectrum not shown). $\mathrm{a}=\left[\mathrm{Cu}\left(\mathrm{CF}_{3}\right)_{2}\right]^{-}$. Right: Mass spectrum of mass-selected $\left[\mathrm{Cu}\left(\mathrm{CF}_{3}\right)_{4}\right]^{-}$and its fragment ions produced upon collision-induced dissociation at $E_{\mathrm{LAB}}=15 \mathrm{eV}$.

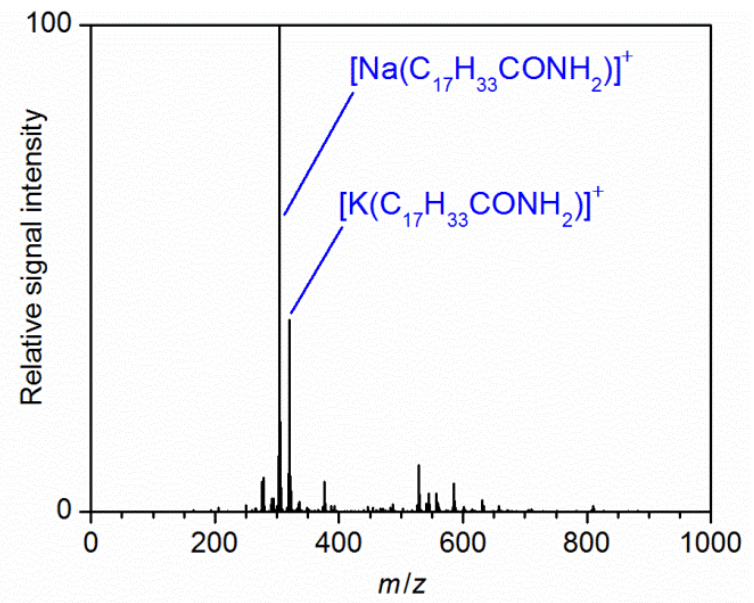

Figure 25. Positive-ion mode ESI mass spectrum of a solution of the products formed in the reaction of $\mathrm{Cul}, \mathrm{KF}$, and $\mathrm{Si}\left(\mathrm{CH}_{3}\right)_{3} \mathrm{CF}_{3}$ in THF.

\subsubsection{In-Situ Formed Heteroleptic Cuprate Complexes}

Trifluoromethyl-cuprate solutions treated with phenyl acetylene showed the already known ions $\left[\mathrm{Cu}\left(\mathrm{CF}_{3}\right)_{4}\right]^{-},\left[\mathrm{Cu}\left(\mathrm{CF}_{3}\right)_{2}\right]^{-}$, and $\left[\mathrm{CuI}_{2}\right]^{-}$as well as the heteroleptic cuprate $\left[\mathrm{Cu}\left(\mathrm{CF}_{3}\right)_{3} \mathrm{R}\right]^{-}(\mathrm{R}=\mathrm{CC}-\mathrm{Ph})$ upon negative-ion mode ESI (Figure 26, left). In contrast to $\left[\mathrm{Cu}\left(\mathrm{CF}_{3}\right)_{4}\right]^{-},\left[\mathrm{Cu}\left(\mathrm{CF}_{3}\right)_{3} \mathrm{R}\right]^{-}$did not lose a $\mathrm{CF}_{3}$ radical or the homo-coupling product $\mathrm{CF}_{3} \mathrm{CF}_{3}$ when subjected to fragmentation, but selectively released the cross-coupling product $\mathrm{R}-\mathrm{CF}_{3}$ in a reductive elimination (Eq. 20, Figure 26, right). As an additional fragment ion, $\left[\mathrm{Cu}\left(\mathrm{CF}_{3}\right) \mathrm{F}\right]^{-}$was observed, which presumably originated from the consecutive decomposition of $\left[\mathrm{Cu}\left(\mathrm{CF}_{3}\right)_{2}\right]^{-}$(Eq. 18).

$$
\left[\mathrm{Cu}\left(\mathrm{CF}_{3}\right)_{3} \mathrm{R}\right]^{-} \longrightarrow\left[\mathrm{Cu}\left(\mathrm{CF}_{3}\right)_{2}\right]^{-}+\mathrm{R}-\mathrm{CF}_{3}
$$



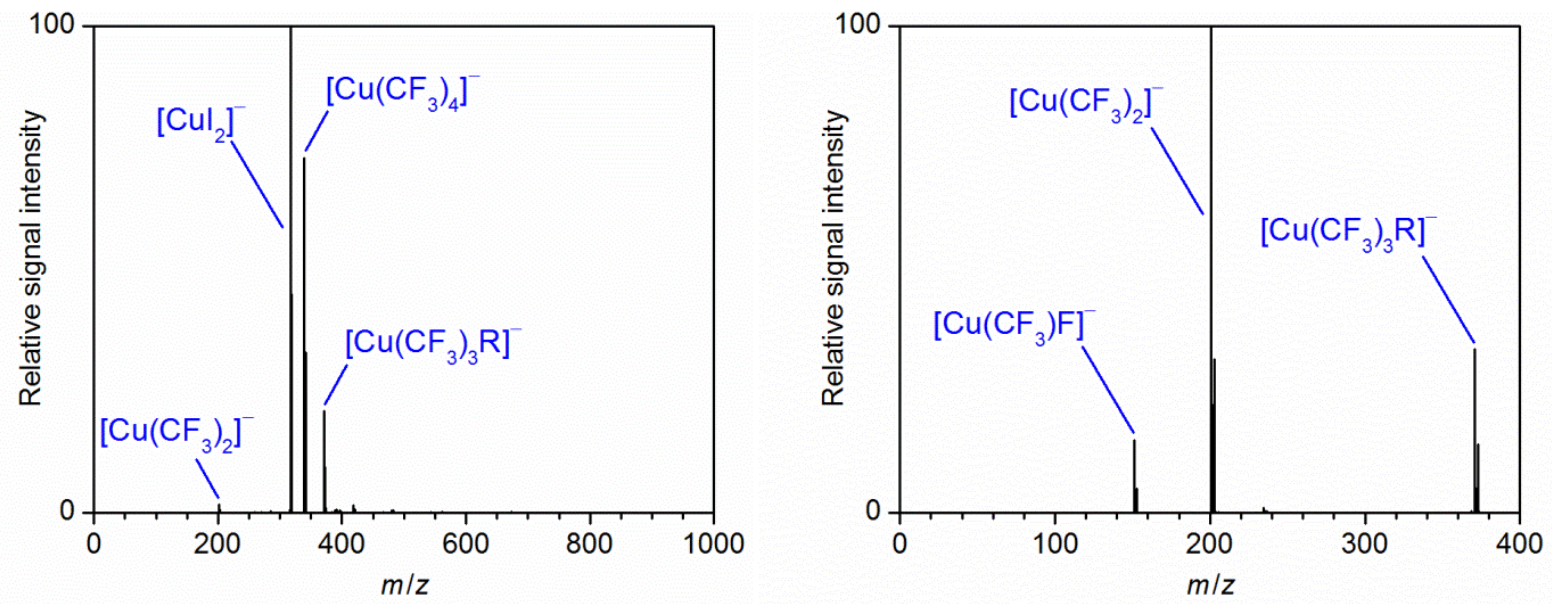

Figure 26. Left: Negative-ion mode ESI mass spectrum of a solution of the products formed in the reaction of Cul with $\mathrm{KF}, \mathrm{Si}\left(\mathrm{CH}_{3}\right)_{3} \mathrm{CF}_{3}$, and phenyl acetylene in THF (R = CC-Ph). Right: Mass spectrum of mass-selected $\left[\mathrm{Cu}\left(\mathrm{CF}_{3}\right)_{3} \mathrm{R}\right]^{-}(\mathrm{R}=\mathrm{CC}-\mathrm{Ph})$ and its fragment ions produced upon collision-induced dissociation at $E_{\mathrm{LAB}}=5 \mathrm{eV}$.

Analogous experiments were performed with several other aromatic alkynes (Scheme 9). Except for the case of ethynyl pyridine, which did not react, all of them showed heteroleptic cuprate complexes of the general formula $\left[\mathrm{Cu}_{(}\left(\mathrm{CF}_{3}\right)_{3} \mathrm{R}\right]^{-}(\mathrm{R}=$ aromatic alkynyl) in the obtained negative-ion mode ESI mass spectra as well as $\left[\mathrm{Cu}\left(\mathrm{CF}_{3}\right)_{4}\right]^{-},\left[\mathrm{Cu}\left(\mathrm{CF}_{3}\right)_{2}\right]^{-}$, and $\left[\mathrm{CuI}_{2}\right]^{-}$. In another experiment, both phenyl acetylene and (4-methoxy)phenyl acetylene were added to a trifluoromethyl-cuprate solution. As expected, heteroleptic cuprates $\left[\mathrm{Cu}\left(\mathrm{CF}_{3}\right)_{3} \mathrm{R}\right]^{-}$of both of the acetylenes could be observed, but no trifluoromethyl cuprate $\left.\left[\mathrm{Cu}\left(\mathrm{CF}_{3}\right)_{2} \mathrm{RR}^{\prime}\right)\right]^{-}\left(\mathrm{R}=\mathrm{CC}-\mathrm{C}_{6} \mathrm{H}_{5}, \mathrm{R}^{\prime}=\mathrm{CC}-\mathrm{C}_{6} \mathrm{H}_{4}-\mathrm{OCH}_{3}\right)$ bearing two different alkynyl substituents.<smiles>C#Cc1ccccc1</smiles><smiles>C#Cc1ccc(OC)cc1</smiles><smiles>C#Cc1ccc(Cl)cc1</smiles><smiles>C#Cc1ccc(C(=O)OC)cc1</smiles><smiles>C#Cc1ccc(-c2ccccc2)cc1</smiles><smiles>C#Cc1ccccn1</smiles>

Scheme 9. Aromatic alkynes used.

Upon fragmentation, the heteroleptic cuprates $\left[\mathrm{Cu}\left(\mathrm{CF}_{3}\right)_{3} \mathrm{R}\right]^{-}$produced $\left[\mathrm{Cu}\left(\mathrm{CF}_{3}\right)_{2}\right]^{-}$(Eq. 20), along with $\left[\mathrm{Cu}\left(\mathrm{CF}_{3}\right) \mathrm{F}\right]^{-}$. Thus, again only cross-coupling, but no homo-coupling was observed. The large preference for the former reaction channel can be attributed to the different electronic properties of the trifluoromethyl group on the one hand and the alkynyl substituents on the other. The strongly electron-withdrawing character of the former ${ }^{[130]}$ can better help to stabilize the negative charge of the $\mathrm{Cu}(\mathrm{l})$ fragment ion generated in the reductive elimination than the less electron-withdrawing alkynyl substituents. Therefore, the formation of $\left[\mathrm{Cu}\left(\mathrm{CF}_{3}\right)_{2}\right]^{-}$, together with the cross-coupling product, is favored on energetic grounds. A similar behavior had previously been observed for tetraalkyl cuprates $\left[\mathrm{Cu}\left(\mathrm{CH}_{3}\right)_{3} \mathrm{R}^{\prime \prime}\right]^{-}\left(\mathrm{R}^{\prime \prime}=\right.$ alkyl). ${ }^{\left[{ }^{[6 a]}\right.}$ Positive-ion mode ESI mass spectra again did not show any copper-containing ions.

\subsubsection{Cuprates Formed in the Presence of 1,10-Phenanthroline}

Trifluoromethyl cuprates binding 1,10-phenanthroline (phen) as a ligand have been proposed as key intermediates in the oxidative trifluoromethylation of alkynes (Scheme 6$).{ }^{[9 b, 26 a, 31 a]}$ To test this 
hypothesis, solutions of Cul, KF, 1,10-phenanthroline, and $\mathrm{Si}\left(\mathrm{CH}_{3}\right)_{3} \mathrm{CF}_{3}$ in THF were prepared. Negative-ion mode ESI mass spectra of these solutions showed $\left[\mathrm{Cu}\left(\mathrm{CF}_{3}\right)_{4}\right]^{-}$and $\left[\mathrm{Cu}\left(\mathrm{CF}_{3}\right)_{2}\right]^{-}$, but no $\left[\mathrm{CuI}_{2}\right]^{-}$and no phenanthroline-containing anions (Figure 27, left). Furthermore, trifluoromethyl cuprates prepared in the presence of 1,10-phenanthroline were allowed to react with phenyl acetylene. In this case, negative-ion mode ESI mass spectra exhibited $\left[\mathrm{Cu}\left(\mathrm{CF}_{3}\right)_{4}\right]^{-}$as well as $\left[\mathrm{Cu}\left(\mathrm{CF}_{3}\right)_{3} \mathrm{R}\right]^{-}(\mathrm{R}=\mathrm{CC}-\mathrm{Ph})$, but again neither $\left[\mathrm{CuI}_{2}\right]^{-}$nor phenanthroline-containing cuprates were found (Figure 27, right). As the present results clearly prove, ESI MS is well capable of detecting alkynylcontaining cuprate anions. Thus, the absence of the species postulated by Chu and Qing in the recorded mass spectra provides strong evidence against their formation and involvement in the trifluoromethylation of alkynes (unless the phenanthroline is bound to the copper center only very weakly). Presumably, the coordination of Lewis bases to copper(I) or (III) ate complexes is intrinsically rather unfavorable because it would disturb their preferred linear or tetragonal geometries.

To test for the possible presence of uncharged phenanthroline-containing copper complexes, control experiments with 4,7-dihydroxy-1,10-phenanthroline (HO-phen) were performed. Under the reaction conditions, this ligand should be easily deprotonated, thus possibly giving rise to complexes of the type [(O-phen) $\left.\mathrm{CuCF}_{3}\right]^{-}$, which would be amenable to ESI-mass spectrometric detection. However, ESImass spectra of solutions of Cul, $\mathrm{KF}$, 4,7-dihydroxy-1,10-phenanthroline, and $\mathrm{Si}\left(\mathrm{CH}_{3}\right)_{3} \mathrm{CF}_{3}$ in THF did not find this complex or related species, but only the anions already known. This negative result may at least partly reflect the poor solubility of 4,7-dihydroxy-1,10-phenanthroline in THF. Notwithstanding this complication, the absence of $\left[(\mathrm{O}-\text { phen }) \mathrm{CuCF}_{3}\right]^{-}$is also in accordance with a previous study, which found $\left[(\right.$ phen $\left.) \mathrm{Cu}\left(\mathrm{CF}_{3}\right)\right]$ to be unstable in solution and to undergo a spontaneous ionic disproportionation to afford $\left[\mathrm{Cu}(\text { phen })_{2}\right]\left[\mathrm{Cu}_{(}\left(\mathrm{CF}_{3}\right)_{2}\right]{ }^{[28 \mathrm{~h}]}$
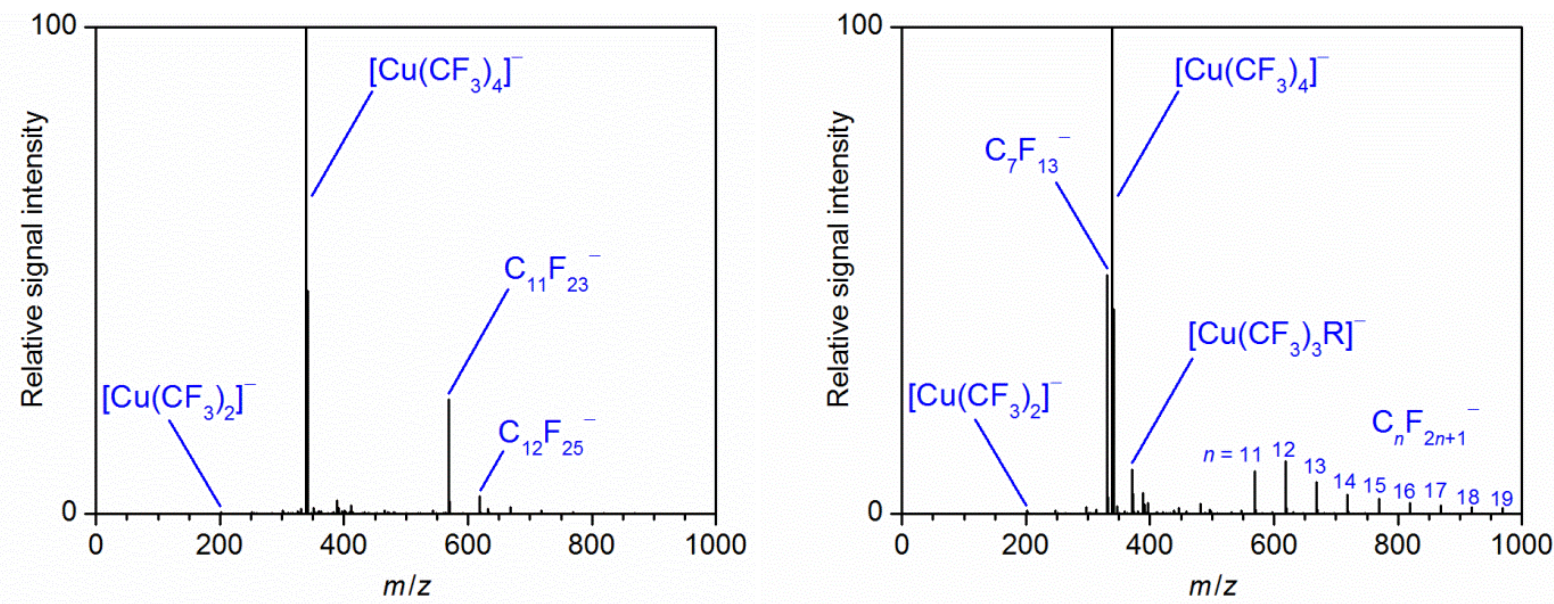

Figure 27. Left: Negative-ion mode ESI mass spectrum of a solution of the products formed in the reaction of $\mathrm{Cul}$ with $\mathrm{KF}, 1,10$-phenanthroline, and $\mathrm{Si}\left(\mathrm{CH}_{3}\right)_{3} \mathrm{CF}_{3}$ in THF. Right: Negative-ion mode ESI mass spectrum of a solution of the products formed in the reaction of Cul with $\mathrm{KF}$, 1,10-phenanthroline, $\mathrm{Si}\left(\mathrm{CH}_{3}\right)_{3} \mathrm{CF}_{3}$, and phenyl acetylene $(\mathrm{R}=$ phenylethynyl) in THF.

The positive-ion mode ESI mass spectra found $\left[\mathrm{Cu}(\text { phen })_{2}\right]^{+}$as well as phenanthroline complexes of $\mathrm{Na}^{+}$and $\mathrm{K}^{+}$, the origin of the sodium ions probably being the used glassware (Figure 28). Possibly, the beneficial effect of the phenanthroline mainly lies in its ability to help dissolve the otherwise not completely soluble Cul, thus making it available for its participation in the trifluoromethylation reaction. 

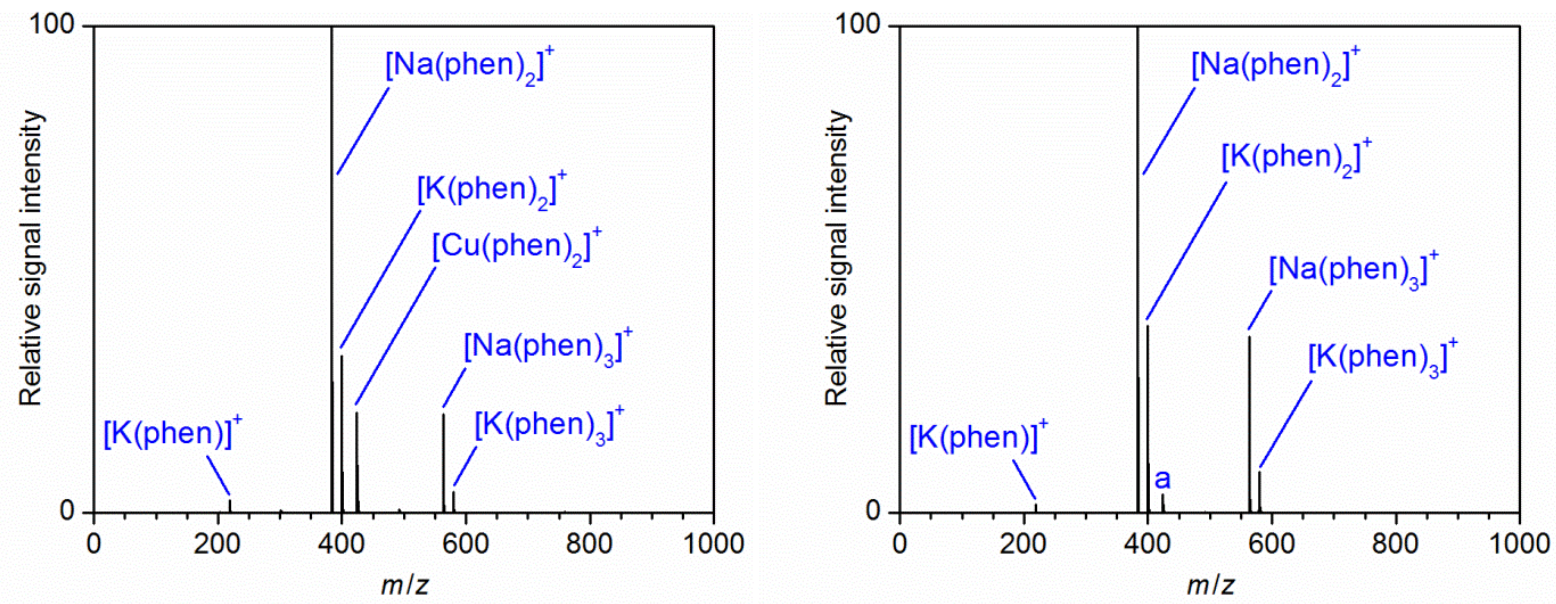

Figure 28. Left: Positive-ion mode ESI mass spectrum of a solution of the products formed in the reaction of Cul with KF, 1,10-phenanthroline (phen), and $\mathrm{Si}\left(\mathrm{CH}_{3}\right)_{3} \mathrm{CF}_{3}$ in THF. Right: . Positive-ion mode ESI mass spectrum of a solution of the products formed in the reaction of Cul with $\mathrm{KF}$, 1,10-phenanthroline (phen), $\mathrm{Si}\left(\mathrm{CH}_{3}\right)_{3} \mathrm{CF}_{3}$, and phenyl acetylene in THF. $\mathrm{a}=\left[\mathrm{Cu}(\text { phen })_{2}\right]^{+}$.

Furthermore, negative-ion mode ESI mass spectra of phenanthroline-containing cuprate solutions featured perfluorinated carbanions (Figure 27). $\mathrm{Si}\left(\mathrm{CH}_{3}\right)_{3} \mathrm{CF}_{3}$ is known to react to the perfluorinated branched carbanion 1 in the presence of fluoride ions (Scheme 10). ${ }^{[131]}$ As has been demonstrated by ${ }^{19} \mathrm{~F}$-NMR spectroscopy, $\mathbf{1}$ further decomposes into a another carbanion $\mathbf{2}$, a fluorine atom, and the organic radical $3{ }^{[131]}$ The present experiments detected ions with sum formulas consistent with those of $\mathbf{1}$ and $\mathbf{2}$ as well as several further perfluorinated carbanions (Figure 27). This observation implies that $\mathrm{Si}\left(\mathrm{CH}_{3}\right)_{3} \mathrm{CF}_{3}$ does undergo partial degradation under the applied reaction conditions.<smiles>FC(=C(C(F)(F)F)C(F)(F)F)C(C(F)(F)F)(C(F)(F)F)C(F)(F)C(F)(F)C(F)(F)F</smiles>

1<smiles>C[CH-]F</smiles>

2<smiles>FC(=C(C(F)(F)F)C(F)(F)F)C(F)(F)C(F)(F)F</smiles><smiles>FC(F)(F)C(F)(F)C(F)(F)C(F)(F)F</smiles>

3

Scheme 10. In the presence of $\mathrm{F}^{-}, \mathrm{Si}\left(\mathrm{CH}_{3}\right)_{3} \mathrm{CF}_{3}$ reacts to the perfluorinated carbanion 1, which subsequently decomposes into $\mathbf{2}$, a fluorine atom, and $\mathbf{3}$, as reported by Tyrra et. al. ${ }^{[131]}$

\subsubsection{Solvent Effects}

Additional experiments sampled solutions of $\mathrm{Cul}, \mathrm{KF}$ and $\mathrm{Si}\left(\mathrm{CH}_{3}\right)_{3} \mathrm{CF}_{3}$ in dichloromethane and acetonitrile, respectively. ${ }^{[132]}$ Negative-ion mode ESI mass spectra of these solutions showed $\left[\mathrm{Cu}\left(\mathrm{CF}_{3}\right)_{4}\right]^{-},\left[\mathrm{Cu}\left(\mathrm{CF}_{3}\right)_{2}\right]^{-}$, and $\left[\mathrm{Cu}_{n} I_{n+1}\right]^{-}(n=1,3,4)$, much alike those of the corresponding solutions in THF. The solutions in $\mathrm{CH}_{2} \mathrm{Cl}_{2}$ afforded lower signal intensities, however, whereas those in $\mathrm{CH}_{3} \mathrm{CN}$ gave also rise to additional mono-, di- and trinuclear copper complexes incorporating deprotonated acetonitrile moieties or cyanide (Figure 29). 


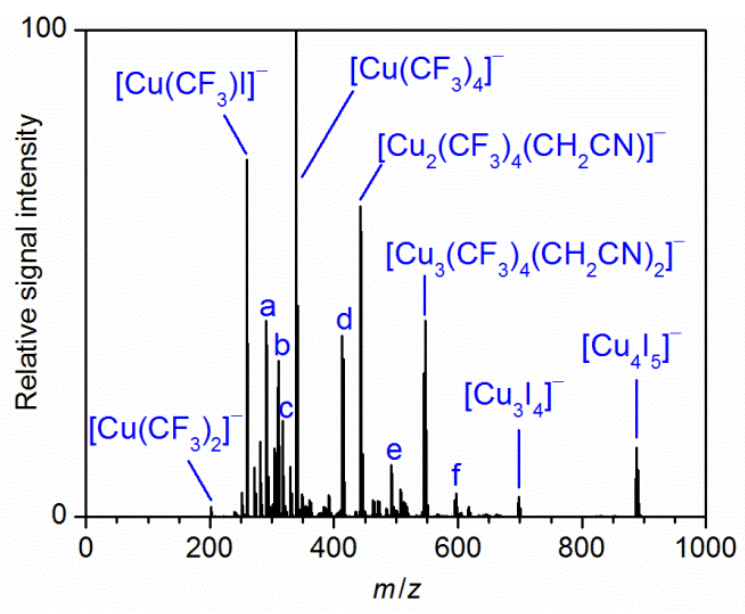

Figure 29. Negative-ion mode $\mathrm{ESI}$ mass spectrum of a solution of the products formed in the reaction of $\mathrm{Cul}$ with $\mathrm{KF}$ and $\mathrm{Si}\left(\mathrm{CH}_{3}\right)_{3} \mathrm{CF}_{3}$ in $\mathrm{CH}_{3} \mathrm{CN}$. a: $\left[\mathrm{Cu}_{2}\left(\mathrm{CF}_{3}\right)_{2}(\mathrm{CN})\right]^{-}$, b: $\left[\mathrm{Cu}\left(\mathrm{CF}_{3}\right)_{3}\left(\mathrm{CH}_{2} \mathrm{CN}\right)\right]^{-}$, c: $\left[\mathrm{Cul}_{2}\right]^{-}$, d: $\left[\mathrm{Cu}_{2}\left(\mathrm{CF}_{3}\right)_{3}\left(\mathrm{CH}_{2} \mathrm{CN}\right)_{2}\right]^{-}$, e: $\left[\mathrm{Cu}_{2}\left(\mathrm{CF}_{3}\right)_{4}\left(\mathrm{CF}_{2}\right)\left(\mathrm{CH}_{2} \mathrm{CN}\right)\right]^{-}$, f: $\left[\mathrm{Cu}_{3}\left(\mathrm{CF}_{3}\right)_{4}\left(\mathrm{CF}_{2}\right)\left(\mathrm{CH}_{2} \mathrm{CN}\right)_{2}\right]^{-}$.

Presumably, the bidentate nature of deprotonated acetonitrile is essential for stabilizing these polynuclear aggregates. The apparent deprotonation of the solvent under typical reaction conditions is not surprising given that acetonitrile and phenyl acetylene have similar acidities. ${ }^{[133]}$ The deprotonation of $\mathrm{CH}_{3} \mathrm{CN}$ by $\mathrm{F}^{-}$or $\mathrm{CF}_{3}{ }^{-}$, respectively, has actually been demonstrated. ${ }^{[12 a, 134]}$ Most likely, the observed deprotonation of the solvent will interfere with the intended trifluoromethylation of alkynes and, thus, may account for the rather poor yields reported for this transformation in $\mathrm{CH}_{3} \mathrm{CN} .{ }^{[9 \mathrm{~b}]}$ Treatment of solutions of trifluoromethyl cuprates in $\mathrm{CH}_{3} \mathrm{CN}$ with phenyl acetylene led to the detection of small amounts of the heteroleptic cuprate $\left[\mathrm{Cu}\left(\mathrm{CF}_{3}\right)_{3} \mathrm{R}\right]^{-}(\mathrm{R}=\mathrm{CC}-\mathrm{Ph})$

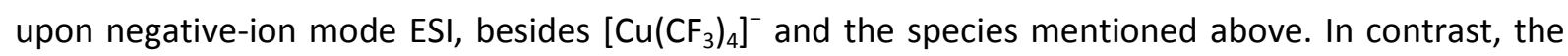
analogous experiments with 4-chlorophenyl acetylene or (4-methoxy)phenyl acetylene, respectively, did not find the corresponding heteroleptic cuprate complexes.

\subsubsection{Genesis of Heteroleptic Cuprates}

The formation of the heteroleptic cuprates $\left[\mathrm{Cu}\left(\mathrm{CF}_{3}\right)_{3} \mathrm{R}\right]^{-}$constitutes a crucial step in the trifluoromethylation reaction. As no heteroleptic copper $(\mathrm{I})$ ate complexes $\left[\mathrm{Cu}\left(\mathrm{CF}_{3}\right) \mathrm{R}\right]^{-}$were detected upon negative-ion mode ESI of solutions of trifluoromethyl cuprates treated with aromatic acetylenes, it seems less likely that anionic copper(I) species act as precursors of the observed heteroleptic copper(III) ate complexes $\left[\mathrm{Cu}_{(}\left(\mathrm{CF}_{3}\right)_{3} \mathrm{R}\right]^{-}$. This finding is consistent with the results of the Vicic group, who studied trifluoromethylation reactions mediated by an $(\mathrm{NHC}) \mathrm{Cu}_{-} \mathrm{CF}_{3}$ complex $\left(\mathrm{NHC}=\mathrm{N}\right.$-heterocyclic carbene).${ }^{\left[\mathrm{ga}^{3}\right]}$ This complex turned out to be in an equilibrium with the cuprate(I) salt $\left[(\mathrm{NHC})_{2} \mathrm{Cu}\right]\left[\mathrm{Cu}\left(\mathrm{CF}_{3}\right)_{2}\right]$, with the $\left[\mathrm{Cu}\left(\mathrm{CF}_{3}\right)_{2}\right]^{-}$anion appearing to be no reactive intermediate in the examined trifluoromethylations.

An alternative way of formation of $\left[\mathrm{Cu}\left(\mathrm{CF}_{3}\right)_{3} \mathrm{R}\right]^{-}$might be the substitution of one $\mathrm{CF}_{3}{ }^{-}$moiety in $\left[\mathrm{Cu}\left(\mathrm{CF}_{3}\right)_{4}\right]^{-}$by an acetylide $\mathrm{R}^{-}$(Eq. 21).

$$
\left[\mathrm{Cu}\left(\mathrm{CF}_{3}\right)_{4}\right]^{-}+\mathrm{R}^{-} \longrightarrow\left[\mathrm{Cu}\left(\mathrm{CF}_{3}\right)_{3} \mathrm{R}\right]^{-}+\mathrm{CF}_{3}^{-}
$$

To test for this possibility, it was necessary to reduce the complexity of the system under investigation and to probe solutions containing solely $\left[\mathrm{Cu}\left(\mathrm{CF}_{3}\right)_{4}\right]^{-}$as copper component. Therefore, the pre-formed $\left[\mathrm{NBu}_{4}\right]\left[\mathrm{Cu}\left(\mathrm{CF}_{3}\right)_{4}\right]$ complex ${ }^{[9 c]}$ was dissolved in THF and phenyl acetylene was added. 
Analysis by negative-ion mode ESI MS showed the absence of any heteroleptic cuprates (Figure 30 ). The addition of either $\mathrm{KF}$ or both $\mathrm{KF}$ and $\mathrm{Si}\left(\mathrm{CH}_{3}\right)_{3} \mathrm{CF}_{3}$ did not change this negative result.

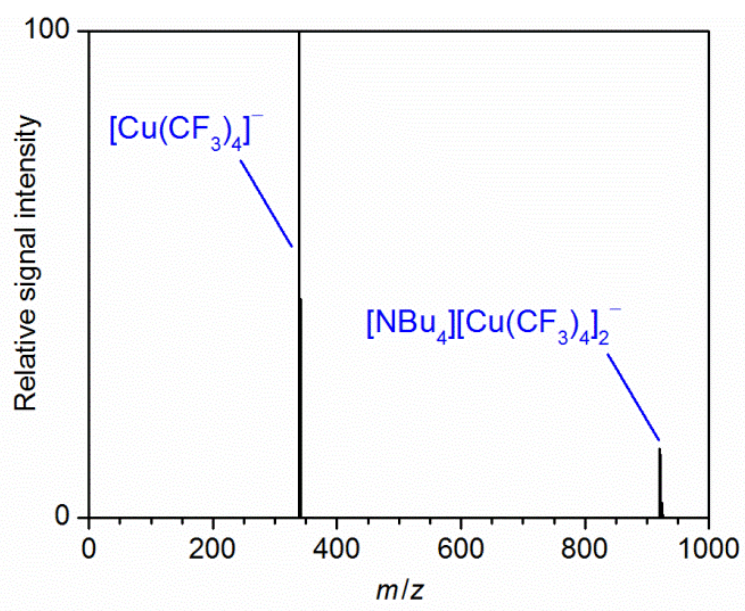

Figure 30. Negative-ion mode ESI mass spectrum of a solution of pre-formed $\left[\mathrm{NBu}_{4}\right]\left[\mathrm{Cu}\left(\mathrm{CF}_{3}\right)_{4}\right]$ and phenyl acetylene in THF.

In a series of additional experiments, the absolute negative-ion mode ESI signal intensities of $\left[\mathrm{Cu}\left(\mathrm{CF}_{3}\right)_{4}\right]^{-}$and $\left[\mathrm{Cu}\left(\mathrm{CF}_{3}\right)_{3} \mathrm{R}\right]^{-}$of solutions of trifluoromethyl-cuprate solutions were recorded over a period of $100 \mathrm{~min}$ after the addition of phenyl acetylene, (4-methoxy)phenyl acetylene, or methyl 4-ethynylbenzoate, respectively. If an interconversion between the two cuprates took place, the signal intensity of $\left[\mathrm{Cu}\left(\mathrm{CF}_{3}\right)_{3} \mathrm{R}\right]^{-}$should increase at the expense of that of $\left[\mathrm{Cu}\left(\mathrm{CF}_{3}\right)_{4}\right]^{-}$. In no case, however, a clear trend could be discerned. These findings confirm that $\left[\mathrm{Cu}\left(\mathrm{CF}_{3}\right)_{4}\right]^{-}$does not represent the precursor of $\left[\mathrm{Cu}\left(\mathrm{CF}_{3}\right)_{3} \mathrm{R}\right]^{-}$; the inferred low reactivity of $\left[\mathrm{Cu}\left(\mathrm{CF}_{3}\right)_{4}\right]^{-}$is fully in line with recent reports by Nebra and Grushin. ${ }^{\left[{ }^{9 c]}\right.}$ Presumably, the heteroleptic cuprates $\left[\mathrm{Cu}\left(\mathrm{CF}_{3}\right)_{3} \mathrm{R}\right]^{-}$originate from uncharged copper species, such as $\mathrm{Cu}\left(\mathrm{CF}_{3}\right)_{3}$, which are not amenable to analysis by ESI MS.

\subsubsection{Oxidation of $\mathrm{Cu}(\mathrm{I})$ Complexes}

Although the performed experiments started from a copper(I) reactant, the obtained ESI mass spectra showed the presence of copper(III) ate complexes in significant abundance. Likewise, the detection of $\mathrm{I}_{3}{ }^{-}$pointed to the occurrence of oxidation reactions. Previous reports invoked oxygen as oxidizing agent in oxidative trifluoromethylations of terminal alkynes, ${ }^{[96,31]}$ as these reactions are commonly performed under air. Indeed, the exclusion of oxygen in the present experiments significantly decreased the amount of detected copper(III) species, thus corroborating the postulated role of oxygen as oxidizing agent (Figure 31). Note, however, that the radical products resulting from the inferred decomposition of $\mathrm{Si}\left(\mathrm{CH}_{3}\right)_{3} \mathrm{CF}_{3}$ (see Scheme 10) may also contribute to the oxidation of the copper(I) reactant. 


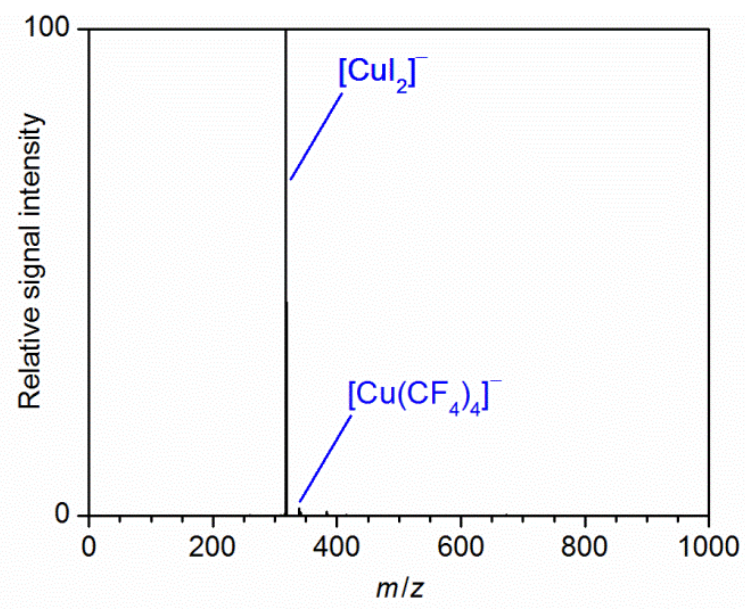

Figure 31. Negative-ion mode ESI mass spectrum of a solution of the products formed in the reaction of Cul, $\mathrm{KF}$, and $\mathrm{Si}\left(\mathrm{CH}_{3}\right)_{3} \mathrm{CF}_{3}$ in THF. For this control experiment under the exclusion of oxygen, the $\mathrm{Si}\left(\mathrm{CH}_{3}\right)_{3} \mathrm{CF}_{3}$ reagent was carefully degassed by passing a stream of argon gas through it and by subjecting it to repeated freeze-evacuate-thaw cycles. 
The following section ("4.4 Argentate(I) and (III) Complexes as Intermediates in SilverMediated Cross-Coupling Reactions") is based on the publication given below . Excerpts of this publication were taken, partly modified, and extended by further results.

The following figures were taken from this publication:

$$
32 \text { (left) and } 35
$$

The following figures were taken from the Supporting Information of this publication: 32 (right) and 37 (left and right)

Argentate(I) and (III) complexes as intermediates in silver-mediated cross-coupling reactions

Sebastian Weske, Richard A. Hardin, Thomas Auth,

Richard A. J. O'Hair, Konrad Koszinowski, Craig A. Ogle,

Chemical Communications 2018, 54, 5086-5089.

DOI: $10.1039 / \mathrm{c} 8 \mathrm{cc} 01707 \mathrm{~g}$

https://pubs.rsc.org/en/content/articlelanding/2018/cc/c8cc01707g\#!divAbstract

Reproduced with permission from the Royal Society of Chemistry. 


\subsection{Argentate(I) and (III) Complexes as Intermediates in Silver-Mediated Cross-Coupling Reactions}

\subsubsection{In-Situ Formed Organoargentate(III) Complexes}

Upon the addition of methyl or allyl iodide so solutions of $\mathrm{LiAgMe}_{2} \cdot \mathrm{Li}(\mathrm{CN})$ in THF (see chapter 4.2), the negative-ion mode ESI mass spectra showed mononuclear $\mathrm{Ag}(\mathrm{III})$ ate anions as well as the corresponding higher aggregates as new species (Figure 32). The reaction with methyl iodide afforded the lithium-bound dimer $\left[\mathrm{LiAg}_{2} \mathrm{Me}_{8}\right]^{-}$as base peak. The same ion as well as the related heteroleptic species $\left[\mathrm{LiRAg}_{2} \mathrm{Me}_{7}\right]^{-}$and $\left[\mathrm{LiR}_{2} \mathrm{Ag}_{2} \mathrm{Me}_{6}\right]^{-}$were observed for the reaction with allyl iodide.
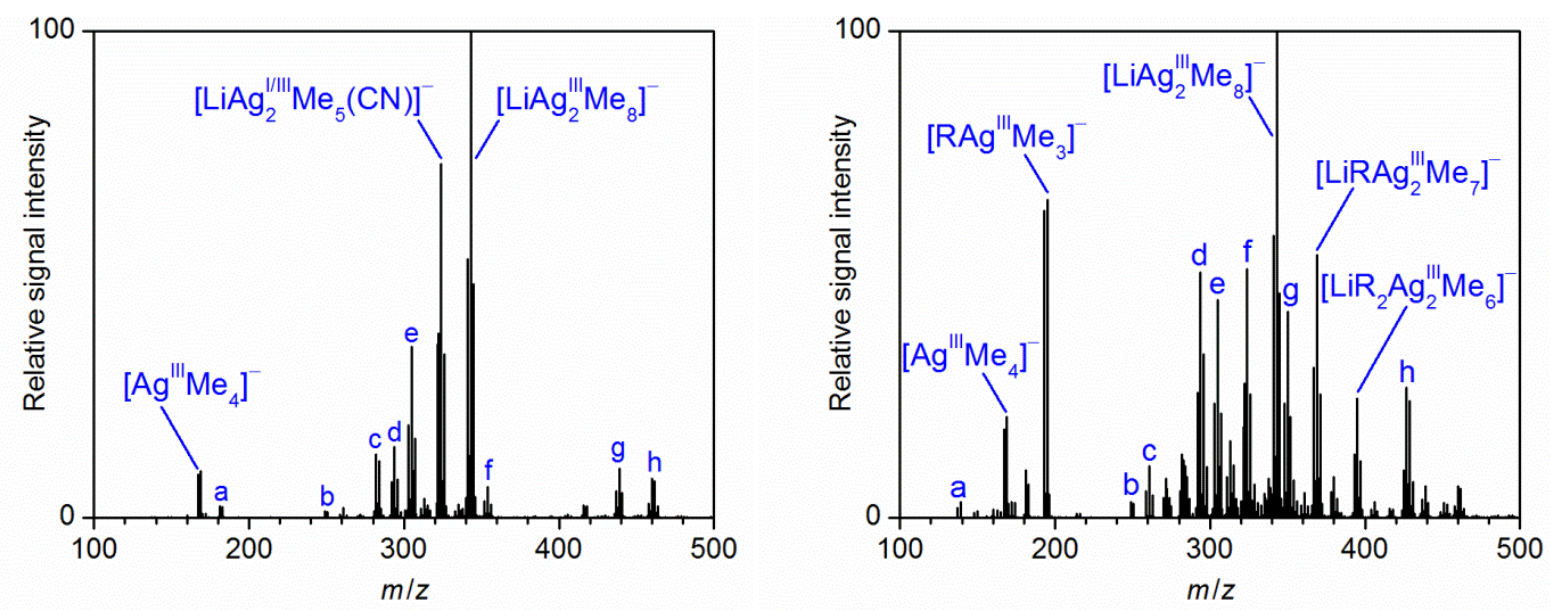

Figure 32. Left: Negative-ion mode ESI mass spectrum of the products formed upon reaction of $\mathrm{LiAgMe}_{2} \cdot \mathrm{Li}(\mathrm{CN})$ with methyl iodide (0.5 equiv.) in THF. a: $\left[\mathrm{LiAg}^{\prime} \mathrm{Me}(\mathrm{CN})_{2}\right]^{-}$, b: $\left[\mathrm{Ag}^{\prime} \mathrm{Me}(\mathrm{I})\right]^{-}$, c: $\left[\mathrm{LiAg}^{\prime} \mathrm{Me}(\mathrm{CN})(\mathrm{I})\right]^{-}, \quad \mathrm{d}: \quad\left[\mathrm{LiAg}_{2}^{\prime} \mathrm{Me}_{3}(\mathrm{CN})\right]^{-}$and $\left[\mathrm{LiAg}_{2}^{\prime} \mathrm{Me}_{2}(\mathrm{OH})(\mathrm{CN})\right]^{-}$, e: $\left[\operatorname{LiAg}_{2} \mathrm{Me}_{2}(\mathrm{CN})_{2}\right]^{-}$, f: [LiAg $\left.{ }_{2}{ }_{2} \mathrm{Me}_{7}(\mathrm{CN})\right]^{-}$, g: $\left[\mathrm{Li}_{2} \mathrm{Ag}_{2}^{\prime} \mathrm{Me}_{2}(\mathrm{CN})_{2}(\mathrm{I})\right]^{-}$, h: $\left[\mathrm{Li}_{2} \mathrm{Ag}_{3}^{\prime} \mathrm{Me}_{3}(\mathrm{CN})_{3}\right]^{-}$. Right: Negative-ion mode ESI mass spectrum of a solution of the products formed in the reaction of $\mathrm{Ag}(\mathrm{CN})$ with methyl lithium (2 equiv.) and allyl iodide (0.5 eq) in THF $\left(\mathrm{R}=\right.$ allyl). a: $\left[\mathrm{Ag}^{\prime} \mathrm{Me}_{2}\right]^{-}, \mathrm{b}:[\mathrm{Ag} \mathrm{Me}(\mathrm{I})]^{-}, \mathrm{c}:\left[\mathrm{Ag}_{2}^{\prime} \mathrm{Me}_{3}\right]^{-}, \mathrm{d}$ : $\left[\mathrm{LiAg}_{2} \mathrm{Me}_{3}(\mathrm{CN})\right]^{-}+\left[\mathrm{LiAg}_{2}^{1} \mathrm{Me} \mathrm{e}_{2}(\mathrm{OH})(\mathrm{CN})\right]^{-}$, e: $\left[\operatorname{LiAg}_{2}^{1} \mathrm{Me}_{2}(\mathrm{CN})_{2}\right]^{-}, \quad$ f: $\quad\left[\mathrm{LiAg}^{1 / 1 / 1}{ }_{2} \mathrm{Me}_{5}(\mathrm{CN})\right]^{-}, \quad \mathrm{g}:$ $\left[\operatorname{LiRAg}^{1 / 1 / 1}{ }_{2} \mathrm{Me}_{4}(\mathrm{CN})\right]^{-}, \mathrm{h}:\left[\mathrm{Li}_{2} \mathrm{Ag}_{3}^{\prime} \mathrm{Me}_{6}\right]^{-}(\mathrm{R}=$ allyl).

Similar spectra were obtained if butyl or phenyl iodide were used (Figure 33). In particular, $\left[\mathrm{RAgMe}_{3}\right]^{-}$ and $\left[\mathrm{LiRAg}_{2} \mathrm{Me}_{7}\right]^{-}\left(\mathrm{R}=\right.$ butyl, phenyl) could be detected as well, but $\left[\mathrm{AgMe}_{4}\right]^{-}$and $\left[\mathrm{LiR}_{2} \mathrm{Ag}_{2} \mathrm{Me}_{6}\right]^{-}$ $\left(\mathrm{R}=\right.$ butyl, phenyl) were missing in both cases, while $\left[\mathrm{LiAg}_{2} \mathrm{Me}_{8}\right]^{-}$was only present in spectra of sample solutions prepared with butyl iodide. The methyl-, allyl-, and butylargentates(III) resemble the respective $\mathrm{Cu}$ (III) species, which have been characterized by ESI mass spectrometry before. ${ }^{[86 a]}$ The formation of $\left[\mathrm{PhAgMe}_{3}\right]^{-}$and $\left[\mathrm{LiPhAg}_{2} \mathrm{Me}_{7}\right]^{-}$(Figure 34), however, is particularly noteworthy, as it shows, that the ability of the dimethylargentate ion to undergo oxidative addition reactions is not restricted to alkyl halides but includes aryl halides as well. Additionally, the presence of these phenylargentates(III) points to different reactivities of dimethylargentate and dimethylcuprate, as the corresponding phenylcuprates(III) have not been observed in a previous study. ${ }^{[86 a]}$

The mass spectrometric results alone cannot provide information about the geometry of the observed organoargentates(III). However, quantum chemical calculations predicted a square-planar geometry for $\left[\mathrm{AgMe}_{4}\right]^{-}$in the gas phase, ${ }^{[90]}$ which is in full accordance with the experimentally determined solid-state structures of several $\left[\mathrm{AgR}_{4}\right]^{-}$complexes ${ }^{[48,60,63,64]}$ as well as the higher homologue $\left[\mathrm{AuMe}_{4}\right]^{-{ }^{[57]}}$ (see chapter 1.3.1). Therefore, it is reasonable to assume that the 
heteroleptic species $\left[\mathrm{RAgMe}_{3}\right]^{-}(\mathrm{R}=$ butyl, allyl, phenyl) feature similar structures. According to further calculations, the higher aggregate $\left[\mathrm{LiAg}_{2} \mathrm{Me}_{8}\right]^{-}$consists of two $\left[\mathrm{AgMe}_{4}\right]^{-}$units that are bound together by a central lithium cation. ${ }^{[90]}$ Presumably, the related heteroleptic species [ $\left[\mathrm{LiRAg}_{2} \mathrm{Me}_{7}\right]^{-}$and $\left[\mathrm{LiR}_{2} \mathrm{Ag}_{2} \mathrm{Me}_{6}\right]^{-}$adopt comparable configurations.
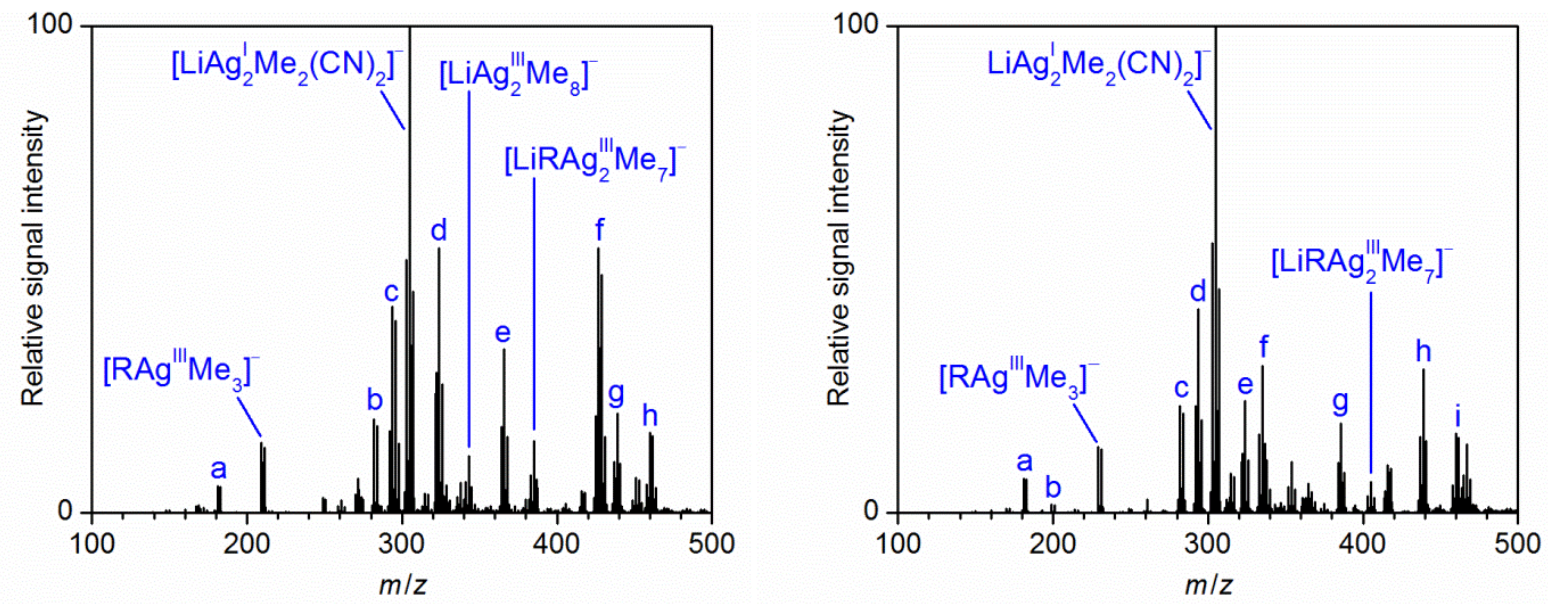

Figure 33. Left: Negative-ion mode ESI mass spectrum of the products formed upon reaction of $\mathrm{LiAgMe}_{2} \cdot \mathrm{Li}(\mathrm{CN})$ with butyl iodide (0.5 equiv.) in THF. a: $\left[\mathrm{LiAg}^{\prime} \mathrm{Me}(\mathrm{CN})_{2}\right]^{-}$, b) $\left[\mathrm{LiAg}^{\prime} \mathrm{Me}(\mathrm{CN})(\mathrm{I})\right]^{-}$, c) $\left[\mathrm{LiAg}_{2}^{\prime} \mathrm{Me}_{3}(\mathrm{CN})\right]^{-}$, d) $\left[\mathrm{LiAg}^{1 / 1 / 1}{ }_{2} \mathrm{Me}_{5}(\mathrm{CN})\right]^{-}$, e) $\left[\mathrm{LiRAg}^{1 / 1 / 1}{ }_{2} \mathrm{Me}_{5}\right]^{-}$, f) $\left[\mathrm{Li}_{2} \mathrm{Ag}_{3}^{\prime} \mathrm{Me}_{6}\right]^{-}$, g) $\left.\left[\mathrm{Li}_{2} \mathrm{Ag}_{2}^{\prime} \mathrm{Me}_{2}(\mathrm{CN})_{2}(\mathrm{I})\right]^{-}, \mathrm{h}\right)$ $\left[\mathrm{Li}_{2} \mathrm{Ag}_{3}{ }_{3} \mathrm{Me}_{3}(\mathrm{CN})_{3}\right]^{-}(\mathrm{R}=$ butyl). Right: Negative-ion mode ESI mass spectrum of the products formed upon reaction of $\mathrm{LiAgMe}_{2} \cdot \mathrm{Li}(\mathrm{CN})$ with phenyl iodide (0.5 equiv.) in THF. a) [ $\left.\mathrm{LiAg}^{\prime} \mathrm{Me}(\mathrm{CN})_{2}\right]^{-}$, b) $\left[\mathrm{RAg}^{\prime} \mathrm{Me}\right]^{-}$-, c) $\left[\mathrm{LiAg}^{\prime} \mathrm{Me}(\mathrm{CN})(\mathrm{I})\right]^{-}$, d) $\left[\mathrm{LiAg}_{2}^{\prime} \mathrm{Me}_{3}(\mathrm{CN})\right]^{-}$, e) $\left[\mathrm{LiAg}^{1 / 111}{ }_{2} \mathrm{Me}_{5}(\mathrm{CN})\right]^{-}$, f) $\left.\left[\mathrm{LiAg}^{1 / 111}{ }_{2} \mathrm{Me}_{4}(\mathrm{CN})_{2}\right]^{-}, \mathrm{g}\right)$ $\left.\left[\mathrm{LiRAg}^{\mathrm{I} / \mathrm{III}}{ }_{2} \mathrm{Me}_{4}(\mathrm{CN})\right]^{-}, \mathrm{h}\right)\left[\mathrm{Li}_{2} \mathrm{Ag}_{2}^{\prime} \mathrm{Me}_{2}(\mathrm{CN})_{2}(\mathrm{I})\right]^{-}$, i) $\left[\mathrm{Li}_{2} \mathrm{Ag}_{3}^{\prime} \mathrm{Me}_{3}(\mathrm{CN})_{3}\right]^{-}(\mathrm{R}=$ phenyl).
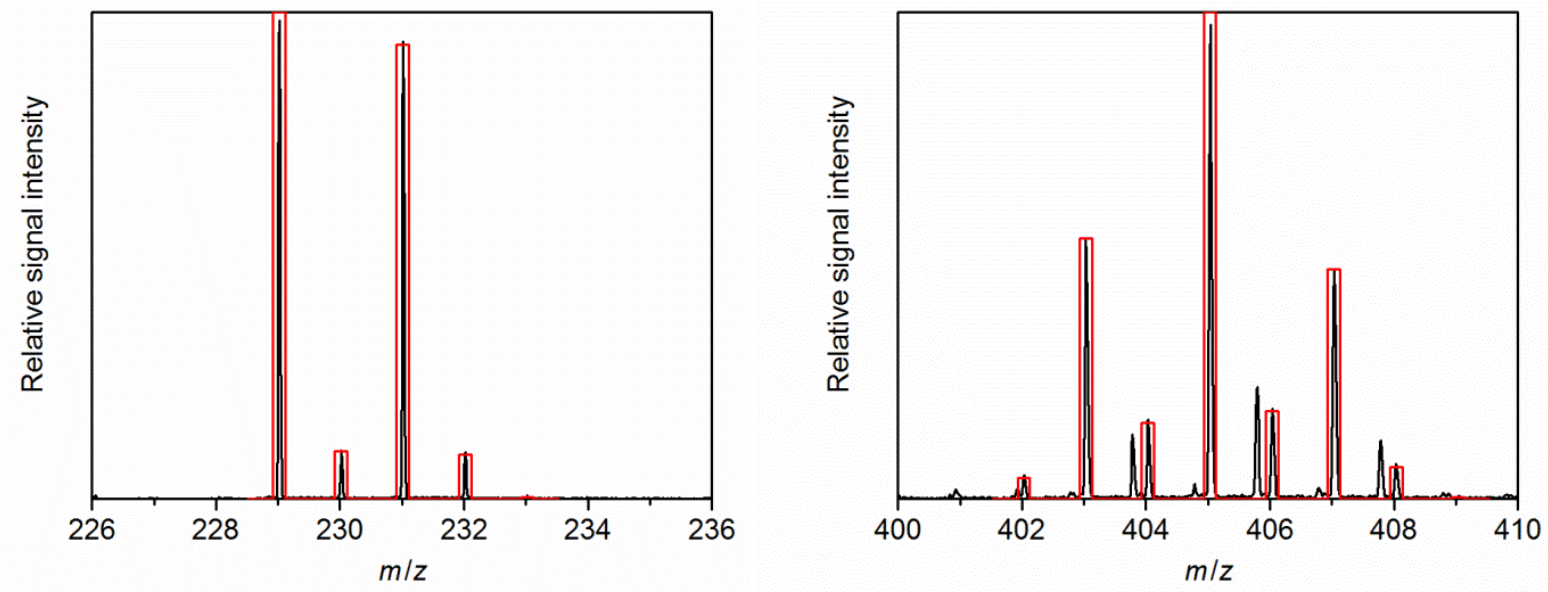

Figure 34. Left: Measured (black) and simulated (red) isotopic pattern of $\left[\mathrm{PhAg}^{\mathrm{II}} \mathrm{Me}_{3}\right]^{-}$. Right: Measured (black) and simulated (red) isotopic pattern of [ $\left.\mathrm{LiPhAg}_{2}{ }_{2} \mathrm{Me}_{7}\right]^{-}$.

In order to study the formation of argentate(III) complexes in solvents that are less polar than THF (relative permittivity $\varepsilon^{298 \mathrm{~K}}=7.42$ ), ${ }^{[135]}$ additional experiments were performed in cyclopentyl methyl ether $\left(\mathrm{CPME}, \varepsilon^{298 \mathrm{~K}}=4.76\right)^{[135]}$ and tert-butyl methyl ether (MTBE, $\left.\varepsilon^{298 \mathrm{~K}}=2.60\right),{ }^{[136]}$ respectively. ESI mass spectrometry of CPME and MTBE solutions of $\mathrm{LiAgMe}_{2} \cdot \mathrm{Li}(\mathrm{CN})$ that were treated with methyl iodide also showed argentate(III) complexes. The spectra from CPME solutions featured $\left[\mathrm{Ag}^{\prime \prime \prime} \mathrm{Me}_{4}\right]^{-}$ 
and $\left[\mathrm{Li}_{2} \mathrm{Ag}_{2}{ }_{2}{ }_{2} \mathrm{Me}_{8}\right]^{-}$in significant abundances (the latter species being even the main peak). However, only minor amounts of these species were detected in the spectra obtained from MTBE solutions. Instead, $\left[\mathrm{Li}_{2} \mathrm{Ag}_{3} \mathrm{Me}_{6}\right]^{-}$dominated the spectrum, and significant amounts of the hydroxide-containing ions $\left[\mathrm{Li}_{4} \mathrm{Ag}_{5}{ }_{5} \mathrm{Me}_{8}(\mathrm{OH})_{2}\right]^{-},\left[\mathrm{Li}_{4} \mathrm{Ag}_{5}^{\prime} \mathrm{Me}_{7}(\mathrm{OH})_{3}\right]^{-}$, and $\left[\mathrm{Li}_{5} \mathrm{Ag}_{6}{ }_{6} \mathrm{Me}_{8}(\mathrm{OH})_{4}\right]^{-}$were observed. The presence of organoargentates in spectra of both CPME and MTBE solutions clearly shows, that the formation of these organometallic species is also possible in solvents that are less polar than THF, although hydrolysis was apparently an issue in the case of MTBE.

\subsubsection{Gas-Phase Fragmentation Reactions of Organoargentate(III) Complexes}

The gas-phase fragmentation of the mass-selected homoleptic mononuclear complex $\left[\mathrm{AgMe}_{4}\right]^{-}$solely led to the reductive elimination of ethane (Eq. 22), which is in full agreement with results of quantum chemical calculations carried out by Thomas Auth in the Koszinowski group. ${ }^{\left[{ }^{[0]}\right.}$ According to these calculations, the exothermic release of ethane from $\left[\mathrm{AgMe}_{4}\right]^{-}$proceeds via a $C_{2}$-symmetric transition structure, which is predicted to be $166 \mathrm{~kJ} \mathrm{~mol}^{-1}$ higher in energy than the reactant, followed by an easy dissociation of the resulting ion-molecule complex into $\left[\mathrm{AgMe}_{2}\right]^{-}$and the coupling product. $\mathrm{A}$ natural population analysis (NPA) showed that the release of ethane is accompanied by a decrease of the charge of the silver center from 0.56 to 0.25 , consistent with a reduction from $\mathrm{Ag}(\mathrm{III})$ to $\mathrm{Ag}(\mathrm{I}){ }^{[90]}$

$$
\left[\mathrm{AgMe}_{4}\right]^{-} \longrightarrow\left[\mathrm{AgMe}_{2}\right]^{-}+\mathrm{Me}_{2}
$$

The heteroleptic complex [RAgMe $]^{-}(\mathrm{R}=$ allyl) also underwent reductive elimination (Figure 35) and preferentially released the cross-coupling product RMe (Eq. 23a), whereas the homo-coupling product $\mathrm{Me}_{2}$ (Eq. 23b) was formed only to a much smaller extent.

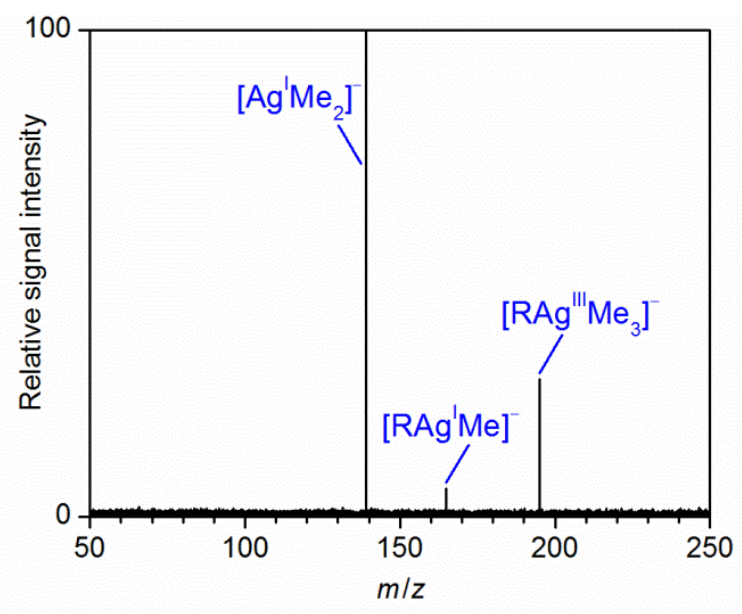

Figure 35. Mass spectrum of mass-selected $\left[\mathrm{RAg}^{\mathrm{III}} \mathrm{Me}_{3}\right]^{-}(\mathrm{R}=$ allyl) and its fragment ions produced upon collision-induced dissociation at $E_{\mathrm{LAB}}=7.5 \mathrm{eV}$.

$$
\begin{aligned}
{\left[\mathrm{RAgMe}_{3}\right]^{-} } & \longrightarrow\left[\mathrm{AgMe}_{2}\right]^{-}+\mathrm{RMe} \\
& \longrightarrow\left[\mathrm{RAgMe}^{-}+\mathrm{Me}_{2}\right.
\end{aligned}
$$

This result is consistent with solution-phase NMR experiments, ${ }^{[90]}$ but is in stark contrast with gasphase fragmentation of the related allylcuprate, $\left[\mathrm{RCuMe}_{3}\right]^{-}$, for which the dominant channel affords the homo-coupling product. ${ }^{[86 a]}$ The butylmetallates $\left[\mathrm{RAgMe}_{3}\right]^{-}$and $\left[\mathrm{RCuMe}_{3}\right]^{-}(\mathrm{R}=$ butyl) also exhibited significant differences in their gas-phase fragmentation behavior. Similar to the 
allylargentate, the butylargentate showed a high selectivity in favour of the cross-coupling product (Figure 36, left), while fragmentation of the butylcuprate led to the formation of both coupling products in approximately equal amounts. ${ }^{[86 a]}$ In $\mathrm{CID}$ experiments of [ $\left.\mathrm{PhAgMe}_{3}\right]^{-}$, cross-coupling was only slightly preferred over homo-coupling (Figure 36, right). In this case, however, the analogous $\mathrm{Cu}$ (III) species has not been observed at all (see above). ${ }^{[86 a]}$ Preliminary quantum chemical calculations on the competition between the reductive elimination elementary steps for isolated $\left[\mathrm{RAgMe}_{3}\right]^{-}$and $\left[\mathrm{RCuMe}_{3}\right]^{-}$anions $(\mathrm{R}=$ allyl) revealed that fundamentally different mechanisms operate. $^{[90,137]}$
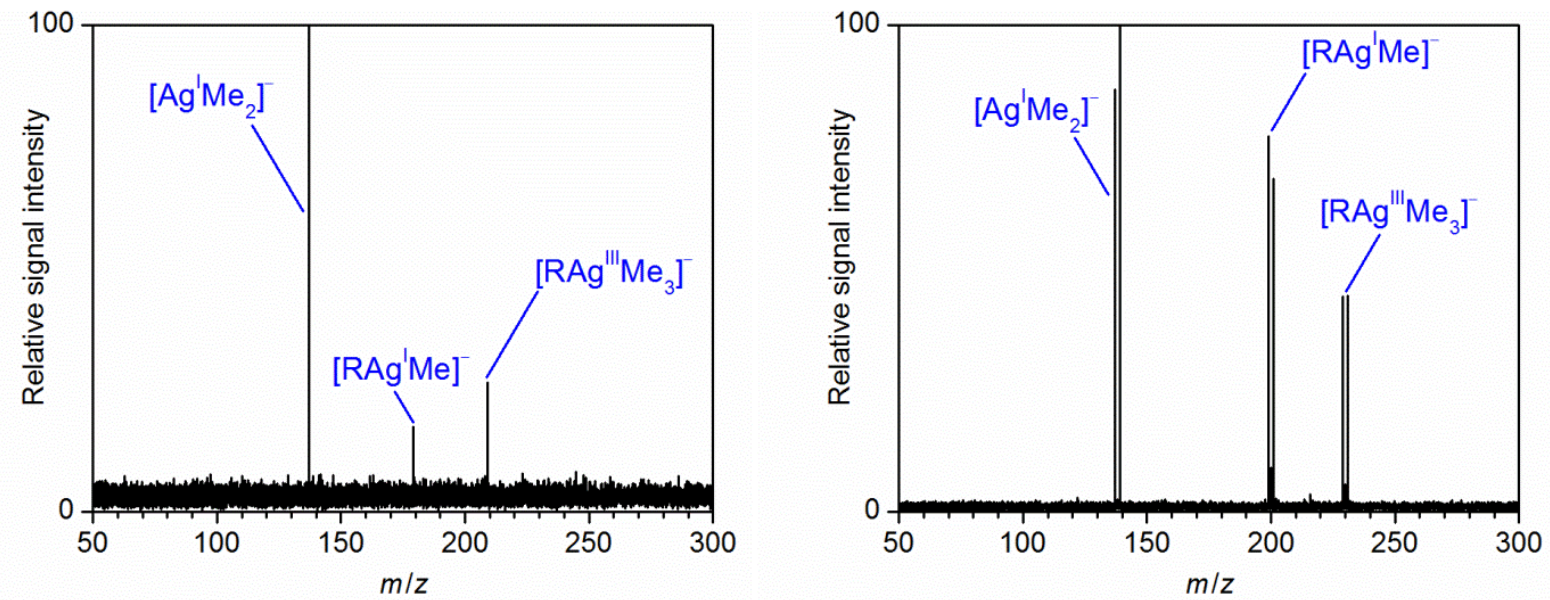

Figure 36. Left: Mass spectrum of mass-selected $\left[\mathrm{RAg}^{\prime \prime \prime} M \mathrm{e}_{3}\right]^{-}(\mathrm{R}=$ butyl) and its fragment ions produced upon collision-induced dissociation at $E_{\mathrm{LAB}}=10.0 \mathrm{eV}$. Right: Mass spectrum of massselected $\left[\mathrm{RAg}^{\mathrm{III}} \mathrm{Me}_{3}\right]^{-}(\mathrm{R}=$ phenyl) and its fragment ions produced upon collision-induced dissociation at $E_{\mathrm{LAB}}=7.5 \mathrm{eV}$.

Fragmentation of the lithium-bound dimers [ $\left.\mathrm{LiRAg}_{2} \mathrm{Me}_{7}\right]^{-}(\mathrm{R}=$ methyl, allyl) resulted in formation of the mononuclear complexes (Eqs. 24a and 24b) and reductive eliminations (Eqs. 25a and 25b). For the heteroleptic complexes, cross-coupling (Eq. 25a) again strongly prevailed over homo-coupling (Eq. 25b, Fig. 37). Secondary fragmentation reactions were also observed (Eqs. 26 and 27). Due to the low signal intensities of [LiRAg $\left.\mathrm{Me}_{7}\right]^{-}(\mathrm{R}=$ butyl, phenyl), fragmentation experiments of these ions were not feasible.

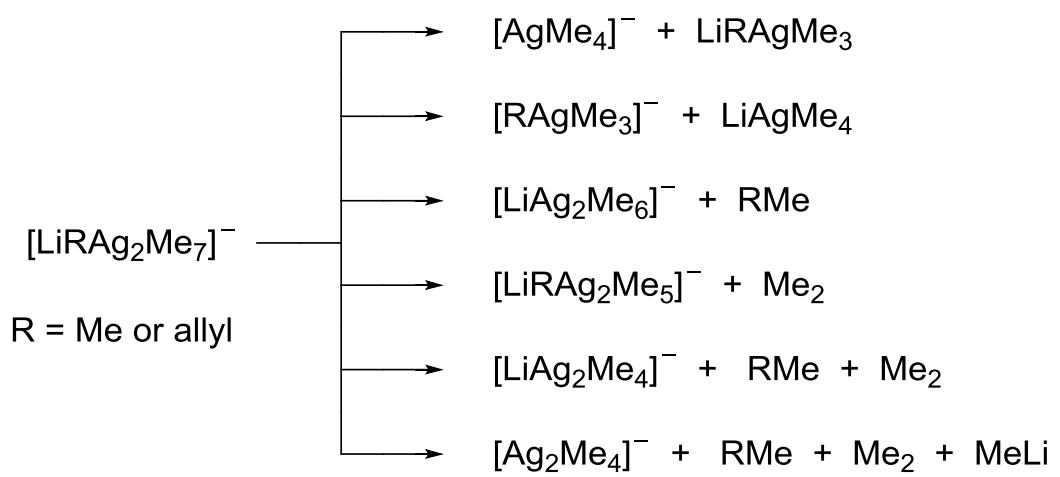



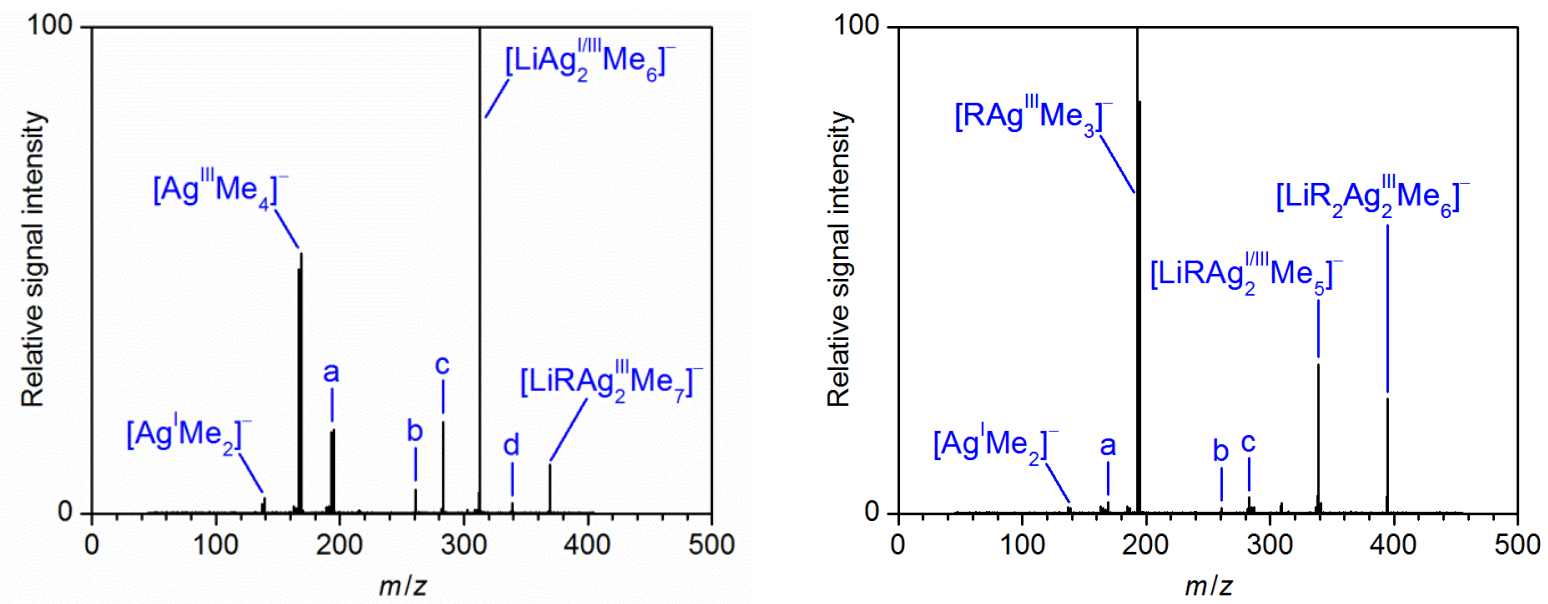

Figure 37. Left: Mass spectrum of mass-selected $\left[\mathrm{LiRAg}^{\prime \prime \prime}{ }_{2} \mathrm{Me}_{7}\right]^{-}(\mathrm{R}=$ allyl) and its fragment ions produced upon collision-induced dissociation at $E_{\mathrm{LAB}}=7.5 \mathrm{eV} ;$ a: $\left[\mathrm{RAg}^{\prime \prime \prime} \mathrm{Me}_{3}\right]^{-}, \mathrm{b}:\left[\mathrm{Ag}_{2}^{\prime} \mathrm{Me}_{3}\right]^{-}, \mathrm{c}:$ [LiAg $\left.{ }_{2} \mathrm{Me}_{4}\right]^{-}, \mathrm{d}$ : [LiRAg $\left.{ }_{2}^{1 / I I I}{ }_{2} \mathrm{Me}_{5}\right]^{-}$. Right: Mass spectrum of mass-selected $\left[\mathrm{LiR}_{2} \mathrm{Ag}^{\prime \prime \prime}{ }_{2} \mathrm{Me}_{6}\right]^{-}(\mathrm{R}=$ allyl) and its fragment ions produced upon collision-induced dissociation at $E_{\mathrm{LAB}}=5.0 \mathrm{eV} ; \mathrm{a}:\left[\mathrm{Ag}^{\prime \prime \prime} \mathrm{Me}_{4}\right]^{-}, \mathrm{b}$ : $\left[\mathrm{Ag}_{2}^{\prime} \mathrm{Me}_{3}\right]^{-}, \mathrm{c:}\left[\mathrm{LiAg}_{2}^{\prime} \mathrm{Me}_{4}\right]^{-}$.

Again, the outcome of these gas-phase fragmentation experiments is fully consistent with theoretical results. For the lithium-bound dimer $\left[\mathrm{LiAg}_{2} \mathrm{Me}_{8}\right]^{-}$the energy of the transition structure associated with the reductive elimination of ethane is calculated at $127 \mathrm{~kJ} \mathrm{~mol}^{-1}$, a value significantly lower than for the mononuclear complex. ${ }^{[90]}$ Apparently, the interaction with the lithium center lowers the barrier substantially. This effect can be rationalized by $\mathrm{Li}^{+}$withdrawing electron density from the ate complex and thereby raising the propensity of the silver(III) center to regain its preferred oxidation state of $+\mathrm{I}$ by reductive elimination. A similar trend has been found for the corresponding cuprate(III) complexes $\left[\mathrm{CuMe}_{4}\right]^{-}$and $\left[\mathrm{LiCu}_{2} \mathrm{Me}_{8}\right]^{-}{ }^{-[86 a]}$ The competing dissociation of [ $\left.\mathrm{LiAg}_{2} \mathrm{Me}_{8}\right]^{-}$(Eq. 24) requires an energy of $173 \mathrm{~kJ} \mathrm{~mol}^{-1}$ and, thus, is energetically more demanding than the reductive elimination. ${ }^{[90]}$ However, the latter reaction is entropically favored, which explains why it is found to compete with the former in the experiment. ${ }^{[90]}$

Theoretical methods were also used to investigate the mechanism of silver-mediated $\mathrm{C}-\mathrm{C}$ coupling in $\mathrm{THF}^{\left[{ }^{[90]}\right.}$ The results indicate that reductive elimination from $\mathrm{Ag}(\mathrm{III})$ ate complexes is also a key step in these transformations in solution. Apart from free $\left[\mathrm{AgMe}_{4}\right]^{-}$, solvent-separated and contact-ion pairs were also considered. The calculations predict that ion pairing does not strongly affect the Gibbs energy of the reactant argentate(III) complex, but that the interaction with $\mathrm{Li}^{+}$in the contact-ion pair substantially stabilizes the transition state, thus facilitating the overall reaction. This reactivityenhancing effect of lithium essentially equals that already found for the gaseous [ $\left.\mathrm{LiAg}_{2} \mathrm{Me}_{8}\right]^{-}$complex discussed above. For comparison, the analysis also included the neutral species $\mathrm{AgMe}_{3}$, but the overall reaction proceeding via neutral $\mathrm{AgMe}_{3}$ was found to be less favorable than the reaction via the contact-ion pair. 
Parts of the following section (" 5 Conclusions") were taken from or are based on the publications given below.

The Role of Ate Complexes in the Copper-Mediated Trifluoromethylation of Alkynes Sebastian Weske, Ramona Schoop, Konrad Koszinowski, Chemistry - A European Journal, 2016, 22, 11310-11316.

DOI : 10.1002/chem.201601261

https://onlinelibrary.wiley.com/doi/full/10.1002/chem.201601261

Copyright Wiley-VCH Verlag GmbH \& Co. KGaA. Reproduced with permission.

Argentate(I) and (III) complexes as intermediates in silver-mediated cross-coupling reactions Sebastian Weske, Richard A. Hardin, Thomas Auth, Richard A. J. O'Hair, Konrad Koszinowski, Craig A. Ogle, Chemical Communications 2018, 54, 5086-5089.

DOI: $10.1039 / \mathrm{c} 8 \mathrm{cc} 01707 \mathrm{~g}$

https://pubs.rsc.org/en/content/articlelanding/2018/cc/c8cc01707g\#!divAbstract

Reproduced with permission from the Royal Society of Chemistry. 


\section{Conclusions}

Negative-ion mode ESI mass spectra of solutions of magnesium cuprates in THF show $\left[\mathrm{Cu}_{n} \mathrm{R}_{n+1}\right]^{-}$ anions, $n=1-6$. The stoichiometry of these aggregates deviates from the $1: 2$ ratio of the $\mathrm{CuX} / \mathrm{RMgCl}$ reactants and, thus, points to the occurrence of degradation reactions. For the case of the butylcuprates, such degradation reactions, which apparently produced colloidal copper, could directly be observed. Possibly, the degradation of the butylcuprates proceeds via $\beta$-hydrogen eliminations as these reactions also occurred upon their deliberate fragmentation in the gas phase. Another type of decomposition reaction was observed for $\left[\mathrm{Cu}\left(\mathrm{CH}_{2} \mathrm{SiMe}_{3}\right)_{2}\right]^{-}$, which underwent a $\beta$ methyl elimination. Only few examples of these reactions have been previously reported for complexes of late transition metals. In all cases, the gas-phase fragmentation of the polynuclear $\left[\mathrm{Cu}_{n} \mathrm{R}_{n+1}\right]^{-}$anions also led to deaggregation processes.

The behavior of the magnesium cuprates differs considerably from that of the extensively studied lithium cuprates. The latter preferentially form heteronuclear species, whose stoichiometry matches the ratio of the used reactants and, thereby, excludes the occurrence of degradation reactions. Presumably, the incorporation of lithium in the cuprates enhances their stability, possibly by restricting their conformational flexibility. Indeed, the $\left[\mathrm{Li}_{2} \mathrm{Cu}_{3} \mathrm{Bu}_{6}\right]^{-}$complex proved to be much more reluctant toward decomposition by $\beta$-hydrogen elimination than its $\left[\mathrm{Cu}_{n} \mathrm{Bu}_{n+1}\right]^{-}$congeners.

The different tendencies of lithium and magnesium cations to bind to the cuprate anions are in accordance with quantum chemical calculations. These calculations point to the critically important role of the preferred association state of the lithium and magnesium counter-ions. In the case of lithium, the easy availability of free $\left[\mathrm{Li}(\mathrm{THF})_{4}\right]^{+}$ions facilitates the formation of heteronuclear complexes. In contrast, the high stability of the dinuclear magnesium cation $\left[(\mathrm{THF})_{6} \mathrm{Mg}_{2} \mathrm{Cl}_{3}\right]^{+}$severely limits the availability of free solvated $\mathrm{MgCl}^{+}$cations and renders their incorporation into hypothetical heteronuclear magnesium cuprates energetically unfavorable. These finding show how the speciation of cuprate reagents in solution is influenced by rather subtle effects. Knowing these effects and the microscopic composition of organocuprates is also the prerequisite for understanding their reactivity and for their well-directed use in synthetic applications.

Negative-ion mode ESI mass spectra of solutions of $\mathrm{MCN}(\mathrm{M}=\mathrm{Cu}, \mathrm{Ag}, \mathrm{Au})$ treated with PhLi in THF show organometallates with the general sum formula $\left[\mathrm{Li}_{n-1} \mathrm{M}_{n} \mathrm{Ph}_{2 n}\right]^{-}$. These complexes closely resemble species that were detected in previous ESI mass spectrometric studies of cyanocuprates and Gilman cuprates in ethereal solvents. Beyond that, lithium phenylmetallate solutions that were prepared from mixtures of two or all three coinage metals additionally featured the mixed anions $\left[\mathrm{LiM}^{1} \mathrm{M}^{2} \mathrm{Ph}_{4}\right]^{-},\left[\mathrm{Li}_{2} \mathrm{M}_{2}^{1} \mathrm{M}^{2} \mathrm{Ph}_{6}\right]^{-}$and $\left[\mathrm{Li}_{2} \mathrm{M}^{1} \mathrm{M}_{2}{ }_{2} \mathrm{Ph}_{6}\right]^{-}$, as well as $\left[\mathrm{Li}_{2} \mathrm{CuAgAuPh}_{6}\right]^{-}$. Among the detected organometallates, the pentanuclear anions $\left[\mathrm{Li}_{2} \mathrm{M}_{3} \mathrm{Ph}_{6}\right]^{-}$and the respective mixed species are of particular interest because their sum formulas match those of the copper and silver complexes $\left[\mathrm{Li}_{2} \mathrm{Cu}_{3} \mathrm{Ph}_{6}\right]^{-}$and $\left[\mathrm{Li}_{2} \mathrm{Ag}_{3} \mathrm{Ph}_{6}\right]^{-}$that were found in the solid state by $\mathrm{X}$-ray crystallography. These structures exhibit strong similarities, thereby indicating a common structural motif for all ions belonging to the $\left[\mathrm{Li}_{2} \mathrm{M}_{3} \mathrm{Ph}_{6}\right]^{-}$type. In addition, the gas-phase fragmentation behavior of $\left[\mathrm{Li}_{2} \mathrm{M}_{2}^{1} \mathrm{M}^{2} \mathrm{Ph}_{6}\right]^{-},\left[\mathrm{Li}_{2} \mathrm{M}^{1} \mathrm{M}_{2}^{2}{ }_{2} \mathrm{Ph}_{6}\right]^{-}$, and $\left.\left[\mathrm{Li}_{2} \mathrm{CuAgAuPh}\right]_{6}\right]^{-}$exactly mirrors that of $\left[\mathrm{Li}_{2} \mathrm{M}_{3} \mathrm{Ph}_{6}\right]^{-}$, which further supports the assumption of a common structure for all of these ions. Moreover, the observation of mixed pentanuclear phenylmetallates can be rationalized by the action of association/dissociation equilibria between mononuclear phenylmetallates $\left[\mathrm{MPh}_{2}\right]^{-}$and neutral dimers $\mathrm{Li}_{2} \mathrm{M}_{2} \mathrm{Ph}_{4}$ containing different coinage metals. These findings are in full accordance with results of previous studies on 
organocuprates and point to close similarities in the aggregation behavior of organocuprates, -argentates, and -aurates. Even more, the presence of heterobimetallic cations such as $\left[\mathrm{Li}_{2} \mathrm{MPh}_{2}(\mathrm{THF})_{x}\right]^{+}$, which were quite abundant in positive-ion mode mass spectra of all investigated phenylmetallate solutions, hint at further association/dissociation equilibria between the neutral homodimers (THF) ${ }_{x} \mathrm{Li}_{2} \mathrm{M}_{2} \mathrm{Ph}_{2}$ and $\left[\mathrm{Li}_{2} \mathrm{MPh}_{2}(\mathrm{THF})_{x}\right]^{+}$as well as $\left[\mathrm{MPh}_{2}\right]^{-}$. Thus, phenylmetallates of the coinage metals exhibit remarkable similarities with respect to their speciation and the equilibria operative in THF solutions.

Gas-phase fragmentation experiments of both the pentanuclear and the trinuclear phenylmetallates equally resulted in deaggregation reactions that led to the formation of the mononuclear ate complexes. However, in contrast to CID experiments of the mixed pentanuclear anions, which point to a mainly statistical fragmentation process, the intensity ratios of the fragment ions formed upon collisional activation of $\left[\mathrm{LiM}^{1} \mathrm{M}^{2} \mathrm{Ph}_{4}\right]^{-}$deviate from the value expected for a statistical dissociation. This behavior is ascribed to different lithium affinities of the two mononuclear metallates $\left[\mathrm{M}^{1} \mathrm{Ph}_{2}\right]^{-}$ and $\left[\mathrm{M}^{2} \mathrm{Ph}_{2}\right]^{-}$present in $\left[\mathrm{LiM}^{1} \mathrm{M}^{2} \mathrm{Ph}_{4}\right]^{-}$. The mononuclear complexes $\left[\mathrm{MPh}_{2}\right]^{-}(\mathrm{M}=\mathrm{Cu}, \mathrm{Ag}, \mathrm{Au})$ cannot dissociate by deaggregation anymore. Instead, they exhibit qualitatively different fragmentation patterns, which now obviously depend on the nature of the coinage metal. Apparently, the fragmentation behavior differs with regard to the aggregation state: the outcome of collisional activation of the pentanuclear species is determined by their structure, the fragmentation patterns of the mononuclear complexes are governed by the present metal, and the dissociation of the trinuclear ions is affected by both their structure and the included metals.

Sample solutions prepared from coinage metal cyanides and $\mathrm{PhMgCl}$ in $\mathrm{THF}$ also showed phenylmetallates in negative-ion mode ESI mass spectra. Comparable species were identified for all three coinage metals. In particular, high amounts of $\left[\mathrm{CuPh}_{2}\right]^{-}$and $\left[\mathrm{AuPh}_{2}\right]^{-}$were observed, which agrees well with the results obtained by mass-spectrometric analysis of Normant cuprate solutions prepared from $\mathrm{CuCl}$ and $\mathrm{PhMgCl}$. ESI mass spectrometry of solutions prepared from coinage metal cyanides and MeLi detected species equivalent to their phenyl counterparts, but also several species that presumably originated from hydrolysis reactions. Solutions prepared from $\mathrm{MeMgCl}$ were even stronger affected by hydrolysis. Apparently, the methyl metallates are more sensitive towards hydrolysis than the phenyl metallates.

ESI mass spectra of solutions of Cul, $\mathrm{KF}$, and $\mathrm{Si}\left(\mathrm{CH}_{3}\right)_{3} \mathrm{CF}_{3}$ in THF showed the homoleptic cuprates $\left[\mathrm{Cu}\left(\mathrm{CF}_{3}\right)_{2}\right]^{-}$and $\left[\mathrm{Cu}\left(\mathrm{CF}_{3}\right)_{4}\right]^{-}$. Upon the addition of terminal alkynes, heteroleptic cuprates $\left[\mathrm{Cu}\left(\mathrm{CF}_{3}\right)_{3} \mathrm{R}\right]^{-}$ ( $R=$ aromatic alkynyl) could be observed as well. Both $\mathrm{Cu}(\mathrm{III})$ species underwent reductive eliminations upon gas-phase fragmentation: $\left[\mathrm{Cu}_{(}\left(\mathrm{CF}_{3}\right)_{4}\right]^{-}$released the homo-coupling product $\mathrm{CF}_{3} \mathrm{CF}_{3}$, whereas $\left[\mathrm{Cu}\left(\mathrm{CF}_{3}\right)_{3} \mathrm{R}\right]^{-}$exclusively formed the synthetically desired cross-coupling product $\mathrm{R}-\mathrm{CF}_{3}$. The perfect selectivity of the second reaction is ascribed to the strong electron-withdrawing properties of the trifluoromethyl group. By accepting electron density, the $\mathrm{CF}_{3}$ groups help to stabilize the negative charge in the copper(I) fragment anion, thus, rendering the formation of $\left[\mathrm{Cu}\left(\mathrm{CF}_{3}\right)_{2}\right]^{-} / \mathrm{R}-\mathrm{CF}_{3}$ energetically more favorable than that of $\left[\mathrm{Cu}\left(\mathrm{CF}_{3}\right) \mathrm{R}\right]^{-} / \mathrm{CF}_{3} \mathrm{CF}_{3}$.

Changing the solvent from THF to $\mathrm{CH}_{2} \mathrm{Cl}_{2}$ or $\mathrm{CH}_{3} \mathrm{CN}$ led to the detection of essentially the same species, although in lower signal intensities. In $\mathrm{CH}_{3} \mathrm{CN}$ solutions, further anions bearing deprotonated acetonitrile moieties were also observed. The addition of 1,10-phenanthroline did not afford any cuprate anions binding this ligand, which had been postulated in the literature. Presumably, 
phenanthroline does not directly participate in the reaction, but enhances the solubility of the Cul reactant.

The absence of any heteroleptic copper(I) ate complexes $\left[\mathrm{Cu}\left(\mathrm{CF}_{3}\right) \mathrm{R}\right]^{-}$indicates that they do not act as precursors of the $\left[\mathrm{Cu}\left(\mathrm{CF}_{3}\right)_{3} \mathrm{R}\right]^{-}$key intermediates. As preformed $\left[\mathrm{Cu}\left(\mathrm{CF}_{3}\right)_{4}\right]^{-}$did not react with phenyl acetylene under the typical reaction conditions, the former can also be ruled out as a precursor of the heteroleptic $\left[\mathrm{Cu}\left(\mathrm{CF}_{3}\right)_{3} \mathrm{R}\right]^{-}$complexes. Possibly, the latter originate from neutral precursors not amenable to analysis by ESI mass spectrometry. In any case, the presence of $\left[\mathrm{Cu}\left(\mathrm{CF}_{3}\right)_{4}\right]^{-}$and $\left[\mathrm{Cu}\left(\mathrm{CF}_{3}\right)_{3} \mathrm{R}\right]^{-}$implies the occurrence of oxidation processes, which apparently involve oxygen as oxidizing agent. In addition, radical decomposition products of the $\mathrm{Si}\left(\mathrm{CH}_{3}\right)_{3} \mathrm{CF}_{3}$ reagent may also contribute to the oxidation.

The present study has identified key intermediates of the copper-mediated oxidative trifluoromethylation of alkynes and probed their unimolecular reactivity. A mechanistic understanding of this transformation is thus beginning to emerge, which in the long term should help in the rational optimization and extension of this and related trifluoromethylation reactions.

It has also been demonstrated that $\mathrm{Ag}(\mathrm{I})$ and $\mathrm{Ag}(\mathrm{III})$ ate complexes are crucial intermediates in $\mathrm{C}-\mathrm{C}$ coupling. Remarkably, the silver-mediated coupling reactions with butyl and allyl halides differed significantly from the previously studied copper-mediated reactions. For copper, the cross-coupling product evolves from the neutral allyl-containing intermediate [ $\left.\mathrm{RCuMe}_{2}\right]$. The findings of this study, however, suggests that the silver-mediated formation of the cross-coupling product proceeds from anionic $\mathrm{Ag}(\mathrm{III})$ ate complexes. The gas-phase experiments directly show the feasibility of this reaction. This mode of reactivity deviates from that of the analogous cuprate, which preferentially affords the homo-coupling instead of the cross-coupling product. Clearly, organoargentates are more than just a costly variant of the all popular organocuprates. The improved understanding of their mode of action also promises to boost their use in synthesis. 
Parts of the following section ("6.2 Sample Preparation - Procedure for the Preparation of Homoleptic Trifluoromethyl Cuprates, General Procedure for the Preparation of Heteroleptic Trifluoromethyl Cuprates, Procedure for the Preparation of Trifluoromethyl Cuprates in the Presence of 1,10-Phenanthroline or 4,7-Dihydroxy-1,10-phenanthroline, Preparation of $\left.\left[\mathrm{NBu}_{4}\right]\left[\mathrm{Cu}\left(\mathrm{CF}_{3}\right)_{4}\right]^{\prime \prime}\right)$ were taken from the publication given below.

The Role of Ate Complexes in the Copper-Mediated Trifluoromethylation of Alkynes Sebastian Weske, Ramona Schoop, Konrad Koszinowski, Chemistry - A European Journal, 2016, 22, 11310-11316.

DOI : 10.1002/chem.201601261

https://onlinelibrary.wiley.com/doi/full/10.1002/chem.201601261

Copyright Wiley-VCH Verlag GmbH \& Co. KGaA. Reproduced with permission.

Parts of the following section ("6.2 Sample Preparation - General Procedure for the Preparation of Argentate(III) Complexes") were taken from the publication given below.

Argentate(I) and (III) complexes as intermediates in silver-mediated cross-coupling reactions Sebastian Weske, Richard A. Hardin, Thomas Auth, Richard A. J. O'Hair, Konrad Koszinowski, Craig A. Ogle, Chemical Communications 2018, 54, 5086-5089.

DOI: $10.1039 / \mathrm{c} 8 \mathrm{cc} 01707 \mathrm{~g}$

https://pubs.rsc.org/en/content/articlelanding/2018/cc/c8cc01707g\#!divAbstract

Reproduced with permission from the Royal Society of Chemistry. 


\section{Experimental Section}

\subsection{Materials and Methods}

Standard Schlenk techniques were applied in all cases to exclude traces of moisture. Tetrahydrofuran was dried over sodium/benzophenone and freshly distilled. $\mathrm{CH}_{2} \mathrm{Cl}_{2}$ was predried over $\mathrm{CaCl}_{2}$ for $24 \mathrm{~h}$ and freshly distilled from $\mathrm{P}_{2} \mathrm{O}_{5}$. $\mathrm{CH}_{3} \mathrm{CN}$ was predried by distilling it from $\mathrm{NaH}$ and then freshly distilled from $\mathrm{P}_{2} \mathrm{O}_{5}$. Anhydrous cyclopentyl methyl ether (CPME) and anhydrous methyl tert-butyl ether (MTBE) were used as purchased.

Grignard reagents $\mathrm{RMgCl}$ with $\mathrm{R}=2$-thienyl or $\mathrm{Me}_{3} \mathrm{SiCH}_{2}$ were prepared from $\mathrm{Mg}$ turnings and 2-thienyl chloride or (trimethylsilyl)methyl chloride (see chapter 6.2). All other organometallic reagents were used as purchased: $\mathrm{PhMgCl}\left(2.0 \mathrm{~mol} \mathrm{~L}^{-1}\right.$ in THF), $\mathrm{MeMgCl}\left(3.0 \mathrm{~mol} \mathrm{~L}^{-1}\right.$ in THF), BuMgCl ( $2.0 \mathrm{~mol} \mathrm{~L}^{-1}$ in THF), PhLi $\left(1.9 \mathrm{~mol} \mathrm{~L}^{-1}\right.$ in $\left.\mathrm{Bu}_{2} \mathrm{O}\right)$, MeLi $\left(1.6 \mathrm{~mol} \mathrm{~L}^{-1}\right.$ in $\left.\mathrm{Et}_{2} \mathrm{O}\right)$. The exact concentrations of these reagents were determined by iodometric titration. ${ }^{[138]} \mathrm{LiCl}$ was dried by heating under vacuum and stored under argon before use. $\mathrm{AgCN}$ and $\mathrm{AgCN}$-containing sample solutions were handled under the exclusion of light. $\left[\mathrm{NBu}_{4}\right]\left[\mathrm{Cu}\left(\mathrm{CF}_{3}\right)_{4}\right]$ was prepared according to a procedure reported in the literature. ${ }^{[9 c]}$

All other chemicals were purchased and used without further purification.

\subsection{Sample Preparation}

\section{General Procedure for the Preparation of Magnesium Cuprates}

A $10-\mathrm{mL}$ Schlenk flask with magnetic stir bar was charged with $\mathrm{CuCl}(0.625 \mathrm{mmol}, 1.00$ equiv.) and repeatedly evacuated and flushed with argon. The $\mathrm{CuCl}$ was then dried under vacuum at $140{ }^{\circ} \mathrm{C}$ for 90 min. After cooling to room temperature, THF $(5 \mathrm{~mL})$ was added via a syringe through a rubber septum. The resulting suspension was cooled to $-78^{\circ} \mathrm{C}$, and $\mathrm{RMgCl}(1.25 \mathrm{mmol}, 2.00$ equiv, $\mathrm{R}=$ phenyl, 2-thienyl, butyl, (trimethylsilyl)methyl) was added via a syringe through a rubber septum. After stirring the reaction mixture at $-78^{\circ} \mathrm{C}$ for $30 \mathrm{~min}$, an aliquot $(1 \mathrm{~mL})$ was transferred via a syringe to another $10-\mathrm{mL}$ Schlenk flask filled with cold THF $\left(4 \mathrm{~mL},-78^{\circ} \mathrm{C}\right)$. This diluted solution was then injected into the ESI source of the mass spectrometer.

Control experiments were performed with alternative copper precursors ( $\left.\mathrm{CuBr}, \mathrm{CuBr} \cdot \mathrm{Me}_{2} \mathrm{~S}, \mathrm{CuCN}\right)$, an excess of $\mathrm{PhMgCl}$ (3 or 4 equiv.), or an extended reaction time $(60 \mathrm{~min})$. In the case of $\mathrm{CuBr} \cdot \mathrm{Me}_{2} \mathrm{~S}$, a Schlenk flask was charged with the copper compound in an argon-filled glove-box and used directly without any further evacuation or drying in order to avoid removal of the volatile $\mathrm{Me}_{2} \mathrm{~S}$.

\section{Preparation of Grignard Reagents from 2-Thienyl Chloride or (Trimethylsilyl)methyl Chloride}

A Schlenk flask was charged with magnesium turnings $(28.0 \mathrm{mmol}, 1.12$ equiv.) and repeatedly evacuated and flushed with argon at $350{ }^{\circ} \mathrm{C}$. After cooling to room temperature and the addition of THF (20 mL), 2-thienyl chloride or (trimethylsilyl)methyl chloride $(25.0 \mathrm{mmol}, 1.00$ equiv.) was added dropwise. After approx. $0.5 \mathrm{~h}$, an exothermic reaction set in, and the flask was cooled with ice water. The reaction mixture was then stirred overnight at room temperature. 

LiCl

A $10-\mathrm{mL}$ Schlenk flask with magnetic stir bar was charged with $\mathrm{CuCl}(0.625 \mathrm{mmol}, 1.00$ equiv.) and repeatedly evacuated and flushed with argon. The $\mathrm{CuCl}$ was then dried under vacuum at $140{ }^{\circ} \mathrm{C}$ for $90 \mathrm{~min}$. After cooling to room temperature, a solution of anhydrous $\mathrm{LiCl}$ in THF $(1.25 \mathrm{mmol}$, 2.00 equiv., $5 \mathrm{~mL}, 0.25 \mathrm{M}$ ) was added via a syringe through a rubber septum. The resulting suspension was cooled to $-78{ }^{\circ} \mathrm{C}$, and $\mathrm{PhMgCl}(1.25 \mathrm{mmol}, 2.00$ equiv.) was added via a syringe through a rubber septum. The reaction mixture was stirred at $-78{ }^{\circ} \mathrm{C}$ for $30 \mathrm{~min}$. Then, an aliquot $(1 \mathrm{~mL})$ of the reaction mixture was transferred via a syringe to another $10-\mathrm{mL}$ Schlenk flask, which already contained cold THF $\left(4 \mathrm{~mL},-78^{\circ} \mathrm{C}\right)$. This diluted solution was then injected into the the ESI source of the mass spectrometer.

\section{General Procedure for the Preparation of Organometallates from Coinage Metal Cyanides}

A 10-mL Schlenk flask with magnetic stir bar was charged with $\mathrm{MCN}(\mathrm{M}=\mathrm{Cu}, \mathrm{Ag}$, or $\mathrm{Au}$, respectively; $0.625 \mathrm{mmol}, 1.00$ equiv.) and repeatedly evacuated and flushed with argon. The MCN was then dried under vacuum at $140{ }^{\circ} \mathrm{C}$ for $90 \mathrm{~min}$. After cooling to room temperature, THF ( $5 \mathrm{~mL}$ ) was added via a syringe through a rubber septum. The resulting suspension was cooled to $-78^{\circ} \mathrm{C}$, and $\mathrm{RLi}$ or $\mathrm{RMgCl}$ ( $\mathrm{R}=\mathrm{Ph}, \mathrm{Me} ; 1.25 \mathrm{mmol}, 2.00$ equiv.) was added via a syringe through a rubber septum. The reaction mixture was stirred for $30 \mathrm{~min}$ at $-78^{\circ} \mathrm{C}$. Then, an aliquot $(1.0 \mathrm{~mL})$ of the reaction mixture was transferred via a syringe to another $10-\mathrm{mL}$ Schlenk flask, which already contained cold THF $(4.0 \mathrm{~mL}$, $-78^{\circ} \mathrm{C}$ ). This diluted solution was then injected into the ESI source of the mass spectrometer.

Organometallate solutions from two or three coinage metal cyanides were prepared accordingly, but with two coinage metal cyanides $\mathrm{M}^{1} \mathrm{CN}$ and $\mathrm{M}^{2} \mathrm{CN}(0.313 \mathrm{mmol}, 0.50$ equiv. each) or all three coinage metals ( $0.208 \mathrm{mmol}, 0.33$ equiv. each) instead of just one metal cyanide.

\section{Procedure for the Preparation of Homoleptic Trifluoromethyl Cuprates}

An oven-dried 10-mL Schlenk flask with magnetic stir bar was charged with KF ( $1.50 \mathrm{mmol}, 2.00 \mathrm{eq})$ and $\mathrm{Cul}(0.75 \mathrm{mmol}, 1.00 \mathrm{eq})$ under argon. The substances were dried under vacuum at $140{ }^{\circ} \mathrm{C}$ for at least 60 min. After cooling to room temperature, the solvent ( $\mathrm{THF}, \mathrm{CH}_{2} \mathrm{Cl}_{2}$, or $\mathrm{CH}_{3} \mathrm{CN}$, respectively, $5 \mathrm{~mL})$ and $\mathrm{Si}\left(\mathrm{CH}_{3}\right)_{3} \mathrm{CF}_{3}(2.00 \mathrm{mmol}, 2.67 \mathrm{eq})$ were added via syringes through a rubber septum. In standard experiments, the $\mathrm{Si}\left(\mathrm{CH}_{3}\right)_{3} \mathrm{CF}_{3}$ reagent was not degassed and, thus, contained sufficient dissolved oxygen for the occurrence of the reaction (see chapter 4.3.6). For a control experiment under the exclusion of oxygen, the $\mathrm{Si}\left(\mathrm{CH}_{3}\right)_{3} \mathrm{CF}_{3}$ reagent was carefully degassed by passing a stream of argon gas through it and by subjecting it to repeated freeze-evacuate-thaw cycles. The reaction mixture was stirred at room temperature for $5 \mathrm{~min}$ and then allowed to rest for $2 \mathrm{~min}$ so that undissolved substances could settle down. Then, an aliquot $(0.5 \mathrm{~mL})$ of the supernatant solution was transferred via a syringe to another $10-\mathrm{mL}$ Schlenk flask, which already contained the solvent $(4.5 \mathrm{~mL})$. This diluted solution was then injected into the ESI source of the mass spectrometer.

\section{General Procedure for the Preparation of Heteroleptic Trifluoromethyl Cuprates}

A solution of homoleptic cuprates was prepared as described above. After stirring at room temperature for $5 \mathrm{~min}$, the aromatic alkyne (phenylacetylene, 4-ethynylanisole, 1-chloro-4ethynylbenzene, methyl 4-ethynylbenzoate, 4-ethynylbiphenyl, 2-ethynylpyridine, $0.50 \mathrm{mmol}$, 
0.67 eq) was added. After stirring for additional $5 \mathrm{~min}$, the reaction mixture was allowed to rest for 2 min so that undissolved substances could settle down. Then, an aliquot $(0.5 \mathrm{~mL})$ of the supernatant solution was transferred via syringe to another $10-\mathrm{mL}$ Schlenk flask, which already contained the solvent $(4.5 \mathrm{~mL})$. This diluted solution was then injected into the ESI source of the mass spectrometer.

\section{Procedure for the Preparation of Trifluoromethyl Cuprates in the Presence of 1,10-Phenanthroline or 4,7-Dihydroxy-1,10-phenanthroline}

In further experiments, homo- and heteroleptic cuprates were prepared in the presence of 1,10phenanthroline (phen) or 4,7-dihydroxy-1,10-phenanthroline (HO-phen). For this purpose, the respective compound ( $0.75 \mathrm{mmol}, 1.00$ equiv.) was added to the already dried Cul and KF after the flask had cooled to room temperature. The flask was then evacuated once more for at least $30 \mathrm{~min}$ at room temperature (phen) or $100{ }^{\circ} \mathrm{C}$ (HO-phen). The preparation then proceeded as described above.

\section{Preparation of $\left[\mathrm{NBu}_{4}\right]\left[\mathrm{Cu}\left(\mathrm{CF}_{3}\right)_{4}\right]$}

$\left[\mathrm{NBu}_{4}\right]\left[\mathrm{Cu}\left(\mathrm{CF}_{3}\right)_{4}\right]$ was prepared according to a literature procedure. ${ }^{[9 \mathrm{c}]} \mathrm{ESI} \mathrm{MS}: \mathrm{m} / z$ (\%): 920 (13) $\left[\left(\mathrm{NBu}_{4}\right)\left(\mathrm{Cu}\left(\mathrm{CF}_{3}\right)_{4}\right)_{2}{ }^{-}\right], \quad 339$ (100) $\left[\left(\mathrm{Cu}_{\left.\left.\left(\mathrm{CF}_{3}\right)_{4}\right)^{-}\right],} 823\right.\right.$ (8) $\left[\left(\mathrm{NBu}_{4}\right)_{2}\left(\mathrm{Cu}\left(\mathrm{CF}_{3}\right)_{4}\right)^{+}\right], 242$ (100) $\left[\left(\mathrm{NBu}_{4}\right)^{+}\right]$; elemental analysis calcd (\%) for $\mathrm{C}_{20} \mathrm{H}_{36} \mathrm{CuF}_{12} \mathrm{~N}$ : C 41.27, H 6.23, $\mathrm{Cu} 10.92, \mathrm{~F} 39.17 \mathrm{~N} 2.41$; found: $\mathrm{C}$ 41.54, H 6.24, Cu 10.93, N 2.33.

\section{General Procedure for the Preparation of Argentate(III) Complexes}

A 10-mL Schlenk flask with magnetic stir bar was charged with AgCN ( $0.625 \mathrm{mmol}, 1.00$ equiv.) and repeatedly evacuated and flushed with argon. The $\mathrm{AgCN}$ was then dried under vacuum at $140{ }^{\circ} \mathrm{C}$ for $90 \mathrm{~min}$. After cooling to room temperature, THF $(5 \mathrm{~mL})$ was added via a syringe through a rubber septum. The resulting suspension was cooled to $-78^{\circ} \mathrm{C}$, and MeLi $(1.25 \mathrm{mmol}, 2.00$ equiv.) was added via a syringe through a rubber septum. After stirring the reaction mixture for $30 \mathrm{~min}$ at $-78^{\circ} \mathrm{C}$, an aliquot $(1.0 \mathrm{~mL})$ of the reaction mixture was transferred via a syringe to another $10-\mathrm{mL}$ Schlenk flask, which already contained cold THF $\left(4.0 \mathrm{~mL},-78^{\circ} \mathrm{C}\right)$. This diluted solution was injected into the ESI source of the mass spectrometer, and a regular ESI mass spectrum was recorded to ensure that the transmetallation had been successful. Then, an organyl iodide RI $(0.258 \mathrm{mmol}, 0.50$ equiv. with respect to remaining $\mathrm{Ag}^{+} ; \mathrm{R}=$ methyl, butyl, allyl, phenyl) was added to the original reaction mixture, which was then stirred for further $30 \mathrm{~min}$ at $-78^{\circ} \mathrm{C}$. A second aliquot $(1.0 \mathrm{~mL})$ was then transferred via syringe from the reaction mixture to a third $10-\mathrm{mL}$ Schlenk flask, which already contained cold THF $\left(4.0 \mathrm{~mL},-78^{\circ} \mathrm{C}\right)$. This diluted solution was then injected into the ESI source of the mass spectrometer.

In order to study the formation of argentate(III) complexes in solvents that are less polar than THF (relative permittivity $\left.\varepsilon^{298 \mathrm{~K}}=7.42\right),{ }^{[135]}$ analogous experiments were performed in CPME $\left(\varepsilon^{298 \mathrm{~K}}=4.76\right)^{[135]}$ and MTBE $\left(\varepsilon^{298 \mathrm{~K}}=2.60\right),{ }^{[136]}$ respectively.

\subsection{ESI Mass Spectrometry}

Prior to ESI mass spectrometric experiments, the ESI source including the inlet system was flushed with dry solvent for at least $30 \mathrm{~min}$. Sample solutions (typical concentrations of $15-25 \mathrm{mmol} \mathrm{L}^{-1}$ ) were injected into the ESI source of a micrOTOF-Q II mass spectrometer (Bruker Daltonik, Bremen ${ }^{[110]}$ via gastight syringes at a flow rate of $0.5 \mathrm{~mL} \mathrm{~h}^{-1}$ by means of a syringe pump. Nitrogen 
was used as nebulizer gas (typical backing pressure of $0.5-0.7$ bar) and drying gas $\left(60^{\circ} \mathrm{C}\right.$, typical flow rate of $5 \mathrm{~L} \mathrm{~min}{ }^{-1}$ ). ESI voltages of $+3.5 \mathrm{kV}$ (negative-ion mode) and $-4.5 \mathrm{kV}$ (positive-ion mode) with an end-plate offset of $-500 \mathrm{~V}$ were applied. The ESI source was connected to an ion-transfer section consisting of two ion funnels and a hexapole (Funnel 1 RF: $200-300.0 \mathrm{Vpp}$, Funnel 2 RF: 400.0 Vpp, ISCID Energy: $0.0 \mathrm{eV}$, Hexapole RF: $200-400.0 \mathrm{Vpp} ; \mathrm{V}_{\mathrm{pp}}=$ peak-to-peak Voltage). The transfer section was followed by an analytical quadrupole and a collision cell. In gas-phase fragmentation experiments, this quadrupole was used for the isolation of ions which then underwent fragmentation in the collision cell (see below). In experiments without gas-phase fragmentation, these two parts acted as an ion transfer section (Ion Energy: $4.0-5.0 \mathrm{eV}$, Low Mass: $55.00-$ 200.0 m/z, Collision Energy: 0.0 eV, Collision RF: 300.0 Vpp, Transfer Time: 77.0 - 77.6 $\mu$ s, Pre Pulse Storage: $1.0 \mu \mathrm{s})$.

Additional experiments were performed with an HCT quadrupole-ion trap mass spectrometer (Bruker Daltonik, Bremen), ${ }^{[7 a, 92 k]}$ and afforded ESI mass spectra, which were similar to those obtained with the micrOTOF-Q II instrument, but suffered from a lower mass resolution. Sample solutions were injected into the ESI source at a flow rate of $0.3 \mathrm{~mL} \mathrm{~h}^{-1}$. An ESI voltage of $\pm 3.0 \mathrm{kV}$ with an end plate offset of $-500 \mathrm{~V}$ was applied. Nitrogen was used as nebulizer gas and drying gas with the same settings as those employed for the micrOTOF-Q II spectrometer. The ESI source and the quadrupole ion trap were connected by an ion-transport and focusing section consisting of a capillary, a skimmer, two transfer octopoles, and two lenses (Capillary Exit: \pm 20 V, Skimmer: \pm 20.0 V, Oct. 1 DC: $\pm 4.00 \mathrm{~V}$, Oct. 2 DC: $\pm 1.70 \mathrm{~V}$, Oct. RF: $152.8 \mathrm{Vpp}$, Lens $1: \pm 5.0 \mathrm{~V}$, Lens $2: \pm 60.0 \mathrm{~V}$ ). The quadrupole-ion trap itself was operated at a trap drive level of 40 . This instrument was also employed for monitoring the temporal evolution of the observed intermediates in trifluoromethylation reactions (using the alternating polarity mode).

Mass spectra were recorded for an $\mathrm{m} / \mathrm{z}$ range of $50-1000$ (for sample solutions that contained gold, $\mathrm{m} / \mathrm{z}$ ranges of $50-1200$ or $50-1500$ were chosen). In gas-phase fragmentation experiments, ions of interest were mass-selected with isolation widths between 1.0 and $8.0 \mathrm{u}$. They were then accelerated to kinetic energies $E_{\mathrm{LAB}}$ and allowed to collide with nitrogen gas present in the collision cell of the time-of-flight instrument, or subjected to excitation voltages of $V_{\mathrm{EXC}}$ and allowed to collide with helium gas present in the ion trap

Both mass spectrometers were externally calibrated with a mixture of $\mathrm{CF}_{3} \mathrm{COOH}$ and phosphazenes in $\mathrm{H}_{2} \mathrm{O} / \mathrm{CH}_{3} \mathrm{CN}$. Usually, accuracies better than $\pm 0.01 \mathrm{~m} / \mathrm{z}$ (time-of-flight instrument) and $\pm 0.3 \mathrm{~m} / \mathrm{z}$ (quadrupole-ion trap instrument) were achieved within the mass range of $50-1000 \mathrm{~m} / \mathrm{z}$. All given assignments are based on the measured exact $m / z$ ratios, the isotope patterns, and the results of the gas-phase fragmentation experiments. For the calculation of theoretical $\mathrm{m} / \mathrm{z}$ ratios and isotope patterns, the Bruker DataAnalysis software package was used.

After each experiment, the inlet line and ESI source were cleaned with $\mathrm{CH}_{3} \mathrm{OH}$ and, if necessary, a mixture of $\mathrm{CH}_{3} \mathrm{COOH}$ and $\mathrm{CH}_{3} \mathrm{OH}$ in $\mathrm{H}_{2} \mathrm{O}$ to remove material accumulated during the spraying of the relatively concentrated sample solutions and to avoid cross contaminations. To remove the protic solvents, the inlet line was repeatedly flushed with dry THF while the drying gas fed into the ESI source was heated to $290^{\circ}$ for $\geq 1 \mathrm{~h}$. As these routine measures did not completely remove all residual traces of $\mathrm{CH}_{3} \mathrm{OH}$, the process of flushing with dry THF and heating of the ESI source was extended to approximately $72 \mathrm{~h}$ for control experiments. These extra efforts proved effective in achieving methanol-free conditions. 
CSI-mass spectrometric experiments were performed in a similar manner with a commercial CSI source (Bruker Daltonik). Both the nebulizer and dry gas were cooled to $-40^{\circ} \mathrm{C}$ in these experiments. Pressurized sample injection ${ }^{[139]}$ was used to transfer the diluted sample solution $\left(-78^{\circ} \mathrm{C}\right)$ from a Schlenk flask into a home-built ESI inlet system that was thermally isolated and cooled to $-45^{\circ} \mathrm{C}$. This procedure ensured that the sample solution did not warm up to room temperature during the experiment. 


\section{$7 \quad$ References and Notes}

[1] R. Boettger Liebigs Ann. Chem. 1859, 109, 351-362.

[2] R. Reich, Seances Acad. Sci. 1923, 177, 322-324.

[3] H. Gilman, R. G. Jones, L. A. Woods, J. Org. Chem. 1952, 17, 1630-1634.

[4] a) J.-P. Gorlier, L. Hamon, J. Levisalles, J. Wagnon, J. Chem. Soc., Chem. Commun. 1973, 88a88a; b) K. Koosha, J. Berlan, M.-L. Capmau, W. Chodkiewicz, Bull. Soc. Chim. Fr. 1975, 12841290; c) R.-D. Acker, Tetrahedron Lett. 1977, 18, 3407-3410; d) P. Four, H. Riviere, P. Wah Tang, Tetrahedron Lett. 1977, 18, 3879-3882; e) B. H. Lipshutz, R. S. Wilhelm, D. M. Floyd, J. Am. Chem. Soc. 1981, 103, 7672-7674; f) B. H. Lipshutz, J. Kozlowski, R. S. Wilhelm, J. Am. Chem. Soc. 1982, 104, 2305-2307; g) B. H. Lipshutz, R. S. Wilhelm, J. Kozlowski, Tetrahedron Lett. 1982, 23, 3755-3758; h) B. H. Lipshutz, R. S. Wilhelm, J. Am. Chem. Soc. 1982, 104, 4696-4698.

[5] J. F. Normant, Pure \& Appl. Chem. 1978, 50, 709-715.

[6] a) P. Knochel, M. C. P. Yeh, S. C. Berk, J. Talbert, J. Org. Chem. 1988, 53, 2390-2392; b) P. Knochel, R. D. Singer, Chem. Rev. 1993, 93, 2117-2188.

[7] a) E. Krause, B. Wendt, Ber. Dtsch. Chem. Ges. 1923, 56, 2064-2066; b) H. Westmijze, H. Kleijn, P. Vermeer, J. Organomet. Chem. 1979, 172, 377-383; c) D. E. Bergbreiter, T. J. Lynch, J. Org. Chem. 1981, 46, 727-733; d) H. Kleijn, H. Westmijze, J. Meijer, P. Vermeer, J. Organomet. Chem. 1981, 206, 257-264; e) R. Usón, A. Laguna, J. A. Abad, J. Organomet. Chem. 1983, 246, 341-345; f) C. Eaborn, P. B. Hitchcock, J. D. Smith, A. C. Sullivan, J. Chem. Soc., Chem. Commun. 1984, 870-871; g) M. Y. Chiang, E. Böhlen, R. Bau, J. Am. Chem. Soc. $1985,107,1679-1681$.

[8] a) A. Tamaki, J. K. Kochi, J. Organomet. Chem. 1973, 51, C39-C42; b) A. Tamaki, J. K. Kochi, J. Chem. Soc., Dalton Trans. 1973, 23, 2620-2626; c) G. W. Rice, R. S. Tobias, Inorg. Chem. 1975, 14, 2402-2407; d) G. W. Rice, R. S. Tobias, Inorg. Chem. 1976, 15, 489-490; e) R. Usón, A. Laguna, J. Vicente, J. Organomet. Chem. 1977, 131, 471-475; f) S. Komiya, I. Endo, S. Ozaki, Y. Ishizaki, Chem. Lett. 1988, 17, 63-66; g) S. Komiya, S. Ochiai, Y. Ishizaki, Inorg. Chem. 1992, 31, 3168-3169; h) S. Komiya, S. Ozaki, I. Endo, K. Inoue, N. Kasuga, Y. Ishizaki, J. Organomet. Chem. 1992, 433, 337-351; i) R. V. Parish, Gold. Bull. 1997, 30, 3-12.

[9] a) G. G. Dubinina, J. Ogikubo, D. A. Vicic, Organometallics 2008, 27, 6233-6235; b) C. Tresse, C. Guissart, S. Schweizer, Y. Bouhoute, A.-C. Chany, M.-L. Goddard, N. Blanchard, G. Evano, Adv. Synth. Catal. 2014, 356, 2051-2060; c) A. M. Romine, N. Nebra, A. I. Konovalov, E. Martin, J. Benet-Buchholz, V. V. Grushin, Angew. Chem. 2015, 127, 2783-2787; Angew. Chem. Int. Ed. 2015, 54, 2745-2749.

[10] a) S. Martínez de Salinas, Á L. Mudarra, J. Benet-Buchholz, T. Parella, F. Maseras, M. H. PérezTemprano, Chem. Eur. J. 2018, 24, 11895-11898; b) D. Joven-Sancho, M. Baya, A. Martín, B. Menjón, Chem. Eur. J. 2018, 24, 13098-13101.

[11] S. Martínez-Salvador, L. R. Falvello, A. Martín, B. Menjón, Chem. Eur. J. 2013, 19, 1454014552. 
[12] a) D. J. Adams, J. H. Clark, L. B. Hansen, V. C. Sanders, S. J. Tavener, J. Fluorine Chem. 1998, 92, 123-125; b) N. Maggiarosa, W. Tyrra, D. Naumann, N. V. Kirij, Y. L. Yagupolskii, Angew. Chem. 1999, 111, 2392-2393; Angew. Chem. Int. Ed. 1999, 38, 2252-2253; c) X. Liu, C. Xu, M. Wang, Q. Liu, Chem. Rev. 2015, 115, 683-730;

[13] a) Modern Organocopper Chemistry, Ed.: N. Krause, Wiley-VCH, Weinheim; b) The Chemistry of Organocopper Compounds, Eds.: Z. Rappoport, I. Marek, Wiley, Hoboken, 2009.

[14] M. S. Kharasch, P. O. Tawney, J. Am. Chem. Soc. 1941, 63, 2308-2316.

[15] E. J. Corey, G. H. Posner, J. Am. Chem. Soc. 1967, 89, 3911-3912.

[16] H. O. House, W. L. Respess, G. M. Whitesides, J. Org. Chem. 1966, 31, 3128-3141.

[17] G. M. Whitesides, W. F Fisher, J. San Filippo, R. W. Bashe, H. O. House, J. Am. Chem. Soc. 1969, 91, 4871-4882.

[18] G. H. Posner, C. E. Whitten, J. J. Sterling, J. Am. Chem. Soc. 1973, 95, 7788-7800.

[19] a) B. H. Lipshutz, R. S. Wilhelm, J. A. Kozlowski, Tetrahedron, 1984, 40, 5005-5038; b) B. H. Lipshutz, Synthesis, 1987, 325-341.

[20] N. Krause, A. Gerold, Angew. Chem. 1997, 109, 194-213; Angew. Chem. Int. Ed. Engl. 1997, 36, 186-204.

[21] a) D. Polet, A. Alexakis in The Chemistry of Organocopper Compounds, Eds.: Z. Rappoport, I. Marek, Wiley, Hoboken, 2009, pp. 693-730; b) N. Krause, Ö. Aksin-Artok in The Chemistry of Organocopper Compounds, Eds.: Z. Rappoport, I. Marek, Wiley, Hoboken, 2009, pp. 857-879.

[22] C. Spino in The Chemistry of Organocopper Compounds, Eds.: Z. Rappoport, I. Marek, Wiley, Hoboken, 2009, pp. 603-691.

[23] F. Chemla, F. Ferreira, in The Chemistry of Organocopper Compounds, Eds.: Z. Rappoport, I. Marek, Wiley, Hoboken, 2009, pp. 527-584.

[24] a) P. Jeschke, ChemBioChem 2004, 5, 570-589; b) P. Shah, A. D. Westwell, J. of Enzym. Inhib. Med. Chem. 2007, 22, 527-540; c) K. Müller, C. Faeh, F. Diederich, Science 2007, 317, 1881 1886; d) S. Purser, P. R. Moore, S. Swallow, V. Gouverneur, Chem. Soc. Rev. 2008, 37, 320 330; f) W. K. Hagmann, J. Med. Chem. 2008, 51, 4359-4369; g) J. Wang, M. Sánchez-Roselló, J. L. Aceña, C. del Pozo, A. E. Sorochinsky, S. Fustero, V. A. Soloshonok, H. Liu, Chem. Rev. 2014, 114, 2432-2506; h) Y. Zhou, J. Wang, Z. Gu, S. Wang, W. Zhu, J. L. Aceña, V. A. Soloshonok, K. Izawa, H. Liu, Chem. Rev. 2016, 116, 422-518.

[25] The introduction of a trifluoromethyl group offers the possibility to change the physicochemical properties of a given substance, for example, its basicity, lipophilicity, and metabolic stability, and, thus, to enhance its physiological availability. Consequently, trifluoromethylation reactions have recently attracted significant interest: a) S. Roy, B. T. Gregg, G. W. Gribble, V.-D. Le, S. Roy, Tetrahedron 2011, 67, 2161-2195; b) T. Furuya, A. S. Kamlet, T. Ritter, Nature 2011, 473, 470-477; c) O. A. Tomashenko, V. V. Grushin, Chem. Rev. 2011, 111, 4475-4521; d) G. K. S. Prakash, P. V. Jog, P. T. D. Batamack, G. A. Olah, Science 2012, 338, 1324-1327; e) C. Alonso, E. Martínez de Marigorta, G. Rubiales, F. Palacios, Chem. Rev. 2015, 115, 1847-1935; f) T. Besset, T. Poisson, X. Pannecoucke, Eur. J. Org. Chem. 2015, 
2015, 2765-2789; g) P. Gao, X.-R. Song, X.-Y. Liu, Y.-M. Liang, Chem. Eur. J. 2015, 21, 76487661.

[26] a) L. Chu, F.-L. Qing, Acc. Chem. Res. 2014, 47, 1513-1522; b) X. Liu, C. Xu, M. Wang, Q. Liu, Chem. Rev. 2015, 115, 683-730.

[27] a) I. Ruppert, K. Schlich, W. Volbach, Tetrahedron Lett. 1984, 25, 2195-2198; b) G. K. S. Prakash, R. Krishnamurti, G. A. Olah, J. Am. Chem. Soc. 1989, 111, 393-395.

[28] a) V. V. Grushin, W. J. Marshall, J. Am. Chem. Soc. 2006, 128, 4632-4641; b) V. V. Grushin, W. J. Marshall, J. Am. Chem. Soc. 2006, 128, 12644-12645; c) G. G. Dubinina, H. Furutachi, D. A. Vicic, J. Am. Chem. Soc. 2008, 130, 8600-8601; d) N. D. Ball, J. W. Kampf, M. S. Sanford, J. Am. Chem. Soc. 2010, 132, 2878-2879, e) L. Chu, F.-L. Qing, Org. Lett. 2010, 12, 5060-5063; f) T. D. Senecal, A. T. Parsons, S. L. Buchwald, J. Org. Chem. 2011, 76, 1174-1176; g) H. Morimoto, T. Tsubogo, N. D. Litvinas, J. F. Hartwig, Angew. Chem. 2011, 123, 3877-3882; Angew. Chem. Int. Ed. 2011, 50, 3793-3798; h) Z. Weng, R. Lee, W. Jia, Y. Yuan, W. Wang, X. Feng, K.-W. Huang, Organometallics 2011, 30, 3229-3232; i) O. A. Tomashenko, E. C. Escudero-Adán, M. Martínez Belmonte, V. V. Grushin, Angew. Chem. 2011, 123, 7797-7801; Angew. Chem. Int. Ed. 2011, 50, 7655-7659; j) Y. Ye, S. H. Lee, M. S. Sanford, Org. Lett. 2011, 13, 5464-5467; k) X. Jiang, L. Chu, F.-L. Qing, J. Org. Chem. 2012, 77, 1251-1257; I) Y. Ye, M. S. Sanford, Synlett 2012, 23, 2005-2013; m) X. Wu, L. Chu, F.-L. Qing, Tetrahedron Lett. 2013, 54, 249-251; n) X. Wang, Y. Xu, F. Mo, G. Ji, D. Qiu, J. Feng, Y. Ye, S. Zhang, Y. Zhang, J. Wang, J. Am. Chem. Soc. 2013, 135, 10330-10333; o) G. Danoun, B. Bayarmagnai, M. F. Grünberg, L. J. Gooßen, Angew. Chem. 2013, 125, 8130-8133; Angew. Chem. Int. Ed. 2013, 52, 7972-7975; p) H. Wang, D. Vicic, Synlett 2013, 24, 1887-1898.

[29] a) F. Cottet, M. Schlosser, Eur. J. Org. Chem. 2002, 327-330; b) L. Chu, F.-L. Qing, J. Am. Chem. Soc. 2012, 134, 1298-1304.

[30] a) A. Hafner, S. Bräse, Adv. Synth. Catal. 2011, 353, 3044-3048; b) L. Chu, F.-L. Qing, Org. Lett. 2012, 14, 2106-2109; c) X. Wu, L. Chu, F.-L. Qing, Angew. Chem. 2013, 125, 2254-2258; Angew. Chem. Int. Ed. 2013, 52, 2198-2202; d) Z. Mao, F. Huang, H. Yu, J. Chen, Z. Yu, Z. Xu, Chem. Eur. J. 2014, 20, 3439-3445.

[31] a) L. Chu, F.-L. Qing, J. Am. Chem. Soc. 2010, 132, 7262-7263; b) K. Zhang, X.-L. Qiu, Y. Huang, F.-L. Qing, Eur. J. Org. Chem. 2012, 58-61.

[32] a) J. H. Gardner, P. Borgstrom, J. Am. Chem. Soc. 1929, 51, 3375-3377; b) J. H. Gardner, L. Joseph, F. Gollub, J. Am. Chem. Soc. 1937, 59, 2583-2584; c) J. H. Gardner, L. Joseph, J. Am. Chem. Soc. 1939, 61, 2551-2552; e) L. Joseph, J. H. Gardner, J. Org. Chem. 1940, 5, 61-67; f) E. A. Bickley, J. H. Gardner, J. Org. Chem. 1940, 5, 126-132; g) J. H. Gardner, C. J. Snyder, J. Am. Chem. Soc. 1940, 62, 2879-2880.

[33] a) M. Tamura, J. Kochi, Synthesis 1971, 1971, 303-305; b) J. K. Kochi, M. Tamura, J. Am. Chem. Soc. 1971, 93, 1483-1485.

[34] a) H. Westmijze, H. Kleijn, P. Vermeer, Tetrahedron Lett. 1979, 20, 3327-3328; b) H. Westmijze, H. Kleijn, P. Vermeer, J. Organomet. Chem. 1979, 172, 377-383; c) H. Westmijze, H. Kleijn, H. J. T. Bos, P. Vermeer, J. Organomet. Chem. 1980, 199, 293-297; d) H. Westmijze, H. Kleijn, P. Vermeer, L. A. van Dijck, Tetrahedron Lett. 1980, 21, 2665-2666; e) H. Westmijze, 
K. Ruitenberg, J. Meijer, P. Vermeer, Tetrahedron Lett. 1980, 21, 1771-1772; f) H. Westmijze, P. Vermeer, Tetrahedron Lett. 1980, 21, 1789-1790; g) H. Kleijn, H. Westmije, J. Meijer, P. Vermeer, J. Organomet. Chem. 1980, 192, 275-281; h) J. Meijer, K. Ruitenberg, H. Westmijze, P. Vermeer, Synthesis 1981, 1981, 551-554; i) H. Kleijn, H. Westmijze, J. Meijer, P. Vermeer, J. Organom. Chem. 1981, 206, 257-264; j) M. Tigchelaar, J. Meijer, H. Kleijn, H. J. T. Bos, P. Vermeer, J. Organom. Chem. 1981, 221, 117-121; k) E. A. Oostveen, C. J. Elsevier, J. Meijer, P. Vermeer, J. Org. Chem. 1982, 47, 371-373; i) H. Westmijze, H. Kleijn, P. Vermeer, J. Organom. Chem. 1982, 234, 117-122.

[35] a) A. Tamaki, J. K. Kochi, J. Organomet. Chem. 1973, 51, C39-C42; b) A. Tamaki, J. K. Kochi, J. Chem. Soc., Dalton Trans. 1973, 2620-2626.

[36] A. Tamaki, S. A. Magennis, J. K. Kochi, J. Am. Chem. Soc. 1974, 96, 6140-6148.

[37] a) J.-M. Weibel, A. Blanc, P. Pale, Chem. Rev. 2008, 108, 3149-3173; b) Silver in Organic Chemistry, Ed.: M. Harmata, John Wiley \& Sons, Hoboken, 2010; c) J. Cossy in Grignard Reagents and Transition Metal Catalysts, Formation of C-C Bonds by Cross-Coupling, Ed.: J. Cossy, De Gruyter, Berlin/Boston, 2016, pp. 269-280; d) K. Murakami, K. Hirano, H. Yorimitsu, K. Oshima, Angew. Chem. 2008, 120, 5917-5919; Angew. Chem. Int. Ed. 2008, 47, 5833 5835; e) N. Kambe, Y. Moriwaki, Y. Fujii, T. Iwasaki, J. Terao, Org. Lett. 2011, 13, 4656-4659.

[38] R. V. Parish, Gold Bull. 1998, 31, 14-21;

[39] a) J. K. Kochi, J. Organomet. Chem. 2002, 653, 11-19; b) W. Nakanishi, M. Yamanaka, E. Nakamura, J. Am. Chem. Soc. 2005, 127, 1446-1453.

[40] a) A. S. K. Hashmi, Chem. Rev. 2007, 107, 3180-3211; b) K. Murakami, K. Hirano, H. Yorimitsu, K. Oshima, Angew. Chem. 2008, 120, 5917-5919; Angew. Chem. Int. Ed. 2008, 47, 58335835; c) B. H. Lipshutz, Y. Yamamoto, Chem. Rev. 2008, 108, 2793-2795; d) M. Joost, A. Amgoune, D. Bourissou, Angew. Chem. 2015, 127, 15234-15258; Angew. Chem. Int. Ed. 2015, 54, 15022-15045; e) H. Pellissier, Chem. Rev. 2016, 116, 14868-14917; f) J. Rodriguez, D. Bourissou, Angew. Chem. 2018, 130, 392-394; Angew. Chem. Int. Ed. 2018, 57, 386-388.

[41] R. P. Davies, Coord. Chem. Rev. 2011, 255, 1226-1251.

[42] a) H. Hope, M. M. Olmstead, P. P. Power, J. Sandell, X. Xu, J. Am. Chem. Soc. 1985, 107, 43374338; b) D. F. Dempsey, G. S. Girolami, Organometallics 1988, 7, 1208-1213; c) M. John, C. Auel, C. Behrens, M. Marsch, K. Harms, F. Bosold, R. M. Gschwind, P. R. Rajamohanan, G. Boche, Chem. Eur. J. 2000, 6, 3060-3068.

[43] C. Eaborn, P. B. Hitchcock, J. D. Smith, A. C. Sullivan, J. Organomet. Chem. 1984, 263, C23C25.

[44] H. Hope, D. Oram, P. P. Power, J. Am. Chem. Soc. 1984, 106, 1149-1150.

[45] S. I. Khan, P. G. Edwards, H. S. H. Yuan, R. Bau, J. Am. Chem. Soc. 1985, 107, 1682-1684.

[46] P. G. Edwards, R. W. Gellert, M. W. Marks, R. Bau, J. Am. Chem. Soc. 1982, 104, 2072-2073.

[47] M. Håkansson, H. Eriksson, A. Berglund Åhman, S. Jagner, J. Organomet. Chem. 2000, 595, 102-108.

[48] D. Joven-Sancho, M. Baya, A. Martín, B. Menjón, Chem. Eur. J. 2018, 24, 13098-13101. 
[49] W. E. Tyrra, J. Fluorine Chem. 2001, 112, 149-152.

[50] S. Aboulkacem, W. Tyrra, I. Pantenburg, J. Chem. Crystallogr 2006, 36, 141-145.

[51] R. R. Burch, J. C. Calabrese, J. Am. Chem. Soc. 1986, 108, 5359-5360.

[52] a) D. Zopes, S. Kremer, H. Scherer, L. Belkoura, I. Pantenburg, W. Tyrra, S. Mathur, Eur. J. Inorg. Chem. 2011, 273-280; b) S. Martínez-Salvador, L. R. Falvello, A. Martín, B. Menjón, Chem. Eur. J. 2013, 19, 14540-14552.

[53] a) R. Usón, A. Laguna, J. Vicente, J. Garcia, P. G. Jones, G. M. Sheldrick, J. Chem. Soc., Dalton Trans. 1981, 655-657; b) P. G. Jones, Z. Kristallogr. 1993, 208, 347-350.

[54] M. Blaya, D. Bautista, J. Gil-Rubio, J. Vicente, Organometallics 2014, 33, 6358-6368.

[55] C. Eaborn, P. B. Hitchcock, J. D. Smith, A. C. Sullivan, J. Chem. Soc., Chem. Commun. 1984, 870-871.

[56] L. Pak, B. Zibrowius, M.-W. Lumeij, R. Dronskowski, U. Ruschewitz, Z. Anorg. Allg. Chem. 2014, 640, 3127-3134.

[57] D. Zhu, S. V. Lindeman, J. K. Kochi, Organometallics 1999, 18, 2241-2248.

[58] M. Y. Chiang, E. Böhlen, R. Bau, J. Am. Chem. Soc. 1985, 107, 1679-1681.

[59] D. Naumann, T. Roy, K.-F. Tebbe, W. Crump, Angew. Chem. 1993, 105, 1555-1556; Angew. Chem. Int. Ed. Engl. 1993, 32, 1482-1483.

[60] a) W. Dukat, D. Naumann, Rev. Chim. Miner. 1986, 23, 589; b) U. Geiser, J. A. Schlueter, J. M. Williams, D. Naumann, T. Roy, Acta Crystallogr. Sect. B: Struct. Sci. 1995, B51, 789-797.

[61] S. Martínez-Salvador, L. R. Falvello, A. Martín, B. Menjón, Chem. Eur. J. 2013, 19, 1454014552.

[62] R. Eujen, B. Hoge, D. J. Brauer, J. Organomet. Chem. 1996, 519, 7-20.

[63] R. Eujen, B. Hoge, D. J. Brauer, Inorg. Chem. 1997, 36, 3160-3166.

[64] R. Eujen, B. Hoge, D. J. Brauer, Inorg. Chem. 1997, 36, 1464-1475.

[65] A. Pérez-Bitrián, S. Martínez-Salvador, M. Baya, J. M. Casas, A. Martín, B. Menjón, J. Orduna, Chem. Eur. J. 2017, 23, 6919-6929.

[66] a) H. H. Murray, J. P. Fackler, L. C. Porter, D. A. Briggs, M. A. Guerra, R. J. Lagow, Inorg. Chem. 1987, 26, 357-363; b) P.G. Jones, E. Bembenek, Z. Kristallogr. 1994, 209, 690-692; c) J. Coetzee, W. F. Gabrielli, K. Coetzee, O. Schuster, S. D. Nogai, S. Cronje, H. G. Raubenheimer, Angew. Chem. 2007, 119, 2549-2552; Angew. Chem. Int. Ed. 2007, 46, 2497-2500.

[67] J. A. Schlueter, U. Geiser, H. H. Wang, M. L. VanZile, S. B. Fox, J. M. Williams, A. Laguna, M. Laguna, D. Naumann, T. Roy, Inorg. Chem. 1997, 36, 4265-4269.

[68] A. J. Markwell, J. Organomet. Chem. 1985, 293, 257-263.

[69] R. M. Gschwind, Chem. Rev. 2008, 108, 3029-3053. 
[70] a) S. H. Bertz, J. Am. Chem. Soc. 1990, 112, 4031-4032; b) J. P. Snyder, S. H. Bertz, J. Org. Chem. 1995, 60, 4312-4313. (c) S. H. Bertz, G. Miao, M. Eriksson, Chem. Commun. 1996, 815816.

[71] a) T. Stemmler, J. E. Penner-Hahn, P. Knochel, J. Am. Chem. Soc. 1993, 115, 348-350; b) J. P. Snyder, D. P. Spangler, J. R. Behling, J. Org. Chem. 1994, 59, 2665-2667; c) T. M. Barnhart, H. Huang, J. E. Penner-Hahn, J. Org. Chem. 1995, 60, 4310-4311; d) T. L. Stemmler, T. M. Barnhart, J. E. Penner-Hahn, C. E. Tucker, P. Knochel, M. Böhme, G. Frenking, J. Am. Chem. Soc. 1995, 117, 12489-12497; e) T. A. Mobley, F. Müller, S. Berger, J. Am. Chem. Soc. 1998, $120,1333-1334$.

[72] N. Krause, Angew. Chem. 1999, 111, 83-85; Angew. Chem. Int. Ed. 1999, 38, 79-81.

[73] a) R. M. Gschwind, P. R. Rajamohanan, M. John, G. Boche, Organometallics 2000, 19, 28682873; b) M. John, C. Auel, C. Behrens, M. Marsch, K. Harms, F. Bosold, R. M. Gschwind, P. R. Rajamohanan, G. Boche, Chem. Eur. J. 2000, 6, 3060-3068; c) R. M. Gschwind, X. Xie, P. R. Rajamohanan, C. Auel, G. Boche, J. Am. Chem. Soc. 2001, 123, 7299-7304.

[74] a) A. Putau, K. Koszinowski, Organometallics 2010, 29, 3593-3601; addition/correction: A. Putau, K. Koszinowski, Organometallics 2010, 29, 6841-6842; b) A. Putau, K. Koszinowski, Organometallics 2011, 30, 4771-4778; c) A. Putau, M. Wilken, K. Koszinowski, Chem. Eur. J. 2013, 19, 10992-10999.

[75] F. A. Cotton, G. Wilkinson, Advanced Inorganic Chemistry, Wiley, New York, 1980, pp. 970972.

[76] D. Naumann, W. Wessel, J. Hahn, W. Tyrra, J. Organomet. Chem. 1997, 547, 79-88.

[77] A. Tamaki, J. K. Kochi, J. Organomet. Chem. 1973, 51, C39-C42.

[78] A. Tamaki, J. K. Kochi, J. Chem. Soc., Dalton Trans. 1973, 2620-2626.

[79] G. W. Rice, R. S. Tobias, Inorg. Chem. 1975, 14, 2402-2407.

[80] a) R. Usón, A. Laguna, J. Vicente, J. Chem. Soc., Chem. Commun. 1976, 353-354; b) R. Usón, A. Laguna, J. Vicente, J. Organomet. Chem. 1977, 131, 471-475; c) R. Usón, A. Laguna, J. Garcia, M. Laguna, Inorg. Chim. Ac. 1979, 37, 201-207.

[81] a) R. Eujen, B. Hoge, D. J. Brauer, Inorg./ Chem. 1997, 36, 1464-1475; b) R. Eujen, B. Hoge, D. J. Brauer, Inorg. Chem. 1997, 36, 3160-3166; c) R. Eujen, B. Hoge, Magn. Reson. Chem. 1997, $35,707-711$.

[82] a) E. Nakamura, S. Mori, Angew. Chem., 2000, 112, 3902-3924; Angew. Chem. Int. Ed. 2000, 39, 3750-3771; b) N. Yoshikai, E. Nakamura, Chem. Rev. 2012, 112, 2339-2372.

[83] a) E. Nakamura, S. Mori, K. Morokuma, J. Am. Chem. Soc. 1997, 119, 4900-4910; b) S. Mori, E. Nakamura, Chem. Eur. J. 1999, 5, 1534-1543; c) E. Nakamura, M. Yamanaka, J. Am. Chem. Soc. 1999, 121, 8941-8942.

[84] a) S. H. Bertz, S. Cope, M. Murphy, C. A. Ogle, B. J. Taylor, J. Am. Chem. Soc. 2007, 129, 72087209; b) S. H. Bertz, S. Cope, D. Dorton, M. Murphy, C. A. Ogle, Angew. Chem. 2007, 119, 7212-7215; Angew. Chem. Int. Ed. 2007, 46, 7082-7085; c) E. R. Bartholomew, S. H. Bertz, S. Cope, D. C. Dorton, M. Murphy, C. A. Ogle, Chem. Commun. 2008, 1176-1177; d) E. R. 
Bartholomew, S. H. Bertz, S. Cope, M. Murphy, C. A. Ogle, J. Am. Chem. Soc. 2008, 130, 11244-11245; e) E. R. Bartholomew, S. H. Bertz, S. K. Cope, M. D. Murphy, C. A. Ogle, A. A. Thomas, Chem. Commun. 2010, 46, 1253-1254; f) S. H. Bertz, M. D. Murphy, C. A. Ogle, A. A. Thomas, Chem. Commun. 2010, 46, 1255-1256; g) S. H. Bertz, Y. Moazami, M. D. Murphy, C. A. Ogle, J. D. Richter, A. A. Thomas, J. Am. Chem. Soc. 2010, 132, 9549-9551.

[85] a) T. Gärtner, W. Henze, R. M. Gschwind, J. Am. Chem. Soc. 2007, 129, 11362-11363; b) W. Henze, T. Gärtner, R. M. Gschwind, J. Am. Chem. Soc. 2008, 130, 13718-13726; c) T. Gärtner, N. Yoshikai, M. Neumeier, E. Nakamura, R. M. Gschwind, Chem. Commun. 2010, 46, 46254626.

[86] a) A. Putau, H. Brand, K. Koszinowski, J. Am. Chem. Soc. 2012, 134, 613-622; b) N. J. Rijs, N. Yoshikai, E. Nakamura, R. A. J. O'Hair, J. Am. Chem. Soc. 2012, 134, 2569-2580; c) N. J. Rijs, N. Yoshikai, E. Nakamura, R. A. J. O'Hair, J. Org. Chem. 2014, 79, 1320-1334.

[87] a) N. Krause, A. Gerold, Angew. Chem. 1997, 109, 194-213; Angew. Chem. Int. Ed. Engl. 1997, 36, 186-204; b) N. Krause, Angew. Chem. 1998, 110, 295-297; Angew. Chem. Int. Ed. 1998, $37,283-285$.

[88] M. Yamanaka, E. Nakamura, Organometallics 2001, 20, 5675-5681.

[89] J. K. Kochi, Acc. Chem. Res. 1974, 7, 351-360.

[90] S. Weske, R. A. Hardin, T. Auth, R. A. J. O'Hair, K. Koszinowski, C. A. Ogle, Chem. Commun. 2018, 54, 5086-5089.

[91] a) B. H. Lipshutz, K. L. Stevens, B. James, J. G. Pavlovich, J. P. Snyder, J. Am. Chem. Soc. 1996, 118, 6796-6797; b) B. H. Lipshutz, J. Keith, D. J. Buzard, Organometallics 1999, 18, 15711574.

[92] a) P. F. James, R. A. J. O'Hair, Org. Lett. 2004, 6, 2761-2764; b) L. S. Santos, G. B. Rosso, R. A. Pilli, M. N. Eberlin, J. Org. Chem. 2007, 72, 5809-5812; c) N. Rijs, G. N. Khairallah, T. Waters, R. A. J. O'Hair, J. Am. Chem. Soc. 2008, 130, 1069-1079; d) N. J. Rijs, B. F. Yates, R. A. J. O'Hair, Chem. Eur. J. 2010, 16, 2674-2678; e) K. Koszinowski, J. Am. Chem. Soc. 2010, 132, 60326040; f) N. J. Rijs, R. A. J. O'Hair, Organometallics 2010, 29, 2282-2291; g) M. A. Schade, J. E. Fleckenstein, P. Knochel, K. Koszinowski, J. Org. Chem. 2010, 75, 6848-6857; h) D. Agrawal, D. Schröder, C. M. Frech, Organometallics 2011, 30, 3579-3587; i) J. E. Fleckenstein, K. Koszinowski, Organometallics 2011, 30, 5018-5026; j) A. Tsybizova, D. Schröder, J. Roithová, A. Henke, J. Šrogl, J. Phys. Org. Chem. 2014, 27, 198-203; k) A. Škríba, J. Schulz, J. Roithová, Organometallics 2014, 33, 6868-6878; I) N. V. Orlov, I. V. Chistyakov, L. L. Khemchyan, V. P. Ananikov, I. P. Beletskaya, Z. A. Starikova, J. Org. Chem. 2014, 79, 12111-12121; m) A. Tsybizova, J. Roithová, Mass Spectrom. Rev. 2016, 35, 85-110; n) C. Schnegelsberg, S. Bachmann, M. Kolter, T. Auth, M. John, D. Stalke, K. Koszinowski, Chem. Eur. J. 2016, 22, 7752-7762; о) T. Parchomyk, K. Koszinowski, Chem. Eur. J. 2016, 22, 15609-15613; p) T. Parchomyk, K. Koszinowski, Chem. Eur. J. 2017, 23, 3213-3219; q) M. Kolter, K. Böck, K. Karaghiosoff, K. Koszinowski, Angew. Chem. 2017, 129, 13427-13431; Angew. Chem. Int. Ed. 2017, 56, 13244-13248; r) F. Kreyenschmidt, K. Koszinowski, Chem. Eur. J. 2018, 24, 1168-1177; s) T. Parchomyk, S. Demeshko, F. Meyer, K. Koszinowski, J. Am. Chem. Soc. 2018, 140, 9709-9720; t) T. Parchomyk, K. Koszinowski, Chem. Eur. J. 2018, 24, 16342-16347. 
[93] a) P. Chen, Angew. Chem. 2003, 115, 2938-2954; Angew. Chem. Int. Ed. 2003, 42, 28322847; b) L. S. Santos, Eur. J. Org. Chem. 2008, 2008, 235-253; c) C. A. Müller, C. Markert, A. M. Teichert, A. Pfaltz, Chem. Commun. 2009, 1607-1618; d) D. Agrawal, D. Schröder, Organometallics 2011, 30, 32-35; e) F. Coelho, M. N. Eberlin, Angew. Chem. 2011, 123, 53705372; Angew. Chem. Int. Ed. 2011, 50, 5261-5263; e) N. J. Rijs, R. A. J. O'Hair, Dalton Trans. 2012, 41, 3395-3406; f) D. Schröder, Acc. Chem. Res. 2012, 45, 1521-1532; g) L. P. E. Yunker, R. L. Stoddard, J. S. McIndoe, J. Mass Spectrom. 2014, 49, 1-8; h) K. L. Vikse, Z. Ahmadi, J. Scott McIndoe, Coord. Chem. Rev. 2014, 279, 96-114; i) R. A. J. O'Hair, N. J. Rijs, Acc. Chem. Res. 2015, 48, 329-340.

[94] a) C. Adlhart, P. Chen, Helv. Chim. Act. 2000, 83, 2192-2196.; b) K. L. Vikse, Z. Ahmadi, C. C. Manning, D. A. Harrington, J. S. Mclndoe, Angew. Chem. 2011, 123, 8454-8456; Angew. Chem. Int. Ed. 2011, 50, 8304-8306.

[95] a) J. V. Iribarne, B. A. Thomson, J. Chem. Phys. 1976, 64, 2287-2294, b) B. A. Thomson, J. V. Iribarne, J. Chem. Phys. 1979, 71, 4451-4463; c) a) A. Wortmann, A. Kistler-Momotova, R. Zenobi, M. C. Heine, O. Wilhelm, S. E. Pratsinis, J. Am. Soc. Mass Spectrom. 2007, 18, 385393;

[96] W. D. Luedtke, U. Landman, Y.-H. Chiu, D. J. Levandier, R. A. Dressler, S. Sok, M. S. Gordon, J. Phys. Chem. A 2008, 112, 9628-9649.

[97] N. B. Cech, C. G. Enke, Mass Spectrom. Rev. 2001, 20, 362-387.

[98] J. H. Gross, Mass Spectrometry, Springer, Berlin/Heidelberg, 2011.

[99] P. M. Mayer, C. Poon, Mass Spectrom. Rev. 2009, 28, 608-639.

[100] a) P. Kebarle, U. H. Verkerk, Mass Spectrom. Rev. 2009, 28, 898-917; b) L. Konermann, E. Ahadi, A. D. Rodriguez, S. Vahidi, Anal. Chem. 2013, 85, 2-9.

[101] a) M. Dole, L. L. Mack, R. L. Hines, R. C. Mobley, L. D. Ferguson, M. B. Alice, J. Chem. Phys. 1968, 49, 2240-2249; b) L. L. Mack, P. Kralik, A. Rheude, M. Dole, J. Chem. Phys. 1970, 52, 4977-4986.

[102] J. B. Fenn, Angew. Chem. 2003, 115, 3999-4024; Angew. Chem. Int. Ed. 2003, 42, 3871-3894.

[103] a) M. Yamashita, J. B. Fenn, J. Phys. Chem. 1984, 88, 4451-4459; b) M. Yamashita, J. B. Fenn, J. Phys. Chem. 1984, 88, 4671-4675.

[104] G. I. Taylor, Proc. R. Soc. Lond. A 1964, 280, 383-397.

[105] a) C. Weickhardt, F. Moritz, J. Grotemeyer, Mass Spectrom. Rev. 1996, 15, 139-162; b) U. Boesl, Mass Spectrom. Rev. 2017, 36, 86-109.

[106] W. Paul, H. Steinwedel, Z. für Naturforsch. A 1953, 8, 448-450.

[107] The Mathieu equations are a set of differential equations named after the French mathematician Émile Mathieu, who originally derived these equations to describe the vibration of elliptical membranes: É. Mathieu, J. Math. Pures Appl. 1868, 137-203.

[108] a) R. E. March, J. Mass Spectrom. 1997, 32, 351-369; b) R. A. J. O'Hair, Chem. Commun. 2006, 1469-1481; c) R. E. March, Mass Spectrom. Rev. 2009, 28, 961-989. 
[109] W. Paul, Angewandte Chemie 1990, 102, 780-789; Angew. Chem. Int. Ed. Engl. 1990, 29, 739-748.

[110] K. Koszinowski, F. Lissy, Int. J. Mass Spectrom. 2013, 354-355, 219-228.

[111] a) L. E. Gusel'nikov, Coord. Chem. Rev. 2003, 244, 149-240; b) V. G. Avakyan, S. L. Guselnikov, V. F. Sidorkin, E. P. Doronina, L. E. Gusel'nikov, Organometallics 2009, 28, 978-989.

[112] a) D. M. Knotter, W. J. J. Smeets, A. L. Spek, G. Van Koten, J. Am. Chem. Soc. 1990, 112, 58955896; b) D. M. Knotter, D. M. Grove, W. J. J. Smeets, A. L. Spek, G. Van Koten, J. Am. Chem. Soc. 1992, 114, 3400-3410.

[113] H. Eriksson, M. Håkansson, Organometallics 1997, 16, 4243-4244.

[114] R. Bomparola, R. P. Davies, S. Hornauer, A. J. P. White, Angew. Chem. 2008, 120, 5896-5899; Angew. Chem. Int. Ed. 2008, 47, 5812-5815.

[115] E. C. Ashby, A. B. Goel, J. Org. Chem. 1983, 48, 2125-2130.

[116] M. Kolter, K. Koszinowski, Chem. Eur. J. 2016, 22, 15744-15750.

[117] T. D. Bluemke, W. Clegg, P. García-Alvarez, A. R. Kennedy, K. Koszinowski, M. D. McCall, L. Russo, E. Hevia, Chem. Sci. 2014, 5, 3552-3562.

[118] a) A. D. Horton, Organometallics 1996, 15, 2675-2677; b) P. J. Chirik, N. F. Dalleska, L. M. Henling, J. E. Bercaw, Organometallics 2005, 24, 2789-2794; c) P. Yang, M. C. Baird, Organometallics 2005, 24, 6005-6012.

[119] For a recent example of a palladium, i.e., a late transition-metal complex undergoing $\beta-$ methyl elimination, see: A. R. Zhugralin, I. J. Kobylianskii, P. Chen, Organometallics 2015, 34, 1301-1306.

[120] T. Auth, K. Koszinowski, unpublished results.

[121] E. V. Brouillet, A. R. Kennedy, K. Koszinowski, R. McLellan, R. E. Mulvey, S. D. Robertson, Dalton Trans. 2016, 45, 5590-5597.

[122] a) H. J. Reich, J. P. Borst, R. R. Dykstra, P. D. Green, J. Am. Chem. Soc. 1993, 115, 8128-8741;

b) B. Lecachey, H. Oulyadi, P. Lameiras, A. Harrison-Marchand, H. Gérard, J. Maddaluno, J. Org. Chem. 2010, 75, 5976-5983.

[123] a) S. H. Bertz, M. Eriksson, G. Miao, J. P. Snyder, J. Am. Chem. Soc. 1996, 118, 10906-10907; b) S. H. Bertz, A. Chopra, M. Eriksson, C. A. Ogle, P. Seagle, Chem. Eur. J. 1999, 5, 2680-2691.

[124] a) X. Xie, C. Auel, W. Henze, R. M. Gschwind; J. Am. Chem. Soc. 2003, 125, 1595-1601; b) W. Henze, A. Vyater, N. Krause, R. M Gschwind, J. Am. Chem. Soc. 2005, 127, 17335-17342.

[125] a) R. G. Cooks, J. S. Patrick, T. Kotiaho, S. A. McLuckey, Mass Spectrom. Rev. 1994, 13, $287-$ 339; b) R. G. Cooks, P. S. H. Wong, Acc. Chem. Res. 1998, 31, 379-386; c) K. M. Ervin, Chem. Rev. 2001, 101, 391-444; d) J.-F. Gal, C. Mayeux, L. Massi, M. Major, L. Charles, T. Haljasorg, J. Chem. Educ. 2012, 89, 1476-1478.

[126] M. I. S. Röhr, J. Petersen, C. Brunet, R. Antoine, M. Broyer, P. Dugourd, V. Bonačić-Koutecký, R. A. J. O’Hair, R. Mitrić, J. Phys. Chem. Lett. 2012, 3, 1197-1201. 
[127] a) A. Tamaki, J. K. Kochi, J. Organomet. Chem. 1972, 40, C81-C84; b) A. Tamaki, J. K. Kochi, J. Organomet. Chem. 1974, 64, 411-425; R. V. Parish, Gold Bull 1997, 30, 55-62.

[128] The Cu'll character of $\left[\mathrm{Cu}(\mathrm{CF})_{3}\right]_{4}{ }^{-}$has been questioned: a) J. P. Snyder, Angew. Chem. 1995, 107, 112-113; Angew. Chem. Int. Ed. Engl. 1995, 34, 80-81; b) R. C. Walroth, J. T. Lukens, S. N. MacMillan, K. D. Finkelstein, K. M. Lancaster, J. Am. Chem. Soc. 2016, 138, 1922-1931.

[129] G. R. McDonald, A. L. Hudson, S. M. J. Dunn, H. You, G. B. Baker, R. M. Whittal, J. W. Martin, A. Jha, D. E. Edmondson, A. Holt, Science 2008, 322, 917.

[130] I. Kieltsch, G. G. Dubinina, C. Hamacher, A. Kaiser, J. Torres-Nieto, J. M. Hutchison, A. Klein, Y. Budnikova, D. A. Vicic, Organometallics 2010, 29, 1451-1456.

[131] W. Tyrra, M. M. Kremlev, D. Naumann, H. Scherer, H. Schmidt, B. Hoge, I. Pantenburg, Y. L. Yagupolskii, Chem. Eur. J. 2005, 11, 6514-6518.

[132] Although dimethylformamide (DMF) is widely employed in copper-mediated trifluoromethylation reactions with $\mathrm{Si}\left(\mathrm{CH}_{3}\right)_{3} \mathrm{CF}_{3}$, it was deliberately not included in this study to avoid severe contamination of the ESI source. In former experiments, complete removal of DMF from an ESI source turned out to be impossible. ${ }^{\text {[92e] }}$

[133] The acidities of $\mathrm{CH}_{3} \mathrm{CN}\left(\mathrm{p} K_{\mathrm{a}}=31.3\right)$ and phenyl acetylene $\left(\mathrm{p} K_{\mathrm{a}}=28.7\right)$ in dimethyl sulfoxide solution have been determined experimentally and may serve as a point of reference for their acidity in $\mathrm{CH}_{3} \mathrm{CN}$ : F. G. Bordwell, Acc. Chem. Res. 1988, 21, 456-463.

[134] K. O. Christe, W. W. Wilson, J. Fluorine Chem. 1990, 47, 117-120.

[135] CRC Handbook of Chemistry and Physics, Ed.: D. R. Lide, CRC Press, Boca Raton, 88th edition, 2008.

[136] K. Watanabe, N. Yamagiwa, Y. Torisawa, Org. Process Res. Dev. 2007, 11, 251-258.

[137] T. Auth, C. J. Stein, R. A. J. O'Hair, K. Koszinowski, in preparation.

[138] A. Krasovskiy, P. Knochel, Synthesis 2006, 2006, 890-891.

[139] K. L. Vikse, M. P. Woods, J. S. McIndoe, Organometallics 2010, 29, 6615-6618. 


\section{Lebenslauf • Sebastian Weske}

\section{Persönliche Daten}

Geburtsdatum:

29.12.1983

Geburtsort:

Berlin-Spandau

Staatsangehörigkeit:

deutsch

\section{Ausbildung}

April 2014 - Promotionsstudium

Januar 2019

Okt. 2008 -

März 2014

Studium in Chemie (Hauptstudium)

Okt. $2004-$

Sept. 2008

Okt. 2003 -

Juni 2004

Sept. 1996 -

Juni 2003
Studium in Chemie (Grundstudium)

Zivildienst

Gymnasium
- Forschungsgruppe von Prof. Dr. K. Koszinowski, Georg-August-Universität Göttingen

- $\quad$ Angestrebter Abschluss: Dr. rer. nat.

- Thema: Untersuchung von metallorganischen Kupfer-, Silber- und Gold-Verbindungen mit ESI-MS und MS $^{n}$

- Georg-August-Universität Göttingen

- Abschluss: Diplom-Chemiker (Dipl. Chem.) Gesamtnote: sehr gut

- Diplomarbeit in der Gruppe von Prof. Dr. K. Koszinowski: Charakterisierung von Organoindium-Reagenzien

- Humboldt-Universität zu Berlin

- Abschluss: Vordiplom Gesamtnote: gut

- Paul-Moor-Schule, Wehretal-Reichensachsen

- Unterstützung von Kindern mit Behinderungen in allen Belangen des täglichen schulischen Lebens

- Rhenanus-Schule, Bad Sooden-Allendorf

- Abschluss: Allgemeine Hochschulreife (Abitur) Gesamtnote: 1,5

\section{Veröffentlichungen und Preise}

[1] S. Weske, R. A. Hardin, T. Auth, R. A. J. O`Hair, K. Koszinowski, C. A. Ogle, Chem. Commun. 2018, 54, 5086-5089.

[2] Jochen Franzen-Posterpreis (Springer Verlag), 50. Jahrestagung der Deutschen Gesellschaft für Massenspektrometrie, Kiel, 2017. Postertitel: Coinage-Metal Ate Complexes - An ESI-MS Study

[3] S. Weske, R. Schoop, K. Koszinowski, Chem. Eur. J. 2016, 22, 11310-11316.

[4] S. Weske, Y. Li, S. Wiegmann, M. John, Magn. Reson. Chem. 2015, 53, 291-294. 